Florida International University

FIU Digital Commons

3-25-2019

\title{
Unleashing Crowd Wisdom: Leveraging Cognitive Memory Structures to Increase Quality of User-Generated Content
}

Mahed Maddah

Florida International University, mmadd011@fiu.edu

Follow this and additional works at: https://digitalcommons.fiu.edu/etd

Part of the Business Analytics Commons, and the Management Information Systems Commons

\section{Recommended Citation}

Maddah, Mahed, "Unleashing Crowd Wisdom: Leveraging Cognitive Memory Structures to Increase Quality of User-Generated Content" (2019). FIU Electronic Theses and Dissertations. 4040.

https://digitalcommons.fiu.edu/etd/4040

This work is brought to you for free and open access by the University Graduate School at FIU Digital Commons. It has been accepted for inclusion in FIU Electronic Theses and Dissertations by an authorized administrator of FIU Digital Commons. For more information, please contact dcc@fiu.edu. 


\title{
FLORIDA INTERNATIONAL UNIVERSITY
}

Miami, Florida

\section{UNLEASHING CROWD WISDOM: LEVERAGING COGNITIVE MEMORY STRUCTURES TO INCREASE QUALITY OF USER-GENERATED CONTENT}

\author{
A dissertation submitted in partial fulfillment of \\ the requirements for the degree of \\ DOCTOR OF PHILOSOPHY \\ in \\ BUSINESS ADMINISTRATION \\ by \\ Mahed Maddah
}




\section{To: Dean Joanne Li}

College of Business

This dissertation, written by Mahed Maddah, and entitled Unleashing Crowd Wisdom: Leveraging Cognitive Memory Structures to Increase Quality of User-Generated Content, having been approved in respect to style and intellectual content, is referred to you for judgment.

We have read this dissertation and recommend that it be approved.

Roman Lukyanenko

Monica Chiarini Tremblay

Pouyan EsmaeilZadeh

Haiying Long

Debra VanderMeer, Major Professor

Date of Defense: March 25, 2019

The dissertation of Mahed Maddah is approved.

Dean Joanne Li College of Business

Andrés G. Gil

Vice President for Research and Economic Development and Dean of the University Graduate School

Florida International University, 2019 
(C) Copyright 2019 by Mahed Maddah

All rights reserved. 


\section{DEDICATION}

To the loving memory of my wonderful Mom who passed away recently. I'll hold you in my heart until I hold you in heaven.

To my lovely wife, Sahar, for her endless love, support, and sacrifice. I am truly thankful for having you in my life.

To my dear Dad and my amazing brother and sister, Omid and Mona, for their incredible support and encouragement. 


\section{ACKNOWLEDGMENTS}

The completion of this dissertation would not have been possible without the support and encouragement of several special people. Hence, I would like to take this opportunity to show my gratitude to those who have assisted me.

I would like to express my special gratitude to my advisor Dr. Debra VanderMeer whose leadership and guidance throughout my dissertation was flawless. I gratefully appreciate her sincere dedication, unreserved support, valuable expertise, and continued encouragement. Moreover, I would like to express my deepest gratitude to Dr. Roman Lukyanenko, who gave me constant guidance, personal attention, and endless encouragement during these years. He has been extremely patient with me and supportive in numerous ways, from providing thoughtful insights and suggestions to writing magnificent recommendation letters. I really feel fortunate and blessed to have him in my Ph.D. life.

I wish to thank my Ph.D. committee members, Dr. Monica Chiarini Tremblay, Dr. Pouyan EsmaeilZadeh and Dr. Haiying Long, for their help, valuable input and accessibility. I am extremely proud to have such wonderful and knowledgeable people serving on my dissertation committee. Special thanks to Dr. Monica Chiarini Tremblay for her generous support during the early stages of this research, serving as my advisor.

I would also like to thank all the faculty, staff, and Ph.D. students in the Department of Information Systems and Business Analytics at FIU. Furthermore, I should acknowledge the support from the university graduate school for offering me the Dissertation Year Fellowship (DYF) to support the writing stage of my dissertation. 


\section{ABSTRACT OF THE DISSERTATION \\ UNLEASHING CROWD WISDOM: LEVERAGING COGNITIVE MEMORY STRUCTURES \\ TO INCREASE QUALITY OF USER-GENERATED CONTENT}

by

Mahed Maddah

Florida International University, 2019

Miami, Florida

Professor Debra VanderMeer, Major Professor

In recent years, online information sharing platforms have opened new opportunities for people to share information and experiences with each other and with organizations that sponsor these platforms. Increasingly, data consumers, both at the organizational and at the individual level, hope to use these User-Generated Content (UGC) in their decision making. However, recent studies uncovered significant challenges associated with the interfaces used to collect high-quality UGC. While many aspects of the information quality (IQ) of UGC have been studied, the role of data structures in gathering UGC and the nature of shared content have yet to receive attention. UGC is created on online platforms with varying degrees of data structure, ranging from unstructured (e.g., open box fields) to highly structured formats (e.g., rigid and specific forms). Despite much research on UGC, we have little understanding of the appropriate degree of data structures in data collection and its impact on the quality of information. Moreover, we know that most of the produced UGC originates in the declarative memory of the contributors. Psychology literature shows that different types of memory are stored and managed differently, and that they are retrieved accordingly. Thus, we argue that the information collection interface for retrieving and collecting each type of memory should be aligned with the way that it was stored. Therefore, we posit that designing interfaces with sensitivity to human memory structures should result in improvements of the IQ of UGC. We conducted several experiments to examine differently-designed information collection interfaces 
for different types of information. We evaluated both data creators' and data consumers' perceived quality of information collection, at the individual level. The findings support our claims of the importance of these factors for information quality. This research demonstrates a connection between information system interface design and human memory, which eventually could result in changes to best practices in interface design. This could, in turn, lead to improved interaction between participants and organizations, including enhanced data creators' self-expression, improved users' attitudes toward UGC systems, and increased value-add from organizations' use of UGC. 


\section{TABLE OF CONTENTS}

CHAPTER

PAGE

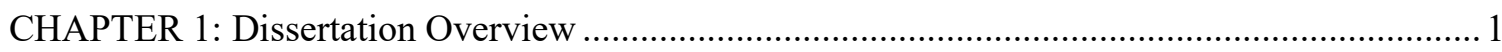

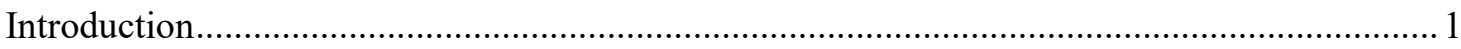

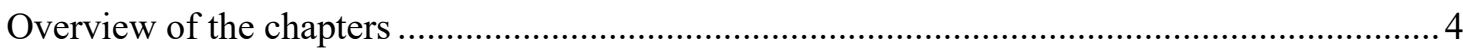

CHAPTER 2: Information Quality in Online Communities..................................................... 6

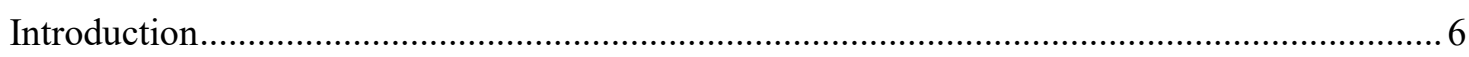

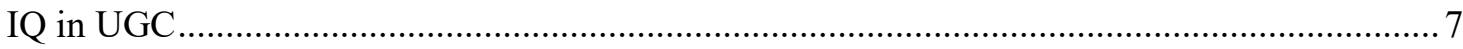

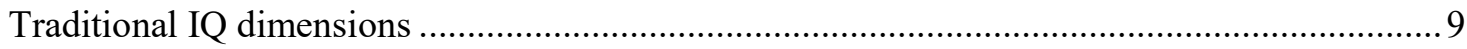

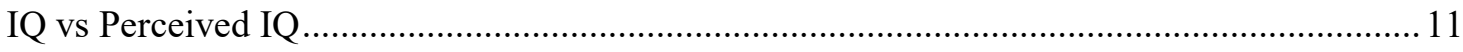

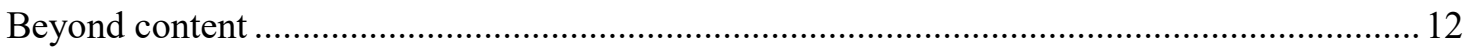

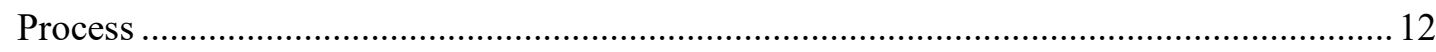

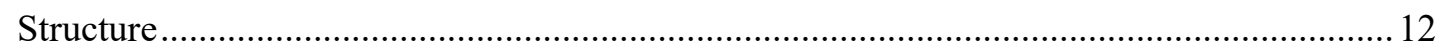

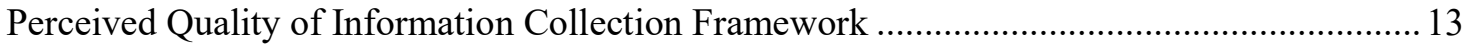

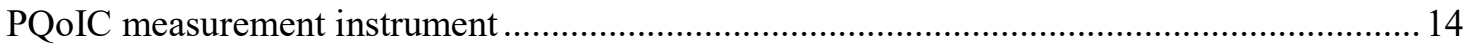

CHAPTER 3: Examining the effects of data structure on PQoIC ............................................. 17

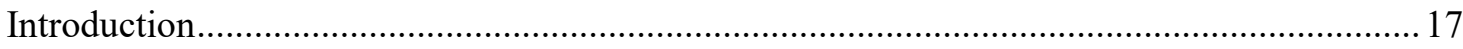

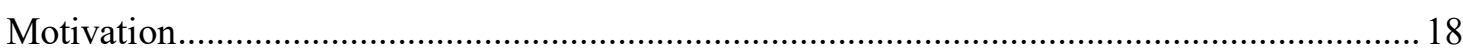

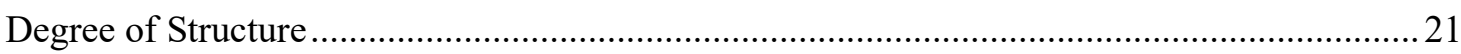

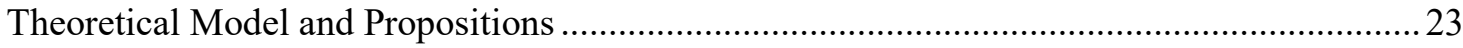

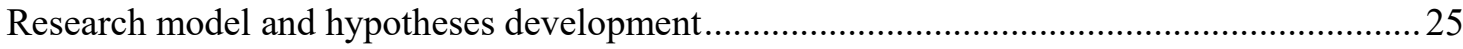

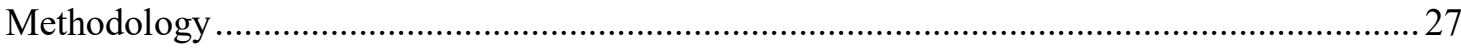

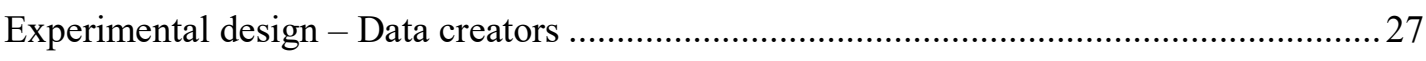

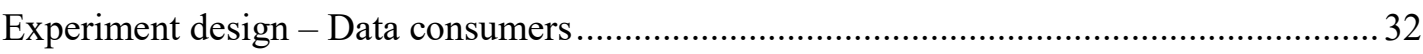

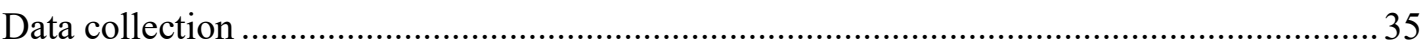

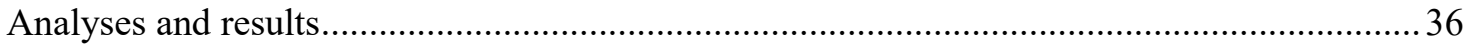

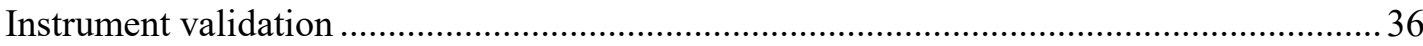

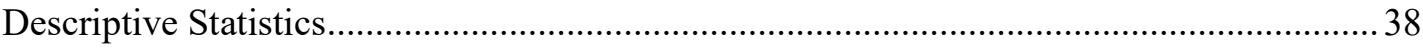

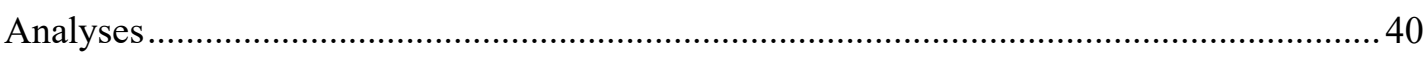

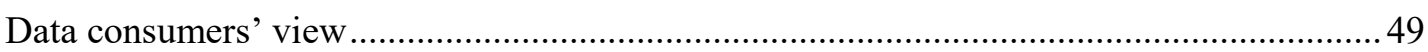

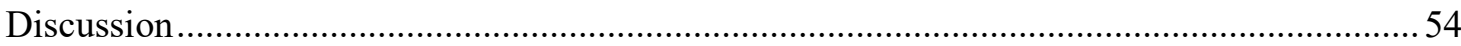

CHAPTER 4: Nature of shared content and its effect on PQoIC ................................................57 


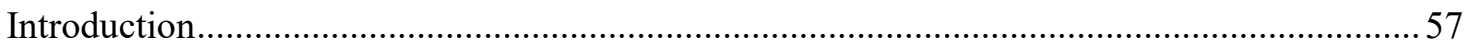

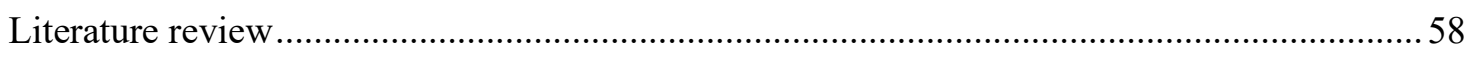

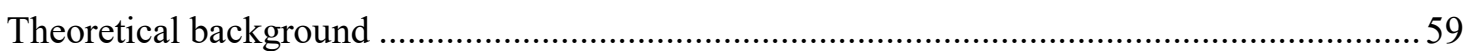

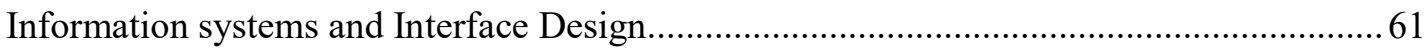

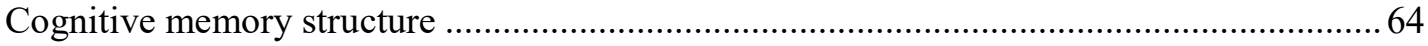

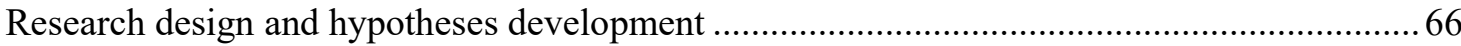

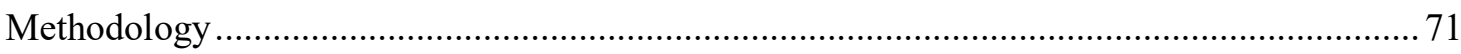

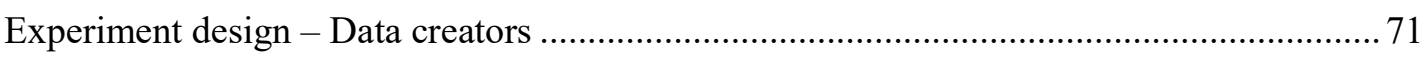

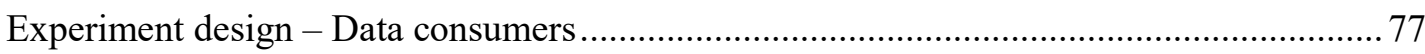

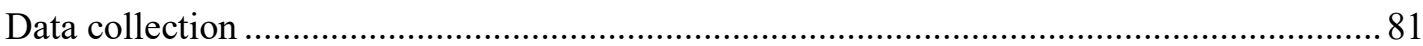

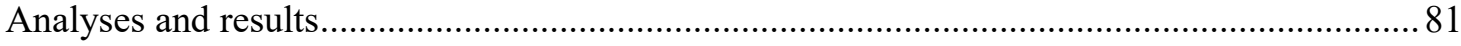

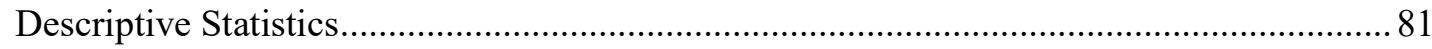

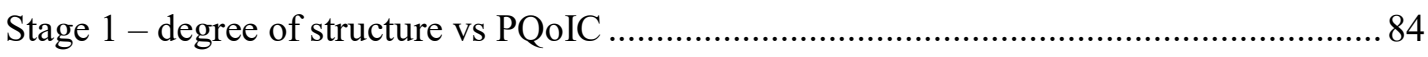

Stage 2 - Effect of Nature of Shared Content (NSC) ......................................................... 90

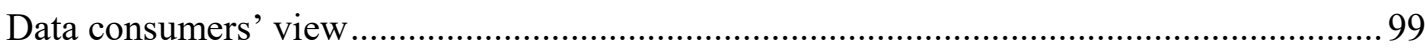

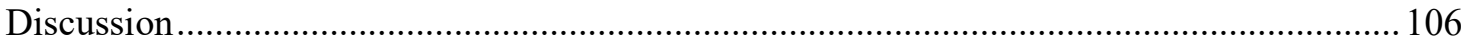

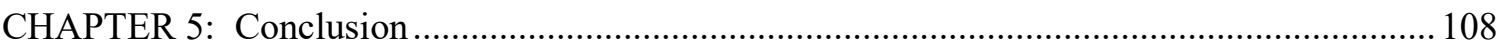

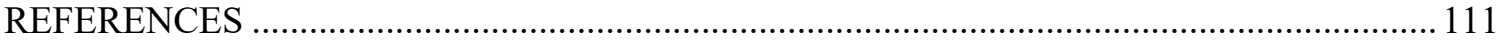

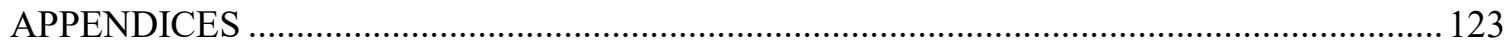

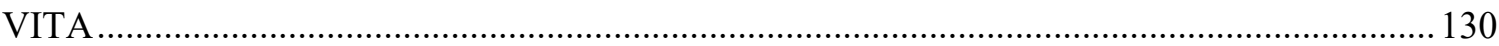




\section{LIST OF TABLES}

TABLE

PAGE

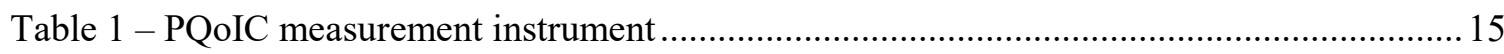

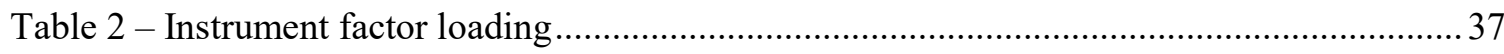

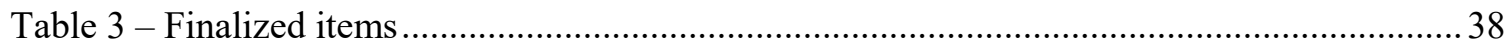

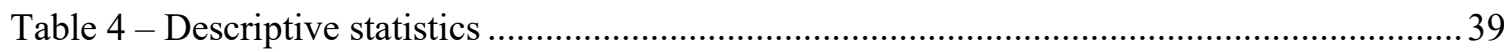

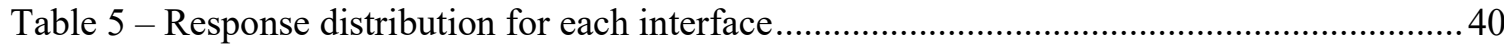

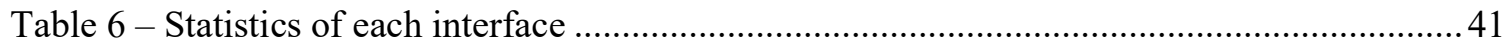

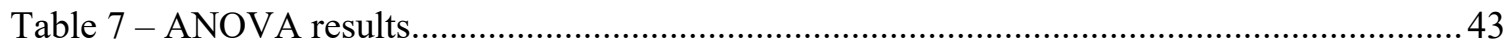

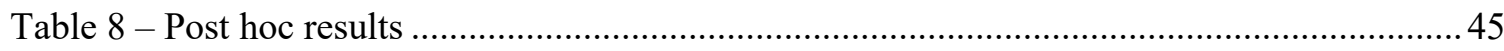

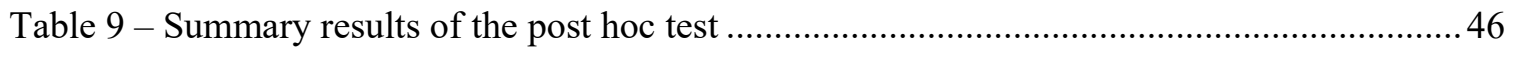

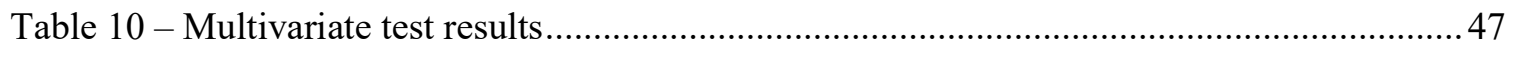

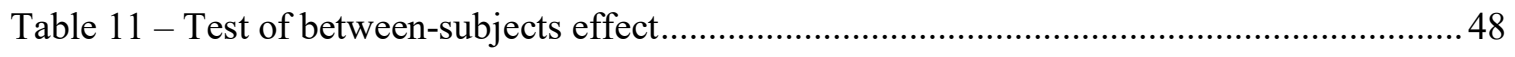

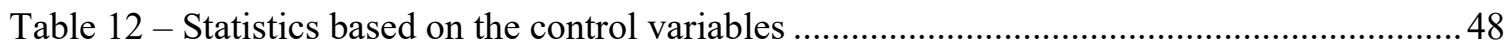

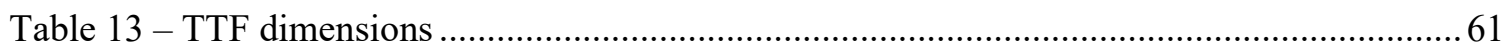

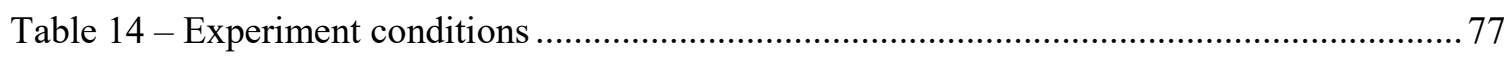

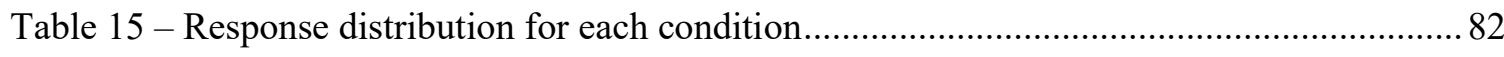

Table 16 - Response distribution percentage for each condition ............................................. 82

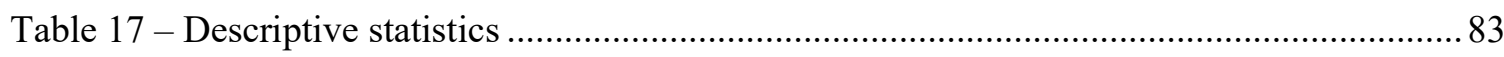

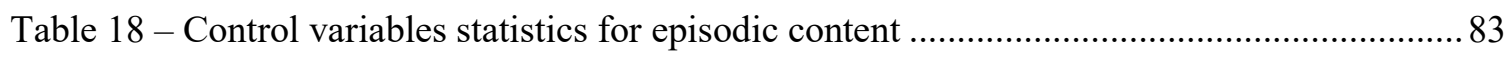

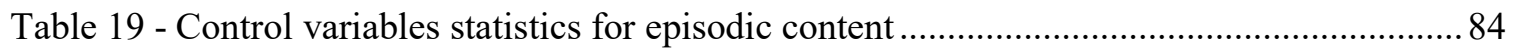

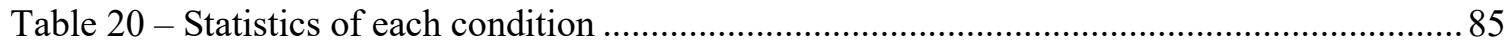

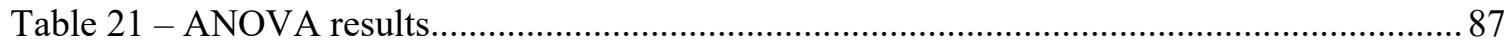

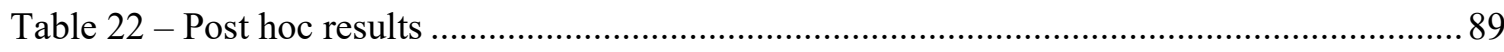

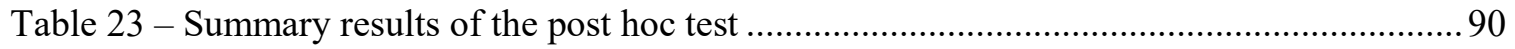




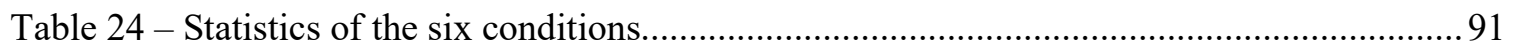

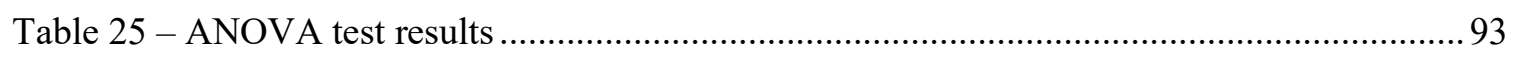

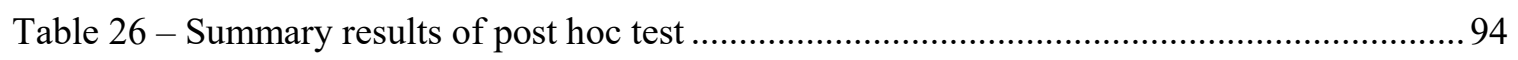

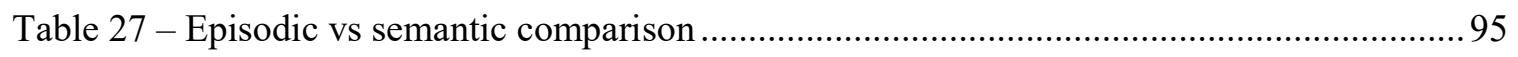

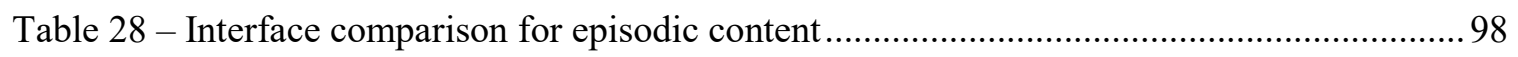

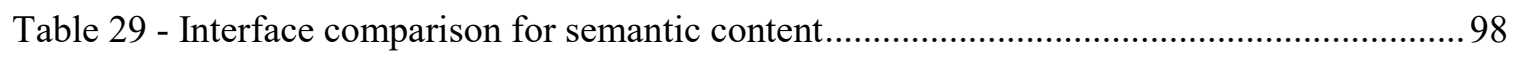

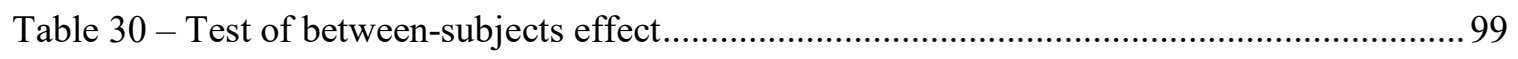

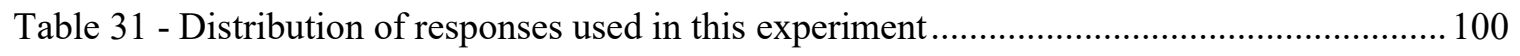




\section{LIST OF FIGURES}

FIGURE

PAGE

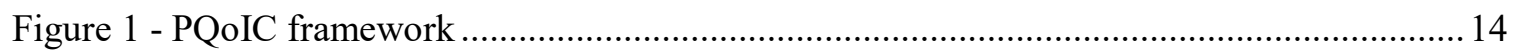

Figure 2 - Screenshot of two similar-purpose websites with different data-entry structure ..........20

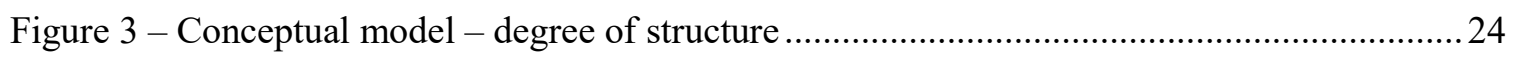

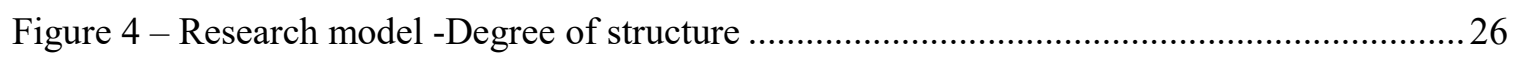

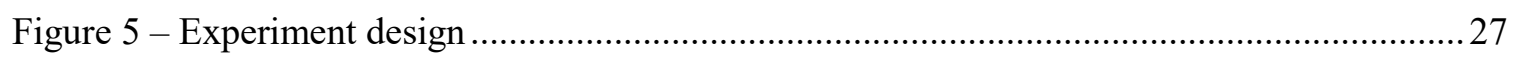

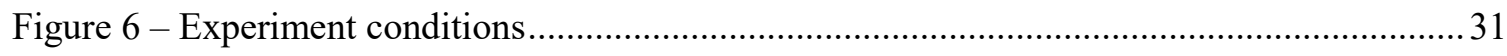

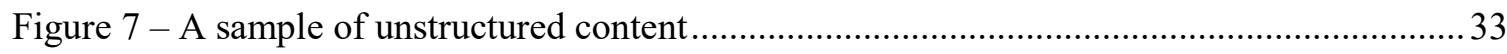

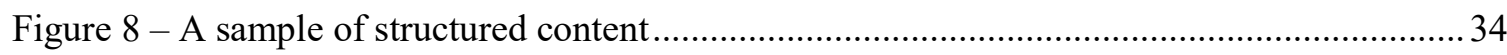

Figure 9 - Changes between interfaces - completeness \& accuracy ........................................ 42

Figure 10 - Changes between interfaces - flexibility \& utility of structure ............................... 42

Figure 11 - Changes between interfaces - ease \& speed of data entry ..................................... 43

Figure 12 - Data creators' vs data consumers' perception of completeness \& accuracy -

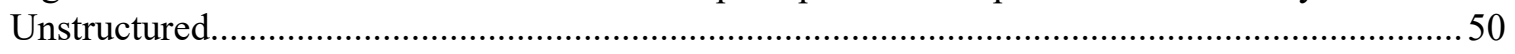

Figure 13 - Data creators' vs data consumers' perception of completeness \& accuracy -

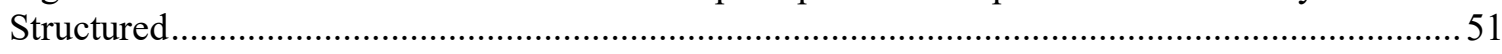

Figure 14 - Data consumers' perceived usefulness vs data creators' sincerity perceived by

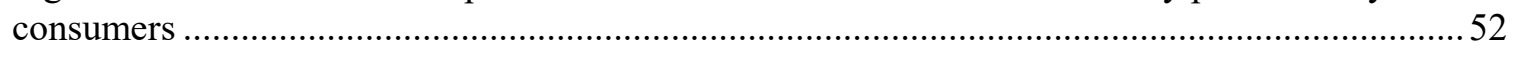

Figure 15 - Memory hierarchy, adapted from Herz and Brunk (2017)...................................... 64

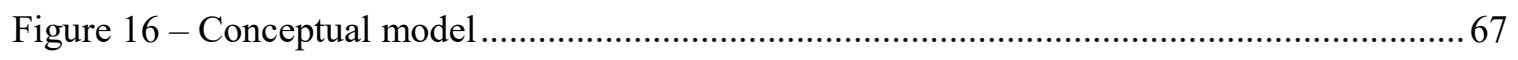

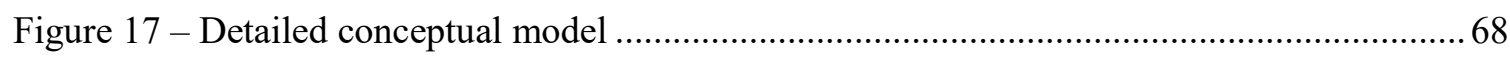

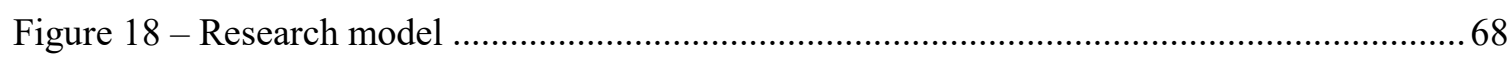

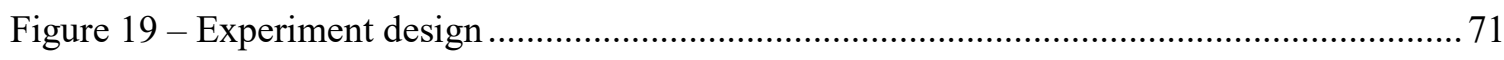

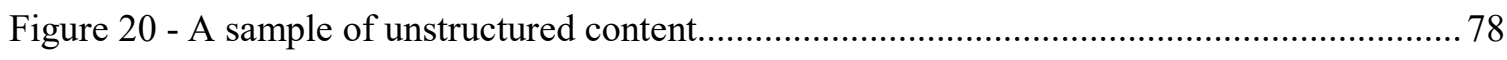

Figure 21 - A sample of episodic content presented in a structured format................................. 79 
Figure 22 - A sample of semantic content presented in a structured format................................ 80

Figure 23 - Changes between interfaces - completeness \& accuracy …................................... 86

Figure 24 - Changes between interfaces - flexibility \& utility of structure ................................. 86

Figure 25 - Changes between interfaces - ease \& speed of data entry ….................................. 87

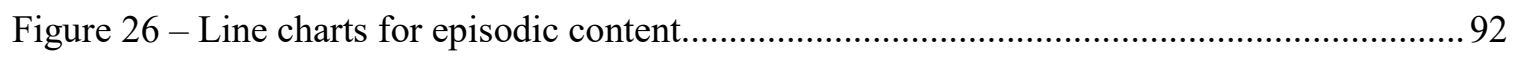

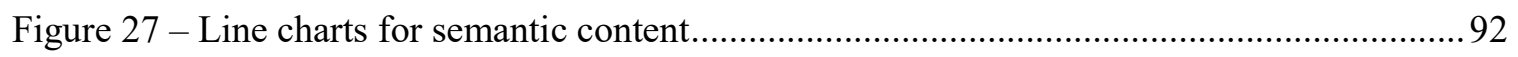

Figure 28 - Mean score - flexibility in unstructured interface ............................................. 96

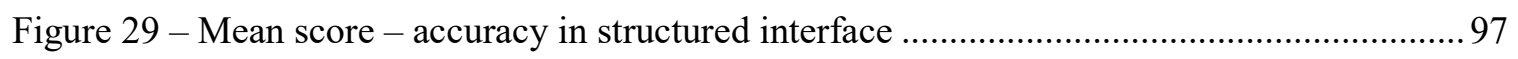

Figure 30 - Data creators vs data consumers' perception of completeness- Unstructured.......... 101

Figure 31 - Data creators vs data consumers' perception of accuracy - Unstructured................. 102

Figure 32 - Data creators vs data consumers' perception of completeness- Structured.............. 103

Figure 33 - Data creators vs data consumers' perception of accuracy - Structured .................... 104

Figure 34 - Data consumers' perceived usefulness vs data creators' sincerity perceived by

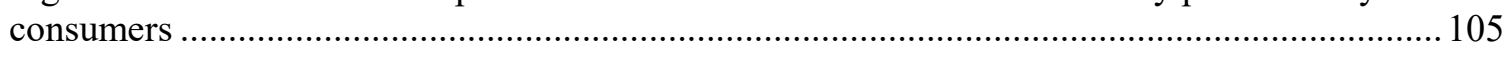




\section{CHAPTER 1: Dissertation Overview}

\section{Introduction}

In the last 20 years, the Internet has grown from a read-mostly system into a platform that supports a wide variety of dynamic and interactive applications. In parallel, users' interaction with online platforms has also evolved in response to the availibility of new opportunities for interaction. This era can be characterized with two major stages of online interaction.

The first stage, which was dominated by the growth of e-commerce, was the beginning of users' online interaction. The process of data creation was fairly simple in the early years of e-commerce. Website owners acted as the main data creators on their online platforms, and the content that online users used to create was mostly limited to transactional data, such as credit card information that was collected through an online purchase. In this stage of online interaction, online users were mostly considered data consumers, who read and used the data for individual decision-making processes.

The appearance of Web 2.0 marked the commencement of a major shift, impacting the creation, dissemination, and interpretation of online content (Sykes et al. 2008). With the unique features of Web 2.0 (Click and Petit 2010), online users have a more prominent and varied role. Every internet user has the potential to become a data creator, alongside his/her data consumer role. As a data creator, online users are able to generate and record content that can be seen and used by other online users in online platforms. This capability results in the emergence of a new type of online content, User-Generated Content (UGC). According to Lukyanenko et al. (2014), UGC is "various forms of digital information (e.g., comments forum posts, tags, product reviews, videos, maps) produced by members of the general public. These are often casual content contributors (i.e. the crowd) rather than employees or others closely associated with an organization". Consequently, we have seen the rise of more personal interactions over social media platforms and online communities. 
Throughout these years, website owners, i.e. businesses and other organizations, keep their data consumer role. In the early days, organizations put significant analytics efforts to study and use the great volumes of transactional data, leading to notable developments in product innovation, e.g., recommendation engines. With the rise of Web 2.0, organizations have gained access to a great source of UGC and now seek to mine this source, looking for interesting and actionable information.

One of the important outcomes of user interaction developments is the vast changes in the nature and volume of information in online platforms. With the prevalent use of online platforms in the current information-sharing era, the volume of produced UGC is far greater than that of traditional transactional data (Lukyanenko and Parsons 2015). Moreover, traditional data is primarily recorded by known employees within an organization, usually in a well-structured format. On the other hand, UGC is mainly recorded by online users who are usually unknown and unrelated to the organization. Consequently, the advent of UGC impacts several aspects of online content management, including data collection techniques, decision-making processes, as well as information quality approaches.

As data consumers - at both individual and organizational level - use the UGC in decision-making, it should be of high quality. Despite much previous research, the literature shows that there is a growing concern about the usability of UGC (Lukyanenko et al. 2014). We argue that the recorded UGC will be useful, when both data creator and data consumer believe that the content reflects what the creator intended to share. In other words, data creators should perceive that their recorded UGC is, in fact, their intended to-be-shared content, then data consumers should consider the recorded content useful for decision-making and analyses. Therefore, we propose that the quality of the outcome in a UGC setting should be examined by assessing both data creators and data consumers perception of quality. 
In this dissertation, we focus on the information quality of user-generated content in online communities. We approach this concern from the data collection perspective, bridging the gap between data collection and data usage in UGC settings. While many aspects of information quality of UGC have been studied, our investigation shows that the role of data structures in gathering UGC and nature of shared content have yet to receive attention. We examine these two aspects of designing a data collection interface as well as their effects on users' perception of information quality.

We study the effects of degree of data structure on the quality of collected UGC. In this research, degree of structure refers to an interface feature that results in various representations of data (R. M. Losee 2006). For example, UGC is created in online platforms at varying degrees of data structure, ranging from unstructured (like open box fields) to highly structured format (like rigid forms). The degree of structure illustrates the extent to which the collected data is assigned to dedicated fields and can thereby be directly processed (Baars and Kemper 2008). We found many real cases, for example PatientsLikeMe and BAFsupport two among many UGC communities, where similar data is being collected through interfaces with different degrees of structure. Despite many studies in Human-Computer Interaction literature (Dix 2009; Jacko 2012; Sutcliffe 1988), there has been little discussion on how to provide a well-structured interface to collect UGC. Moreover, we examine the Nature of Shared Content (NSC) and its influence on the outcome. Previous research in Human-Computer Interaction shows that the design of data-gathering interfaces is typically based on users' preferences and motivational factors (Stoeckl et al. 2007). However, we argue that the nature of shared content, whether it is conveying a personal experience or a general fact, needs to be considered. The UGC is far more personal than the transactional data gathered through product sales and needs to be collected with this consideration. Psychology literature shows that different types of memory are stored and managed differently, and that they are retrieved accordingly. Thus, we argue that the information collection interface for retrieving 
and collecting each type of memory should be aligned with the way that it was stored. Therefore, we posit that examining the nature of to-be-shared content should improve the quality of data in UGC settings.

In this dissertation, we differentiate between information quality and perceived information quality. We examine the two main entities in a UGC setting, data creators and data consumers, and evaluate their perception of the quality of the data collection process and its outcome. At the beginning, we develop a framework to thoroughly assess the perceived quality of information collection. Then, we conduct separate experiments to first study the effects of the degree of structure on the recorded outcome and then examine the nature of to-be-shared content. We show that considering these two aspects in designing an information collection interface in UGC settings improves quality of UGC. This research demonstrates a connection between information system interface design and human memory, which eventually could result in changes to best practices in interface design. This could, in turn, lead to improved interaction between participants and organizations, including enhanced data creators' self-expression, improved users' attitudes toward UGC systems, and increased valueadd from organizations' use of UGC.

\section{Overview of the chapters}

The remainder of this dissertation is organized as follows. Chapter 2 builds a case for the need to explore perceived information quality in a UGC setting. Then, we explore the literature on information quality (IQ). We discuss IQ in online communities and its discrepancies with traditional data collection. We look at the IQ from a data collection perspective, where we provide evidence to demonstrate that there is a need to investigate the process and structure of data creation as well. Thus, we suggest a framework that, from the data creators' point of view, thoroughly evaluates the content, its creation process, and its structure. We call it the Perceived Quality of Information Collection (PQoIC). 
In Chapter 3, we examine the employment of different degrees of structure in data collection. We investigate whether different interface design considerations change users' attitudes about being able to express themselves. To this end, we run several experiments to test interfaces with various degrees of structure. We assess data creators' perception of IQ, using our PQoIC instrument. We also assess data consumers' points of view and compare the results with data creators' perception. In Chapter 4, we take into account the nature of shared content (NSC) in designing the interface. Examining the psychology literature on human memory, we investigate the storage and retrieval of different types of content that are usually shared in online communities. We recognize the differences between content related to knowing and content related to remembering, and we suggest designing information collection interfaces with this consideration. By running multiple experiments, we study the interaction between cognitive memory structures and interface design and the resulting impact on the quality of user-generated content. Further, we intend to identify and exploit synergies between data creator and consumer expectations. 


\section{CHAPTER 2: Information Quality in Online Communities}

\section{Introduction}

Decision makers deal with data and information in their daily interactions (Speier et al. 1999). Whether a decision is being made on a personal level or an organizational level, the reliability of the decision depends on the quality of the information (O'Reilly 1982). In order to make the best decisions, we need high-quality information, since low-quality information could be misleading and impair the decision-making process (Keller and Staelin 1987; Madnick et al. 2009). As a result, researchers and practitioners pay a lot of attention to Information Quality (IQ).

Information quality (IQ) has been a core topic in Information Systems for many decades (Petter et al. 2013). However, the appearance of new concepts and phenomenon, e.g. user-generated content (UGC), has introduced additional challenges to information quality (Lukyanenko and Parsons 2015). Even though previous studies respond to some of these challenges, we argue that some aspects of IQ of UGC have yet to receive attention.

Data consumers, whether at the organizational or personal level, use the UGC for analyses and decisions. Naturally, a high-quality piece of user-generated content results in better decisions and actions. As a result, having high-quality UGC is of much importance to consumers. There have been different information quality approaches used to ensure the high-quality of UGC. However, most of the traditional IQ measurement approaches focus on the quality of the recorded UGC, and not the process of UGC collection. In other words, the assessment of the quality of the content starts, after it is collected.

Given the unique features of the UGC, we argue that the assessment of its quality should start before its creation. UGC is usually created by not-obligated and unpaid participants, whose enthusiastic or efficiency could be affected during the creation process. Therefore, the medium that is used to collect the UGC could affect its quality to some extent. We suggest assessing the quality 
of UGC, we should examine the features of the information collection interface that is used to record UGC.

Primarily, we argue that the process of data entry in a UGC platform affects the data creators' attitude. We define the process of data entry in terms of ease and speed of data entry. A complicated and long data entry process may easily discourage a data creator who wants to voluntary share a useful piece of information quickly and easily. On the other hand, we propose that the design and structure of the information collection interface could affect the recorded outcome. We suggest that

a flexible interface with the high utility of structure could result in better outcome. Alongside with these dimensions, we suggest that the traditional IQ dimensions of completeness and accuracy need to be measured.

In this chapter, we argue that these dimensions need to be measured in terms of data creators' perception. Further, we suggest a new comprehensive framework to assess the perceived quality in a UGC setting.

\section{IQ in UGC}

Traditionally, information quality research was conducted in the context of organizational information production (Abdel-Hamid 1988; Agmon and Ahituv 1987; Redman 1998). However, this approach has changed through time. Internet users are dealing with huge amounts of usergenerated content (Dhar and Chang 2009; Wyrwoll 2014). We can see UGC in almost every kind of website. UGC is produced in multiple formats, including text (e.g., Facebook), pictures (e.g., Flickr, Picasa, Wikimedia), videos (e.g., Facebook, YouTube, Wikimedia), digital art (e.g., DeviantArt), maps (e.g., OpenStreetMap) and their combinations (Arazy et al. 2011; Haklay and Weber 2008; Susarla et al. 2012). It also includes sensor data (e.g., geolocations, timestamps, ambient sounds) that are automatically collected from the devices used by people to create content (Klonner et al. 2015). Moreover, UGC can be found in different outlets such as social media and 
social networks (e.g., Facebook, Twitter, Instagram, YouTube), crowdsourcing (e.g., Wikipedia), product reviews (e.g., Amazon.com), comments (e.g., on CNN, BBC stories online) community portals, amateur news (e.g., Huffington Post), collaborative mapping (e.g., OpenStreetMap), chat rooms, forums and discussion boards, blogs, and amateur websites.

This new stream of information caused some serious changes in decision-making processes, since UGC supports decision making and analysis in different contexts. UGC has influenced both the behavior of internet users and e-business models of some organizations (Li 2010). Considering the proliferation of UGC and the growth of online businesses, UGC became a critical resource for decision makers (R. Lukyanenko et al. 2014). Moreover, companies are increasing their reliance on UGC and making decisions based on UGC. However, considering the unique features of usergenerated content, there is a growing concern about the quality of UGC.

As we mentioned earlier, UGC is different from traditional data in many ways. Unlike content produced by organizational employees and close associates, UGC is created by members of the general public, who often are casual content contributors (the crowd) with weak or no formal ties to the organizations looking to use UGC (Lukyanenko et al. 2019). UGC platforms are usually online and have few participation barriers, engage diverse audiences, and impose little, if any, control on the process of data creation (Lukyanenko and Parsons 2015). In some platforms, the UGC is created by people whose identity and skills are unknown or unapproved (Lee and Strong 2003). The user could be a well-educated expert on the topic or an uneducated teenager. The first could create highly reliable data, while the latter might not. These feature of UGC makes data consumers skeptical about the quality of UGC.

In a UGC environment, traditional processes of data quality control are often severely limited or completely break down. According to Lukyanenko (2014), reaching and influencing (e.g., training, providing quality feedback to) content creators is often infeasible when projects involve millions of semi-anonymous users (e.g., Twitter). Casual online users often lack deep specialized knowledge 
(e.g., bird taxonomy, geography, consumer products) commonly required for organizational decision making (Wiggins et al. 2011). Due to weak and informal ties, online contributors have with the organizations interested in harnessing UGC, data contributors cannot be held accountable for the quality of data they contribute. The context of information production is opaque and the conditions under which online contributors make observations vary drastically, making it challenging to assess the quality of a given contribution and use it in decision making. Considering potential pitfalls associated with UGC, organizational decision-makers remain skeptical about using it in critical tasks (Ali et al. 2014; Dickinson et al. 2010; Engel and Voshell 2002; Flanagin and Metzger 2008).

\section{Traditional IQ dimensions}

As we mentioned earlier, IQ has been studied by information systems researchers for several years. It is generally assumed that an IQ improvement program has to proceed by decomposing quality into its constituent dimensions (e.g. accuracy, timeliness, completeness) (Arazy and Kopak 2011; Ballou and Pazer 1995; Lee et al. 2002). In one of the seminal works, Wand and Wang (1996) highlighted the importance of information quality in the overall effectiveness of an organization and presented definitions of data quality dimensions by anchoring them in ontological foundations. They identified data quality dimensions as accuracy and precision, reliability, timeliness and currency, completeness and consistency.

Through years of research on IQ, several dimensions have been proposed to develop a seminal taxonomy (based on data consumers' needs), including intrinsic (e.g. accuracy, believability, reputation), context (e.g. completeness, timeliness), representation (e.g. consistency in representation, ease of understanding) and accessibility (e.g. ease of accessing the data). In working with various dimensions of IQ, researchers concluded that trade-offs between dimensions appear to be inevitable and are rooted in the complex nature of IQ itself (Batini and Scannapieca 2006; 
Pipino et al. 2002; Scannapieco et al. 2005). Examples of trade-offs identified in prior research include accuracy and timeliness (Ballou and Pazer 1995); consistency and completeness (Ballou and Pazer 2003). Trade-offs between IQ dimensions have been conceptualized ( Parsons, Lukyanenko, \& Wiersma, 2011) and demonstrated in UGC settings (Lukyanenko et al., 2014; Lukyanenko et al., 2014). These findings broadly suggest that any approach to improving IQ should be sensitive to the potential negative impact on some IQ dimensions.

We investigate the mentioned IQ dimensions in detail and look for dimensions that could help to assess the IQ in the online community context. The two most related dimension that we chose are completeness and accuracy. The created data being sufficient is a critical issue for data consumers. We consider this feature as completeness, which, according to Wand and Wang (1996), is "the ability of an information system to represent every meaningful state of the represented real-world system". The data could be assumed as complete, if all relevant data to satisfy the user requirements are available (Parssian et al. 2004). The other important feature for the data is accuracy. Recording the data correctly is crucial. According to Lukyanenko et al. (2014), a statement about a phenomenon is accurate, if the statement is true for that phenomenon.

Although previous studies suggest some other dimensions to measure the content quality, these dimensions seem not applicable to our context. For example, one of the other proposed dimension is timeliness, which has been defined as whether the data is out of date (Wand and Wang 1996). In the context of online communities, this dimension is not a factor when users are discussing a certain issue. So, we chose completeness and accuracy as the two dimensions that could be considered in most situations in online communities. 


\section{IQ vs Perceived IQ}

Another critical point in the UGC setting is the difference between quality and perceived quality. In a traditional setting, we used to assess the information quality, and it used to be conclusive. In other words, a statement or a piece of information used to be considered either true or false. For most situations, an expert user could identify the accuracy of a piece of information. However, for UGC created in online communities, there is a big difference. Because of the nature of this context, most of the content is inconclusive. In other words, in many cases, deciding about accuracy (or completeness, or ...) of a statement is not easy (if possible). For example, assume that two people are sharing their experience of staying in two adjacent hotel rooms on the same night. The first person might say that his room was very quiet. The second person, on the other hand, might say his room was very noisy. They both could be right because they are talking about their own experiences. That is why instead of information quality, we think that perceived information quality should be assessed. Perceived information quality is users' perception of the quality of the content (Chandra and Ibrahim 2015).

In online communities, people talk about their feelings, experiences, and thoughts. And the only person who can judge their statements is the person him/herself. In other words, an online user has something in his mind, he uses the given interface to put that on the screen. The extent that the recorded content matches with what was initially in his mind determines the quality of content. And the only person to rate this match is himself. So, we propose that instead of information quality, we should evaluate the perceived information quality of the content. Therefore, instead of asking about the completeness, we should ask if the information collection interface gave the data creator the ability to record all the content that he wanted to record. 


\section{Beyond content}

So far, we discussed the IQ dimensions by focusing on the traditional dimensions of quality. However, we argue that there are other factors that could eventually affect the IQ of recorded content and needs to receive attention. And similar to content-related dimensions (completeness and accuracy), we look at these factors from data creators' perspective. These factors indirectly affect IQ through the information collection process and interface:

\section{Process}

We propose that the process of data collection should be considered in assessing the quality of the outcome. Essentially, the interaction of data creators and a collection interface could affect the recorded outcome. For example, if a data creator deems the process of data creation not easy, this feeling might influence his/her performance. In other words, a complicated data creation process could discourage a data creator. In an online community, where the data creator is not obligated to contribute, this discouragement could make the data creator unwilling to share or to sacrifice some parts of the intended-to-be-shared content. Thus, we suggest that to assess the perceived quality of recorded content in an online community, we need to evaluate the data creation process. By examining the previous studies on the HCI (Ben-Zion et al. 2014; Ehrler et al. 2015; Hua et al. 2014; Ju and Ding 2015; Rahman et al. 2016), we propose ease of data entry and speed of data entry as two major dimensions of the data creation process.

\section{Structure}

The content generated in an online community is recorded using a specific medium. We argue that the features of this medium could affect the recorded outcome. If we want to have a better assessment of data creators' perception about the quality of the recorded outcome, we need to consider the given interface. A well designed information collection interface could enable a contributor to record the content exactly as he/she wanted to record. For example, an ill-structured 
interface that is not flexible to collect the details of experience will not result in a high-quality piece of information. Thus, we suggest that the structure of the information collection interface needs to be evaluated in the assessment of the perceived quality of information collection. Considering previous studies on the structure of a data collection interface (Chavez et al. 2015; Gong et al. 2016; Granello and Wheaton 2004), we introduced flexibility and utility of structure as two dimensions of the structure.

\section{Perceived Quality of Information Collection Framework}

As we evaluate the quality of the content, we should consider all aspects of data creators' interaction with the interface. In this research, we study the information quality of UGC from the data creators' point of view. As we discussed earlier, we propose that the process of data creation and the structure of information collection interface, alongside with the content itself, should be considered in assessing the outcome. We argue that the combination of these three aspects could give us a comprehensive assessment of the information quality. We went through the literature and developed a new construct to thoroughly measure data creators' interactions with information collection interfaces. We introduced the Perceived Quality of Information Collection (PQoIC) construct that could evaluate this interaction in terms of content, process, and structure. We evaluate content sub-construct in terms of completes and accuracy. We use time and speed of data entry to assess process sub-construct, and flexibility and utility of structure to assess structure subconstruct. The following figure represents our PQoIC construct and its dimensions. 


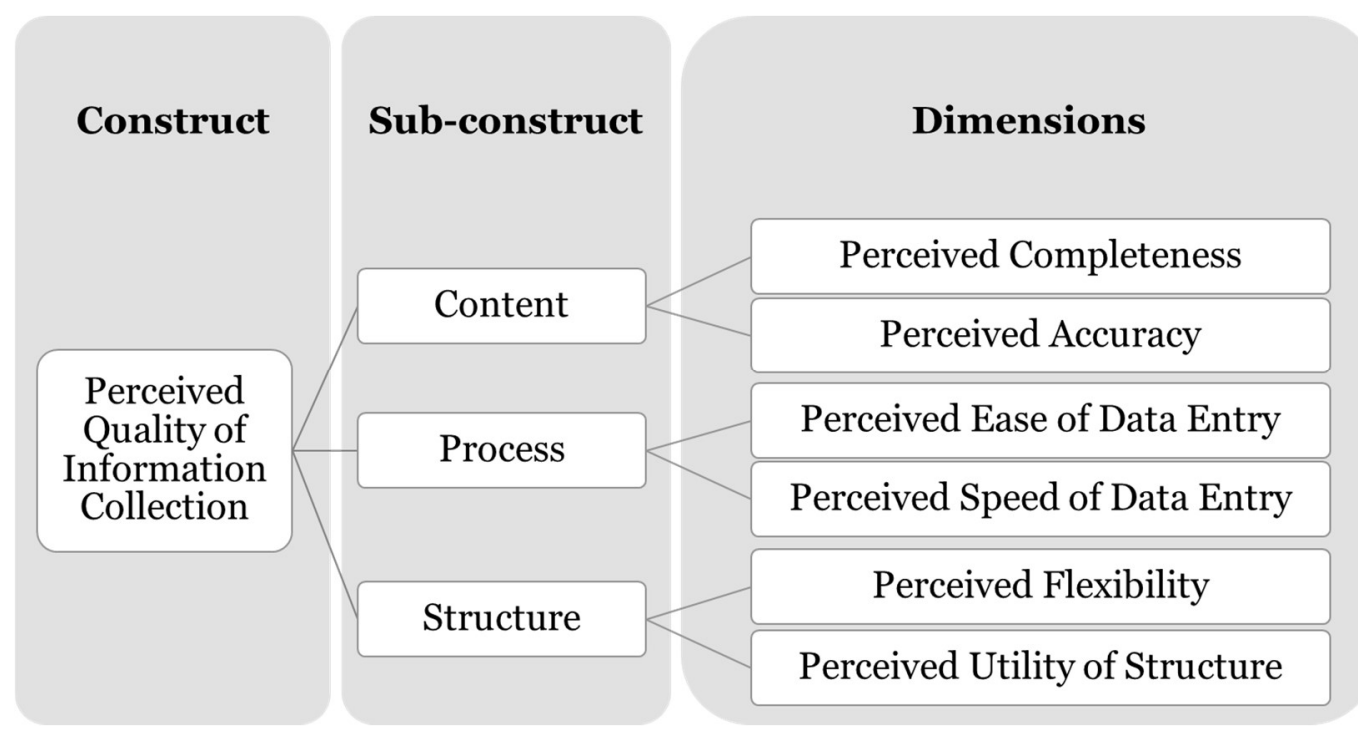

Figure 1 - PQoIC framework

\section{PQoIC measurement instrument}

We use the PQoIC construct as the dependent variable in our studies in Chapter 3 and Chapter 4. We design our construct as a formative construct that is being formed by its dimensions. We introduced this new construct by adopting some related dimensions from the literature. Similarly, we developed the following measures as an instrument to assess this construct. To comply with our research context, we customize and modify some of the items in the instrument. The items are adapted from previous research on IQ (Collier and Barnes 2015; Pikkarainen et al. 2004; Wixom and Todd 2005; Xu et al. 2013) and aims to assess the perceived quality of content, process, and structure of recorded information. The following table presents our items. 


\begin{tabular}{|c|c|c|}
\hline Sub. & Dim & Item \\
\hline \multirow{2}{*}{ 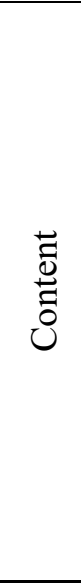 } & 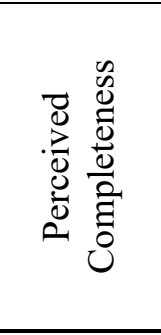 & $\begin{array}{l}\text { - I was able to record all the information that I wanted to record. } \\
\text { - I was able to record thorough information about my experience with this } \\
\text { topic. } \\
\text { - I was able to record thorough information about my knowledge of this } \\
\text { topic. } \\
\text { - The information that I provided is all the information that was asked of } \\
\text { me. }{ }^{*}\end{array}$ \\
\hline & 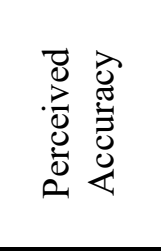 & $\begin{array}{l}\text { - I was able to record precise information. } \\
\text { - I was able to record correct information about my experience with this } \\
\text { topic. } \\
\text { - I was able to record correct information about my knowledge of this topic. } \\
\text { - The information that I provided is error-free. * }\end{array}$ \\
\hline \multirow[b]{2}{*}{$\begin{array}{l}n \\
0 \\
0 \\
0 \\
0 \\
0\end{array}$} & 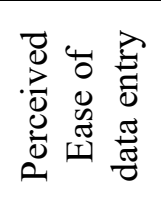 & $\begin{array}{l}\text { - It was easy for me to record the information that was asked of me. } \\
\text { - I found the provided data entry interface easy to use. } \\
\text { - My interaction with the data entry interface was clear and understandable. } \\
\text { - My interaction with the data entry interface took a lot of effort. * }\end{array}$ \\
\hline & 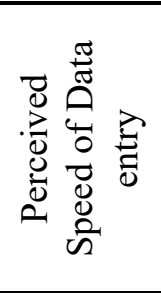 & $\begin{array}{l}\text { - The way that I shared my experience/knowledge was a fast way to do so. * } \\
\text { - The data entry process took too much time. } \\
\text { - The duration of time I spent on sharing my experience/knowledge was } \\
\text { acceptable. } \\
\text { - Considering the information that I wanted to create, the data entry process } \\
\text { took about the time that I expected. }\end{array}$ \\
\hline \multirow[b]{2}{*}{ 㤣 } & 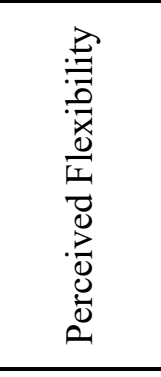 & $\begin{array}{l}\text { - The data entry interface was designed to be flexible to adapt to different } \\
\text { experiences. } \\
\text { - I was able to adjust my experience/knowledge to the provided data entry } \\
\text { interface. } \\
\text { - I felt that it was important to use all of the given fields to fully capture my } \\
\text { experience. } \\
\text { - The interface did not provide sufficient fields to help me capture my } \\
\text { experience. * }\end{array}$ \\
\hline & 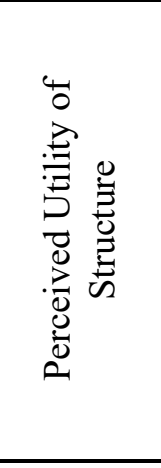 & $\begin{array}{l}\text { - The data entry interface provided sufficient features that I needed to record } \\
\text { the information. } \\
\text { - The structure of the provided data entry interface enabled me to share my } \\
\text { experience/knowledge efficiently. } \\
\text { - The interface that I used was well formatted for the information that I } \\
\text { wanted to create. } \\
\text { - Using the provided interface, I was able to create information that would } \\
\text { be useful to others. * } \\
\text { - The structure provided by the interface allowed me to clearly present my } \\
\text { answer(s) to the question(s). * }\end{array}$ \\
\hline
\end{tabular}

Table 1 - PQoIC measurement instrument 
The items related to content sub-construct are adopted from (Lee et al. 2002; Nicolaou and McKnight 2006; Wang and Benbasat 2008; Wixom and Todd 2005; Xu et al. 2013). To develop the items to evaluate ease and speed of data entry, we used the research on the process of data creation (Cocosila and Trabelsi 2016; Dabholkar and Sheng 2009; Lederer et al. 2000; Pikkarainen et al. 2004; Rahman et al. 2016; Rajan and Baral 2015; Steelman et al. 2014a; Van Dolen et al. 2007). Finally, our structure-related items are adopted from (Bhatt and Stump 2001; Cho et al. 2009; Gong et al. 2016; Kim 2010, p. 20).

This survey will be used to assess data creators' perception of the quality of information collection. After recording their responses in the provided information collection interfaces, each data creator will be given this survey to evaluate his/her perceived quality of information collection. Following Mason and Suri (2012a), we include three "captcha" or "reverse Turing test" questions in the instrument (the bold items). This is a simple way to control the obligation of respondents to the assigned tasks. These questions are designed in a way that it is not reasonable if someone responds to them similar to the next question. We validate the instrument based on the collected data in Chapter 3. Eventually, the items marked with a star $(*)$ is dropped from the instrument.

In the following chapters, we describe our research questions and provide the details of each research, in which we use our PQoIC construct. 


\section{CHAPTER 3: Examining the effects of data structure on PQoIC}

\section{Introduction}

Data collection interfaces are the data creators' medium to record the content they wish to share. Previous findings show that, while recording data, users may get discouraged by inadequate data entry choices (Kaplan and Haenlein 2010). Users' Dissatisfaction can lead to loss of immediate users and potentially other users as well, since a discouraged user will not promote the system to others. As online participation is mostly voluntary, participants are easily dissuaded from using an online system if the process of making contributions is difficult (Ipeirotis et al. 2010; Nov et al. 2011). In addition, a flawed data-entry process can result in databases filled with incomplete or inaccurate data, which brings about serious problems for data consumers hoping to leverage UGC in their decision making and actions (Strong et al. 1997; Wang et al. 1995; Xu et al. 2002). In other words, data entry choices not matching expectations may result in inaccurate data or loss of online participants. These consequences suggest the need for continued research on improvements in designing data entry platforms to increase the IQ of collected UGC.

We can examine designing an online interface from different perspectives. Previous studies analyzed data collection interfaces in terms of usability, ease of use, productivity, and so on. One of the main goals of all these studies is to improve the quality of data creation and the outcome. Data creators expect an easy-to-use and well-structured interface to record what they wish to record. A welcoming interface to data creators is the one that enables them to convey their idea, comment, experience or thought exactly as they intend to convey it.

Examining different online interfaces, we find particular designs that restrict the data creator to a certain structure or give them the freedom of data creation in any format. UGC is created in online platforms at varying degrees of data structure, ranging from totally unstructured (e.g., open box fields) to highly structured formats (e.g., rigid and specific forms) (Maddah et al. 2016). Most importantly, similar data is being collected through interfaces with different degrees of structure. 
In other words, to collect the data creators' response to a specific question, an online platform provides an interface that lets data creators write their responses in form of sentences and paragraphs. Another online platform, however, might provide a very rigid structured form with predefined answers to collect data creators' response to the exact same question. As a result, we decide to scrutinize how an interface is structured to record the intended content.

Naturally, each interface design has advantages and disadvantages, and we will discuss these later. Nonetheless, the existence of diverse UGC platforms and different formats show that the designers and managers have not agreed on a unified design for UGC (Jin et al. 2012; Obrist et al. 2008). While recent research has begun to make progress on this issue, research on UGC indicates that we have little understanding of the appropriate degree of data structure for UGC data gathering and its impact on the quality of information (Lukyanenko and Parsons 2015). In this chapter, we examine the degree of structure in designing interfaces to collect UGC.

\section{Motivation}

When we look at the UGC coming from social media and online communities, we can see the content recorded at various degrees of structures. The diversity in UGC formats starts from a highly unstructured text format, such as commenting on a news story in Yahoo!News or commenting on a video on YouTube, and it goes to a highly structured design, like rigid feedback forms of some services. These two examples are the two extremes of a continuum. There are many other examples, where the interface offers a mix of different options. For instance, on Facebook, other than having an open box to type down the status, users have the option to select a "Feeling/Activity". So, for example, if a user wants to share the experience of watching a movie, he/she can select the act of "Watching", then writes about his/her specific experience in an unstructured way. As another example, the Internet Movie Database (IMDB) provides an open box of summary, a drop-down list 
for a numerical vote and another open review box for users to review a movie (screenshots are provided in Appendix A).

Perhaps it is considered reasonable that each interface with a specific degree of structure is being used to satisfy a certain expectations of data creators or data consumers. However, the interesting point is we found differently designed interfaces, in terms of degree of structure, even in a similar context. In other words, we have many instances where similar data is being collected through interfaces with various degrees of structure. For example, Glassdoor (www.Glassdoor.com), a recruiting website, lets users review companies, by providing a form asking for overall rating ( 1 to 5 stars), employee status (two-choice question), employment status (Drop-down list), review title (blank field), Pros, Cons (open boxes) and advice to management. On the other hand, a similar website, Indeed (www.Indeed.com) asks for different information on reviewing a company including an open review box (other than the pros and cons) and star-ratings for different aspects (Figure 2). 


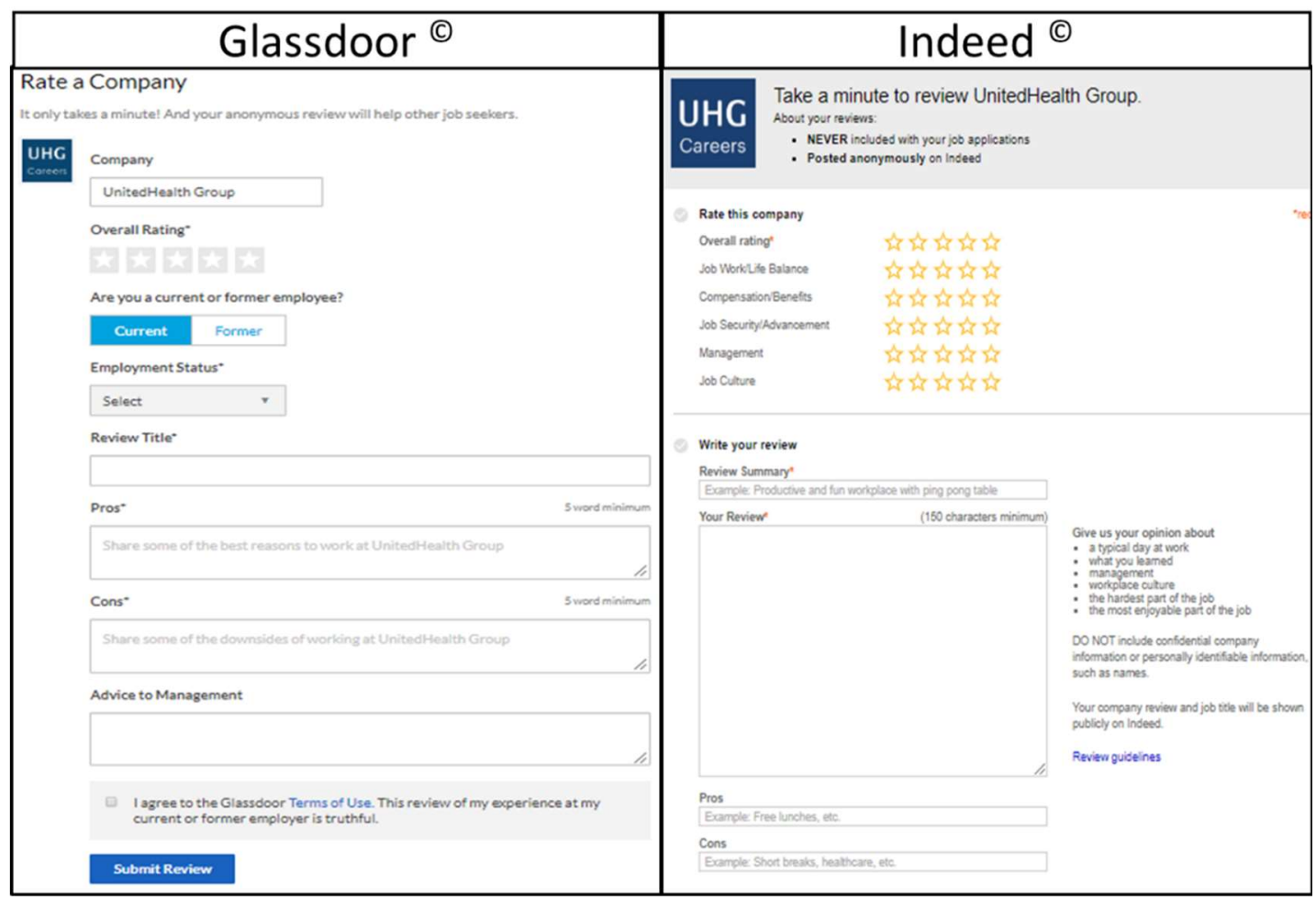

Figure 2 - Screenshot of two similar-purpose websites with different data-entry structure

Other than the existence of differently structured interfaces, there are evidences of users complaining about a given interface due to its level of structure. Some users express their frustration of using an interface that is not designed according to their expectation. For example, an Etsy user - an online marketplace - criticized the review platform for letting her rate the product, only if she writes a review. And since she doesn't want to write a review, she didn't rate the product. In the discussion forum, she literally wrote: "I just tried to leave a review. I clicked 5 stars but did not want to write anything... the page would not let me record the 5 stars without saying something, so I did not leave a review." (2016). As another example, in an online programming forum, a programmer complaining about having a problem gathering data, while users input something like “-5 seconds" in a field that meant to gather numeric data (2004). We can also see development and changes in the data creation platform of popular social networks such as Facebook or Twitter. As 
Gustafson (Gustafson 2011) mentioned, we could improve the Tweet box in Twitter by adding the "label" function. In healthcare, we can also see difficulties that physicians and nurses have with UGC platforms in Electronic Health record systems (EHRs). Doctors, who feel like data entry clerks, complain about lack of free flow of information, hard to find the intended information, usability frustration and time-consuming processes (Green 2015).

Interface design has been a critical focus in Human-Computer Interaction literature for many years. However, the lack of agreement on the appropriate degree of structure in interface design shows that this topic has yet to receive attention. Some studies show that the interface can influence the system outcome and users' perception of the system. In this study, we examine the following research question:

- Does designing information collection interfaces with different degrees of structure make any differences in data creators' Perceived Quality of Information Collection?

With the growing reliance by organizations on information produced by ordinary people, a pressing question is how to design user-generated systems in the most effective way. Specifically, considering the advantages and limitations of structured and unstructured data, we seek to understand which format is most appropriate for any given purpose.

\section{Degree of Structure}

We have to consider the manufacturing approach to the UGC, that the data is being created for being used by data consumers (Bidgoli 2014; Lee et al. 2006). Managers need data to be analyzed for different purposes including finding trends(Mathioudakis and Koudas 2010), predicting future's (Asur and Huberman 2010) needs, providing customized services (Hanna et al. 2011) and so on. Any shortcomings or flaws in the quality of data could lead databases to become filled with incomplete, or even worse, inaccurate data. Incomplete databases result in serious problems for data consumers (Strong et al. 1997; Wang et al. 1995; Xu et al. 2002). Besides, as we perceive from 
the comments of dissatisfied people, users get discouraged from these imperfect platforms (Kaplan and Haenlein 2010). This discouragement could eventually result in losing the user, and even other users, since a discouraged user will not be an advertiser for the system. All these consequences highlight the importance of data collection in the UGC setting.

Considering text as the most common format of UGC (Zhang et al. 2016), we found content recorded in different degrees of structure. Losee (2006) categorized the representation of data as structured, semi-structured or unstructured. The data is considered structured if it is organized in a highly regular way, and the regularity applies to all the data in the dataset (R. Losee 2006; Zhang et al. 2016). However, in semi-structured format, data might be interpreted with structural information supplied as tags, therefore the structural regularity across data items is gone (R. Losee 2006). Unstructured data comes in a variety of formats, including text messages and transcribed comments (Lahl 2011), and contains no explicit structuring information. As indicated by previous studies, there is no consensus on "the best level” of structure for UGC. For example, Walters (1961) argued that structured information outperforms unstructured information in attracting meaningful responses, while Gibson (1998) defended unstructured information in terms of generating greater depth and enabling the identification of details.

Each style of UGC interface design has advantages and disadvantages (R. Lukyanenko et al. 2014) and serves different purposes. Usually, when the data are created and stored in a structured form, the process of data creation is relatively transparent and well-controlled (Strong et al. 1997). Additionally, the resulting data are more organized and understandable. However, the lack of flexibility of structured data does not give users the freedom to create some potentially valuable data not is not specifically asked for (Zhang et al. 2016). On the other hand, the resulting data from an unstructured data entry format may be overarching and complete, but hard to analyze and understand (Buneman et al. 1997). Users have the flexibility in selecting what to input, however, there is always a chance of forgetting or ignoring some potentially valuable data. Notwithstanding 
the flexibility, however, another challenge is interpretation and analysis of unstructured data. Unstructured data is considerably more difficult to analyze.

Designing the interface has been a critical element in Human-Computer Interaction literature for many years. Researchers examined Interface design in different contexts including web retailers (Christine Roy et al. 2001), loyalty (Chang and Chen 2008), healthcare (Thyvalikakath et al. 2014) and so on. The common point of these studies is the importance of an efficient interface (Helander 2014; Plaisant and Shneiderman 2010). Some studies show that the interface can influence the system outcome and users' perception of the system. For example, studying web retailers, Roy et al. (2001) showed a strong relationship between interface design and users' trust in the website, which consequently result in the retailers' growth. Also, Shneiderman and Plaisant (2010) encourage interface improvement. They pointed out poor performance and users' frustration as results of interfaces with tedious and complex procedures and inadequate functionality.

\section{Theoretical Model and Propositions}

The user interface in UGC setting, that we refer to as the information collection interface, can be designed in different ways. There are a wide variety of factors that can be considered in designing the interface. Interface simplicity, generality, convenience, ease of navigation, functionality are some of the factors that have been studied in previous research (Fielding and Taylor 2002; Kim et al. 2001). One of the factors that has yet to be studied is the degree of structure of the interface. Losee (2006) used three categories for interface design in terms of degree of structure. A format with the lowest degree of data structure is the unstructured (flexible) format in which data fields are open boxes, and users can write their answers in sentences or paragraphs. On the other hand, a structured (fixed) format has a higher degree of structure in which users are allowed to select the preferred answer among the pre-defined options. In this format, data is collected through dropdown menus, multiple-choice options, or some kind of predefined categories (R. Losee 2006; 
Zhang et al. 2016). In this research, the design format and arrangement of the data collection interface is referred to as the degree of structure.

The concept of degree of structure has been studied, in previous studies(Buneman et al. 1997; R. Losee 2006; Turoff et al. 2004; Wand and Weber 1990). These studies showed the importance of this factor in collecting data from the crowd. Changes in the degree of structure of user interface result in variously-designed interfaces with different performances. Knowing that a well-designed interface can improve the performance of a system (Plaisant and Shneiderman 2010), we think that there could be a relationship between the degree of structure of information collection interface and the performance of the system. And as we discussed in the previous chapter, in the UGC setting, especially online communities, we assess the performance of the system by the perceived quality of information collection (PQoIC). Therefore, we propose:

Proposition 1 - In a UGC setting, different degrees of data structure for information collection interface result in different Perceptions of the Quality of Information Collection of the recorded outcome.

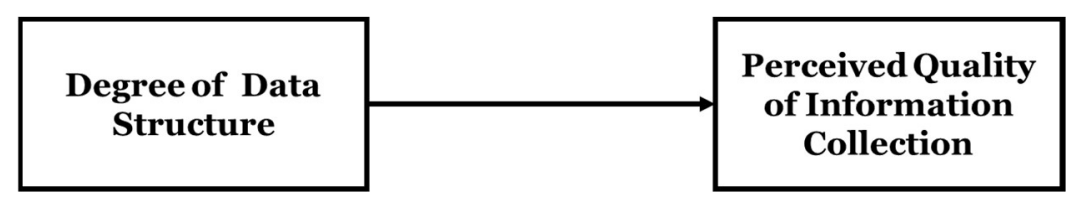

Figure 3 - Conceptual model - degree of structure

In order to decrease the effect of other factors in this relationship, we measure some other elements that could influence the effect. We consider some of the demographic characteristics of the participants and investigate them. Age, gender, education, and English language proficiency are some of the variables that we consider in this study. 


\section{Research model and hypotheses development}

As we discussed earlier, the degree of structure is a continuum and could not be examined for its all possible conditions. However, we can define and examine the two extremes of the degree of structure; totally unstructured and totally structured format. Structured data is organized in a highly regular way, and this regularity applies to all the data in a specific dataset (R. Losee 2006; Zhang et al. 2016). On the other hand, unstructured data comes in a variety of formats, including text messages and transcribed comments (Lahl 2011), and contains diverse, unformatted information (Zhang et al. 2016). In the context of relational database systems, Blumberg and Atre (2003) defined unstructured data as data that can't be stored in rows and columns. Moreover, based on Losee (2006), semi-structured data contains structural information supplied as tags. Lukyanenko et al. (2014) also used the instance-based format in their study, which adopts a similar rationale to semi-structured format. They used instance-based format to collect data, which loosens rigid requirements to classify instances, by letting users store any attribute associated with an observed instance. For the sake of simplicity and in order to see if we could figure out a pattern for different conditions, we follow Losee (2006) and define the third condition for our degree of structure: semistructured. In our study, semi-structured is basically similar to the unstructured format; however, we ask for hashtags to add some structure to our unstructured format.

On the other hand, we already break down our perceived quality of information collection construct into three levels: Content, Process, and Structure. As we discussed in Chapter 2, the content aspect of PQoIC is assessed in terms of perceived accuracy and completeness. Perceived ease and speed of data entry are the two dimensions of process sub-construct of PQoIC. And finally, to evaluate the structure sub-construct, we evaluate perceived flexibility and utility of structure. The following figure presents our research model: 


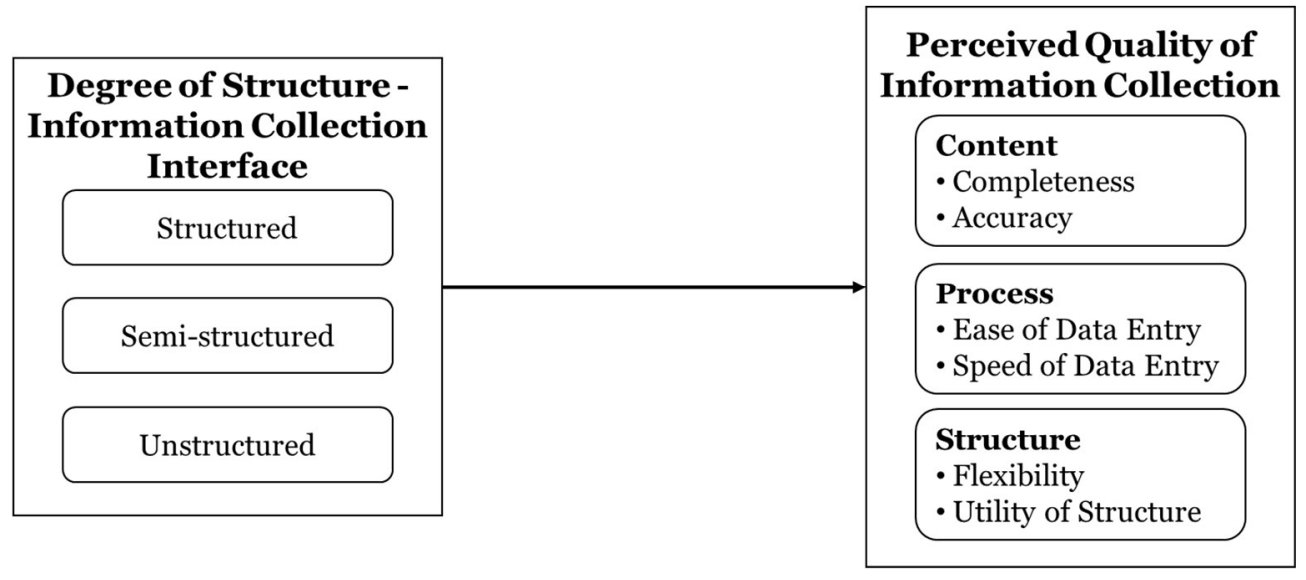

Figure 4 - Research model -Degree of structure

We have studied data creators' reaction to different interfaces. Our observations imply that data consumers chose the less-structured format when they are given the freedom to choose. Given the flexibility of the less-structured format, data creators might consider it more efficient in data collection. As we mentioned before, an unstructured information collection is potentially capable of collecting overarching complete data, because of its openness. On the other hand, a structured data entry format might ignore to collect potentially valuable data. With this consideration, we hypothesize:

- H1a - Data creators perceive that using less-structured information collection interfaces results in recording more complete and accurate data than using more-structured information collection interfaces.

- $\mathrm{H} 1 \mathrm{~b}$ - Data creators perceive that using less-structured information collection interfaces is easier and faster than using more-structured information collection interfaces.

- H1c - Data creators perceive that less-structured information collection interfaces are more flexible and let higher utilize of structure than more-structured information collection interfaces.

The following table summarizes the experiment design and our hypotheses: 


\begin{tabular}{|c|c|c|c|c|c|c|c|}
\hline & \multirow[b]{3}{*}{$\begin{array}{l}\text { Degree of } \\
\text { Structure }\end{array}$} & \multicolumn{6}{|c|}{ Perceived Quality of Information Collection } \\
\hline & & \multicolumn{2}{|c|}{ Content } & \multicolumn{2}{|c|}{ Process } & \multicolumn{2}{|c|}{ Structure } \\
\hline & & Completeness & Accuracy & $\begin{array}{c}\text { Ease of Data } \\
\text { Entry }\end{array}$ & $\begin{array}{l}\text { Speed of } \\
\text { Data Entry }\end{array}$ & Flexibility & $\begin{array}{l}\text { Utility of } \\
\text { Structure }\end{array}$ \\
\hline \multirow{3}{*}{ 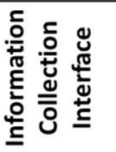 } & Structured & & & & & & \\
\hline & Semi-Structured & & & & & & \\
\hline & Unstructured & & & & & & \\
\hline
\end{tabular}

Figure 5 - Experiment design

In the next section, we discuss the methodology of this study.

\section{Methodology}

An experimental methodology is used to study the relationship between the degree of data structure in interface design and the perceived quality of information collection in online communities. We consider the two main stakeholders in online communities: data creators and data consumers. So, in our study, we examine the perception of both data creators and data consumers. For data creators' point of view, we designed a completed randomized experiment where participants used differently designed interfaces and evaluated their data recording experience for each experiment. For data consumers' point of view, we run another experiment to evaluate the data consumers' perception of the quality of the outcome. The following sections describe our experiment designs.

\section{Experimental design - Data creators}

We want to investigate whether designing information collection interfaces with different degrees of structure make any differences in data creators' perception of Information Quality. So, we decided to run an experiment where similar tasks are being completed using different interfaces. The experiment is conducted via Amazon Mechanical Turk. So, we don't have access to the participants, and we can't control every variable in the experiment. 
To run the experiment, we designed three different interfaces and define a scenario. The participants are randomly assigned to one of the interfaces to respond to the scenario's questions. After responding to the question(s) - using the assigned interface - the participants are given a survey to assess their perception of the quality of information collection based on the used interface. The items in the survey are measured by a 7-point Likert type scale, with values ranging from 1 (very unimportant or strongly disagree) to 7 (very important or strongly agree).

Before beginning the experiment, the participants are presented with a brief description of the experiment and research. When they consent to participate in the study, they are presented with a short demographic survey, which asks about their gender, age range, education, and English language proficiency. We argue that this relationship might be affected by some other factors. According to several studies (Hernández et al. 2011; Ong and Lai 2006; Zheng et al. 2013), age, gender and education may influence online users' data creation performance. Moreover, since some participants are assigned to an interface that requires writing their experience, we think that not being proficient in the English language might affect the responses. So, we decide to control this variable as well.

\section{Information Collection Interface}

As we mentioned earlier, the information collection interface is studied in this research in terms of degree of structure. Following Losee's (2006) categorization, we designed three interfaces with the following features:

- The unstructured (flexible) format which Comes in a variety of formats and contains no explicit structuring information; In our experiment, the unstructured format represents with open box field, where users can write their answers in the form of sentences or paragraphs.

- The semi-structured format in which data might be interpreted with structural information supplied as tags, therefore the structural regularity across data items is gone; 
As we mentioned earlier, there are too many possible conditions for a semi-structured format. For the sake of simplicity and in order to see if we could figure out a pattern for different conditions, our semi-structured format is similar to the unstructured format with one big difference. The unstructured open box field is accompanied by three hashtag fields, and the participants are required to create at least two hashtags. They can create a hashtag by typing \# following by a term. This term can be a keyword or an important point of the answer.

- The structured (fixed) format which is organized in a highly regular way and the regularity applies to all the data in the dataset; This interface has to result in a totally structured outcome. So, we let participants record content only by selecting answers from a pre-defined list. This interface contains a list of multiple-choice questions. One important point in designing this interface was to make sure that we have a comprehensive list of questions. In other words, a participant who uses unstructured format is free to write whatever they want regarding the experience. For example, while talking about the flight experience, he/she can talk about an annoying baby who sat in the front row. However, in a structured format, participants do not have the freedom to write down their experiences and they are only allowed to answer the given questions by choosing from a list of answers. So, we had to make sure that the given questions cover as much as the possible experiences that the participants wanted to share. Therefore, we interviewed 10 different volunteers who had a recent flight experience. The interviewees were 5 male and 5 females ranging from 22 years old to 47 years old. The interviews were unstructured, and we ask volunteers to talk about their experience at the airport and during the flight. Based on the results of these interviews, we came up with a list of questions that covers all the experiences of the interviewees. Even though there could be always a very rare and unique 
piece of experience, we think that our list of questions for structured format could potentially cover almost all the experiences that our future participants are willing to share. A complete list of tasks for this experiment is provided in Appendix B.

\section{Scenario}

To receive more reliable results from the experiment, we needed to mentally and emotionally involve participants with the study. To get them involved, we need to define the tasks in a context that could attract participants' attention. We propose that the context must be something that participants have experience in, care about and feel that their participation might make an improvement. After reviewing different contexts and possible topics for our experiment tasks, we found out that participants' experience with an airline during a flight could be a good topic. It's something that most people deal with. And it usually somehow bothers people. People usually experiencing problems in buying tickets, long lines for check-ins, long lines for getting into the plane, and so on. We argue that seeing tasks in this context evokes participant's emotion and make them emotionally engaged with the experiment hoping their answers might somehow improve the process.

We consider two major elements of this experience: checking-in (including passengers experiences from the moment that they get to the airport to the moment that they get onto the plane) and flight (including passengers experience from the moment that they get onto the plane until they get off at the destination). The scenario asks participants to imagine their last (or most memorable experience) and ask them to share their experience. Before starting the task, we asked participants if they had flight experience within the last 10 years. If they do, they can take the task.

\section{PQoIC instrument}

We aim to examine the effects of the degree of data structure on the perceived quality of information collection. As we explained in Chapter 2, we have defined three sub-constructs to 
evaluate the PQoIC. The content sub-construct focuses on the quality of the outcome and is evaluated by measuring the data creators' perceived completeness and perceived accuracy of the recorded content. The process sub-construct investigating the data creation process with two dimensions that evaluates data creators' perception of ease and speed of data entry. And finally, the structure sub-construct aims to measures data creators' perception of the Flexibility and Utility of structure of the given interface. In our survey instrument, each item is measured by a 7-point Likert type scale, with values ranging from 1 (very unimportant or strongly disagree) to 7 (very important or strongly agree). A higher value represents greater importance or agreement perceived by the respondents.

The following table summarizes the experiment condition.

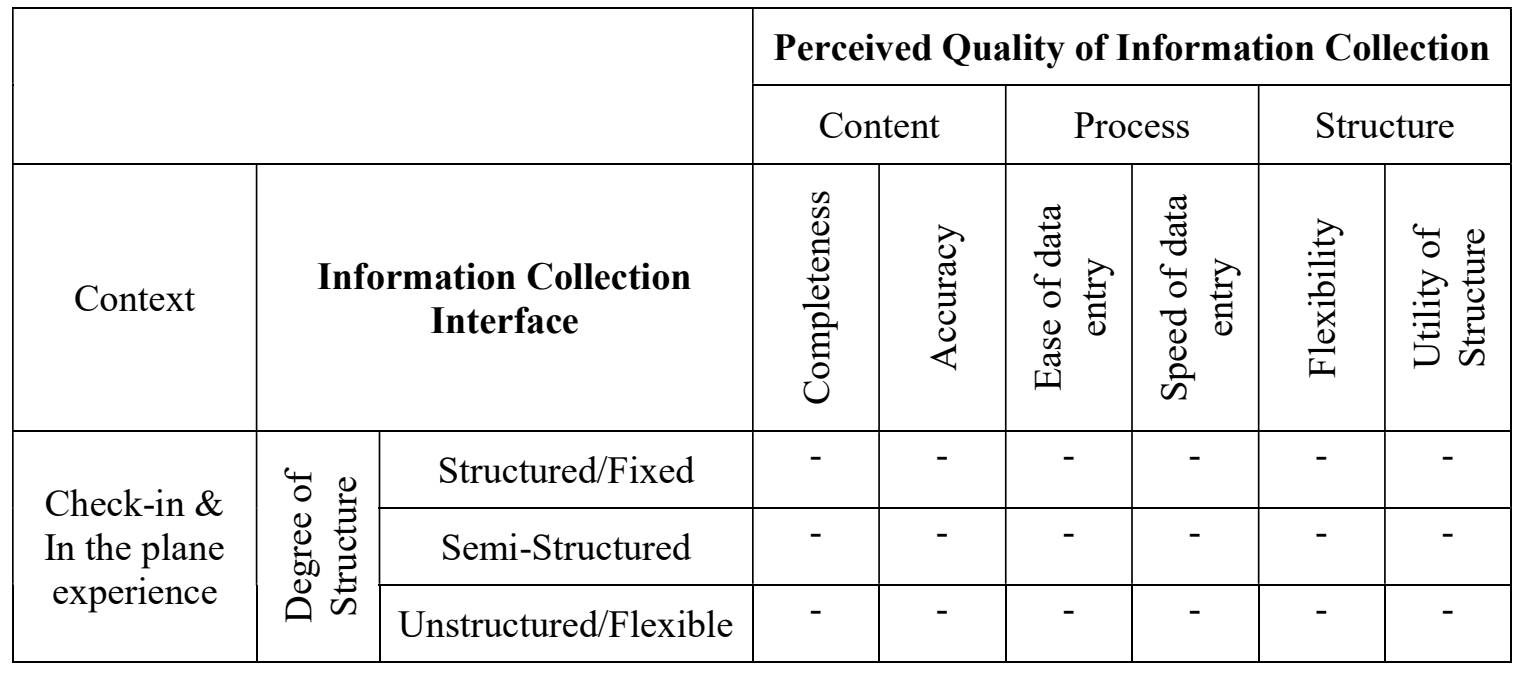

Figure 6 - Experiment conditions

Other than the mentioned control variables, we think that the fact that how well the participant remembers details of the experiment could affect the response. Even though we ask them to share a memorable experience, the perception of how well they remember it should be considered. So, we ask participants to rate their perception of remembering the experience on a 7-point Likert scale. Furthermore, we propose the extent that participants feel they are involved and interested in the 
task should be considered. A not-interested participant might have a different perception of quality than an interested participant. So, we used measurement to assess participants' involvement with the task (Kramer 2007; Wang and Keh 2017).

\section{Experiment design - Data consumers}

To examine data consumers perception about the quality of information collection, we run another experiment. In order to have a better understanding of the quality of the outcome, we need to evaluate both data creators and data consumers perception. As a data creator might feel that he/she was able to record very useful information, but the recorded content might not be of any use for the data consumer. In the previous experiment, we measure data creator's perception of the quality of information that is collected through interfaces with various degrees of structure. In this experiment, we measure data consumers perception of the quality of the content that is recorded using each one of the interfaces.

In this experiment, we evaluate the recorded content of the structured and unstructured format. Each participant is randomly given either an unstructured content or a structured content. The unstructured content is shown as a text box, whereas structured content is shown as a brief table. Figure 7 provides an example of a piece of response collected through an unstructured interface. 
I remember this one time I was flying domestic within the United States on a day with really bad winds along the East Coast. I was travelling with my father to visit a potential college. We were flying in a small plane with many business people. It was a short flight scheduled to land in D.C. and after we were to have a connecting flight home from there. When we arrived above D.C. and it was time to descent for landing, we encountered a lot of turbulence as we came down. The plane had to circle multiple times in an attempt to come in for landing and was unable to descend safely due to the conditions. Everyone was feeling quite nauseated from the turbulence and many people were throwing up. I held onto my stomach, as did my

father, but we felt very ill. The pilot decided we had to divert to Baltimore, MD instead because we were beginning to run low on fuel and we would try landing there instead. The plane was finally able to successfully land in Baltimore to refuel. The plan after that was to

try again to return to D.C. and land there so people could hopefully get where they were intending to go and make their connections. We had the option to get off in Baltimore if we wished or continue on to D.C. More than half of the passengers chose to get off, including my father and me. This was probably my worst flight experience and the worst turbulence

I've ever experienced. I now have a food aversion to a specific granola bar I was eating because of it.

Figure 7 - A sample of unstructured content

Figure 8 provides an example of a piece of content collected through an unstructured interface. 


\begin{tabular}{|c|c|c|c|c|c|c|c|c|c|c|c|c|c|c|c|c|c|}
\hline \multicolumn{12}{|c|}{ *Answers in GREEN. / "Other" indicates answers that are not listed. } & \multicolumn{6}{|c|}{ ID: Flight.T6.HS.G.327 } \\
\hline \multicolumn{6}{|c|}{$\begin{array}{l}\text { When did this experience (the one that } \\
\text { you chose and want to share) happen? }\end{array}$} & \multicolumn{3}{|c|}{$\begin{array}{l}\text { Within past } 6 \\
\text { month }\end{array}$} & \multicolumn{3}{|c|}{$\begin{array}{l}6 \text { months to } \\
1 \text { year ago }\end{array}$} & \multicolumn{2}{|c|}{$\begin{array}{l}1-2 \text { years } \\
\text { ago }\end{array}$} & \multicolumn{2}{|c|}{$\begin{array}{l}2-4 \text { years } \\
\text { ago }\end{array}$} & \multicolumn{2}{|c|}{$\begin{array}{l}\text { More than } 4 \\
\text { years ago }\end{array}$} \\
\hline $\begin{array}{l}\text { Which airline } \\
\text { did you fly on? }\end{array}$ & \multirow{2}{*}{\multicolumn{2}{|c|}{$\begin{array}{l}\text { American } \\
\text { Airlines } \\
\text { you carry } \\
\text { abin? }\end{array}$}} & \multirow{2}{*}{\multicolumn{2}{|c|}{\begin{tabular}{|l}
$\begin{array}{l}\text { Delta } \\
\text { Airlines }\end{array}$ \\
Carry-on \\
bag
\end{tabular}}} & \multirow{2}{*}{\multicolumn{2}{|c|}{$\begin{array}{l}\text { United } \\
\text { Airlines } \\
\text { Laptop } \\
\text { bag }\end{array}$}} & \multicolumn{2}{|c|}{ JetBlue } & \multicolumn{3}{|c|}{$\begin{array}{l}\text { Southwest } \\
\text { Airlines } \\
\end{array}$} & $\begin{array}{l}\text { Spirit } \\
\text { Airlines } \\
\end{array}$ & \multicolumn{2}{|c|}{$\begin{array}{l}\text { Frontier } \\
\text { Airlines }\end{array}$} & $\begin{array}{l}\text { A non-US } \\
\text { Airline }\end{array}$ & \multicolumn{2}{|c|}{ Other } \\
\hline $\begin{array}{l}\text { Which items did you carry } \\
\text { to the aircraft's cabin? }\end{array}$ & & & & & & & \multicolumn{2}{|c|}{ Purse } & \multicolumn{3}{|c|}{$\begin{array}{l}\text { Musical } \\
\text { Instrument }\end{array}$} & Stroller & Cane & \multicolumn{2}{|c|}{ Umbrella } & $\begin{array}{l}\text { Suite } \\
\text { cover }\end{array}$ & Other \\
\hline \multicolumn{6}{|c|}{$\begin{array}{l}\text { After passing through the jetway, how long } \\
\text { did it take for you to get to your seat? }\end{array}$} & & $\begin{array}{l}\text { ess tha } \\
\text { ninutes }\end{array}$ & an 2 & & & $5 \mathrm{~min}$ & utes & $5-10 \mathrm{~m}$ & ninu & $\mathrm{Mc}$ & $\begin{array}{l}\text { lore th } \\
\text { inutes }\end{array}$ & an 10 \\
\hline Where was you & seat? & & & By th & e win & Idow & & $y$ the & aisle & & Betwe & en two o & ther seat & & Other & & \\
\hline Did you have ar & troubl & e get & tting $\mathbf{t}$ & o you & ar sea & & Yes & & & & & A little bit & & & No & & \\
\hline $\begin{array}{l}\text { Where did you } \\
\text { your carry on it }\end{array}$ & & $\begin{array}{l}\text { Und } \\
\text { the }\end{array}$ & $\begin{array}{l}\text { ler } \\
\text { seat }\end{array}$ & & $\begin{array}{l}\text { he o } \\
\text { npart }\end{array}$ & $\begin{array}{l}\text { verhe } \\
\text { tmen }\end{array}$ & & $\begin{array}{l}\text { Fron } \\
\text { pock }\end{array}$ & $\begin{array}{l}\text { nt se } \\
\text { ket }\end{array}$ & & $\begin{array}{l}\text { Holdi } \\
\text { your }\end{array}$ & $\begin{array}{l}\text { ing in } \\
\text { hands }\end{array}$ & $\begin{array}{l}\text { Handing } \\
\text { flight at }\end{array}$ & $\begin{array}{l}\text { g to } \\
\text { tten }\end{array}$ & a & ner & \\
\hline How comfortab & was y & our $s$ & eat? & & & & Very & com & nforta & ble & & Acceptak & ble & & Annoyin & & \\
\hline Did you have ar & troubl & e dur & ring tr & he tal & re of & & Not & at all & & & & Mild disc & comfort & & It was tr & rouble & some \\
\hline Did you have ar & troubl & e dur & ring th & he lar & ding & & Not & at all & & & & Mild disc & comfort & & It was tr & rouble & some \\
\hline $\begin{array}{l}\text { How would you } \\
\text { experience of } d\end{array}$ & $\begin{array}{l}\text { ate you } \\
\text { aling w }\end{array}$ & & & & $\begin{array}{l}y \\
\text { satisfi }\end{array}$ & & $\begin{array}{l}\text { Some } \\
\text { dissat }\end{array}$ & what & & Veutr & tral & $\begin{array}{l}\text { Som } \\
\text { satis }\end{array}$ & $\begin{array}{l}\text { newhat } \\
\text { sfied }\end{array}$ & & $\begin{array}{l}\text { ery } \\
\text { tisfied }\end{array}$ & N/A & \\
\hline $\begin{array}{l}\text { The attendant } \\
\text { the food/bever }\end{array}$ & $\begin{array}{l}\text { ho serv } \\
\text { ge }\end{array}$ & & & & & & & & & & & & & & & & \\
\hline $\begin{array}{l}\text { The attendant } \\
\text { your call }\end{array}$ & o resp & 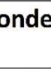 & ed to & & & & & & & & & & & & & & \\
\hline Flight attendan & in gen & eral & & & & & & & & & & & & & & & \\
\hline Person who sat & ext to & jou & & & & & & & & & & & & & & & \\
\hline Other passenge & 5 in gen & eral & & & & & & & & & & & & & & & \\
\hline $\begin{array}{l}\text { Rate the follow } \\
\text { during the fligh }\end{array}$ & g servi & & $\begin{array}{l}\text { Very } \\
\text { dissa }\end{array}$ & tisfie & & $\begin{array}{l}\text { Som } \\
\text { dissa }\end{array}$ & $\begin{array}{l}\text { what } \\
\text { isfied }\end{array}$ & & Veutra & & $\begin{array}{l}\text { Some } \\
\text { satisf }\end{array}$ & $\begin{array}{l}\text { ewhat } \\
\text { fied }\end{array}$ & $\begin{array}{l}\text { Very } \\
\text { satisfied }\end{array}$ & & $\begin{array}{l}\text { Was Not } \\
\text { Offered }\end{array}$ & & $\begin{array}{l}\text { Not } \\
\text { it }\end{array}$ \\
\hline On-seat control & creen & & & & & & & & & & & & & & & & \\
\hline $\begin{array}{l}\text { Personal entert } \\
\text { system }\end{array}$ & ment & & & & & & & & & & & & & & & & \\
\hline Public cabin scr & ens & & & & & & & & & & & & & & & & \\
\hline Radio service & & & & & & & & & & & & & & & & & \\
\hline Internet service & & & & & & & & & & & & & & & & & \\
\hline $\begin{array}{l}\text { In-flight drink/f } \\
\text { purchase servic }\end{array}$ & & & & & & & & & & & & & & & & & \\
\hline Free drink/food & service & & & & & & & & & & & & & & & & \\
\hline Kids entertainm & ent serv & & & & & & & & & & & & & & & & \\
\hline $\begin{array}{l}\text { To the best of y } \\
\text { did each of the }\end{array}$ & $\begin{array}{l}\text { ur reco } \\
\text { ollowin }\end{array}$ & $\begin{array}{l}\text { lecti } \\
\text { tak }\end{array}$ & $\begin{array}{l}\text { ion, ho } \\
\text { e? }\end{array}$ & ow lo & & $\begin{array}{l}\text { less } \\
5 \mathrm{mi}\end{array}$ & $\begin{array}{l}\text { than } \\
\text { nutes }\end{array}$ & & $\begin{array}{l}\text { to } 15 \\
\text { inutes }\end{array}$ & & $\begin{array}{l}15 \mathrm{tc} \\
\min \mathrm{t}\end{array}$ & $\begin{array}{l}\text { to } 30 \\
\text { uutes }\end{array}$ & $\begin{array}{l}30 \text { to } 45 \\
\text { minutes }\end{array}$ & & $\begin{array}{l}45 \text { to } 60 \\
\text { minutes }\end{array}$ & & $\begin{array}{l}\text { e than } \\
\text { our }\end{array}$ \\
\hline $\begin{array}{l}\text { The moment yo } \\
\text { the plane starte }\end{array}$ & $\begin{array}{l}\text { get to } \\
\text { to mo }\end{array}$ & $\begin{array}{l}\text { your } \\
\text { je }\end{array}$ & seat & until & & & & & & & & & & & & & \\
\hline $\begin{array}{l}\text { The moment th } \\
\text { until it took of }\end{array}$ & lane & & ed to & move & & & & & & & & & & & & & \\
\hline The flight durat & & & & & & & & & & & & & & & & & \\
\hline $\begin{array}{l}\text { The moment pl } \\
\text { stopped for dis }\end{array}$ & $\begin{array}{l}\text { e land } \\
\text { Ibarki }\end{array}$ & & ntil t & e pl & & & & & & & & & & & & & \\
\hline $\begin{array}{l}\text { The moment th } \\
\text { got out of the } p\end{array}$ & $\begin{array}{l}\text { plane } \\
\text { le }\end{array}$ & & ped & ntil & & & & & & & & & & & & & \\
\hline
\end{tabular}

Figure 8 - A sample of structured content

After seeing the content, each participant is given a short survey which includes both scaled and open-ended questions. We follow a qualitative approach for this experiment to explore data consumers perception about each type of content. The survey is provided in Appendix C. 


\section{Data collection}

We recruited our participants through the Amazon Mechanical Turk (MTurk). MTurk is a crowdsourcing platform that offers access to large numbers of job requesters (people who post micro-tasks (Deng et al. 2016)) and crowd workers (people who perform the tasks (Deng et al. 2016)). It allows crowd workers to perform tasks in exchange for monetary rewards (Buhrmester et al. 2011; O'Leary et al. 2014). Previous studies show various applications of MTurk in research. It has been widely used for different purposes including language transcriptions (Marge et al. 2010), experiment designs (Bursztein et al. 2010), qualitative designs (Ward and Broniarczyk 2011) and user evaluation studies (Sorokin et al. 2010). To run this experiment, we create microtasks in crowdsourcing (CS) platform, specifically Amazon Mechanical Turk (MTurk), and ask participants to perform the tasks.

In the past few years, MTurk has been increasingly used by researchers from different disciplines, as a method for collecting data. The benefits of MTurk, including diverse (Ross et al. 2010) and motivated (Kaufmann et al. 2011) international online workforce and the monetary incentives (Steelman et al. 2014b), persuade several researchers to consider this crowdsourcing platform as a promising research tool (Mogilner et al. 2012; Yu and Nickerson 2011). For example, Alonso and Mizzaro (2012) used MTurk as a cheap and reliable alternative for the relevance assessment of information retrieval. MTurk has been also used for running field experiments in economics (Chandler and Kapelner 2013). The MTurk is becoming so popular that Mason and Suri (2012b) discussing using it in conducting behavioral research by providing detailed guidelines. Besides, Steelman et al. (Steelman et al. 2014b) proposed using platforms such as MTurk as an alternative to student surveys for conducting research. The reliability of this platform for conducting academic research has been examined by researchers in different aspects (O'Leary et al. 2014). Paolacci et al. (2010) compared MTurk to other subject pools and showed that respondents obtained via MTurk

are at least as representative of the U.S. population as traditional student subject pools. They also 
posited that the MTurk respondents are more representative of the general workforce in terms of age than the traditional respondents. Moreover, MTurk participants tend to have more work experience and be more ethnically diverse (Behrend et al. 2011). Generally, several studies have shown that the reliability of the data obtained from MTurk or similar crowdsourcing platforms, is as good as or even better than data from more traditional subject pools (Behrend et al. 2011; Buhrmester et al. 2011; Casler et al. 2013).

We ask MTurk workers aging from 18 to 60 years old and live in the United States to participate in the experiments. Considering the shortcomings of design features on MTurk, we decided to design the experience on Qualtrics and put a hyperlink on the MTurk task. So, MTurk workers who decided to participate in our study are directed to the Qualtrics experiment using a hyperlink. We want to clarify that this is an exploratory study to examine the effects of the degree of structure on perceived quality. We are investigating three differently designed interfaces. So, there is no treatment or control group in our study, since we don't have any base or standard treatment. Also, in order to minimize the bias in our study, we follow a between-subject design. So, each participant is allowed to take part in the experiment only once. Therefore, the participants record their responses using only one of the three interfaces. Moreover, to decrease the risk of receiving corrupted data, we needed to make sure that the participants are actually sharing their own experience by using the given interface. So, using an JS code, we disabled the copy/paste feature on the page of the experiment.

\section{Analyses and results}

\section{Instrument validation}

We used Confirmatory Factor Analyses to test how well our instrument items measure the related variables. We developed our instrument based on the previous research and modify some items. So, in order to make sure that the instrument is actually measuring what we want it to measure, we 
run a factor analysis using LISREL. The consistency and the stability of a score from a measurement scale are assessed with reliability tests. We performed an internal consistency analysis to assess the reliability and consistency of our instrument. The results of the CFA suggest dropping one item from each of the variables. For testing internal consistency reliability, we used Cronbach's alpha. Cronbach's alpha helps in estimating the proportion of systematic or consistent variance in a given sample of test scores.

\begin{tabular}{|c|c|c|c|}
\hline Dimension & $\begin{array}{c}\text { Number } \\
\text { of items }\end{array}$ & $\begin{array}{c}\text { Cronbach's } \\
\text { alpha }\end{array}$ & $\begin{array}{c}\text { Cronbach's alpha based on } \\
\text { standardized items }\end{array}$ \\
\hline Completeness & 3 & .942 & .942 \\
\hline Accuracy & 3 & .870 & .884 \\
\hline Ease of data entry & 3 & .894 & .894 \\
\hline Speed of data entry & 3 & .839 & .847 \\
\hline Flexibility & 3 & .729 & .735 \\
\hline Utility of structure & 3 & .870 & .873 \\
\hline
\end{tabular}

Table 2 - Instrument factor loading

This shows that the final listed items are internally consistent and reliable. The following table lists the measurement items that we used in the final questionnaire.

\begin{tabular}{|c|c|c|c|c|c|c|c|}
\hline Sub & Dimension & Item & $\begin{array}{c}\text { CFA } \\
\text { Loading }\end{array}$ & Mean & $\begin{array}{c}\text { Cronbach's } \\
\text { Alpha }\end{array}$ & $\begin{array}{c}\text { Cronbach's } \\
\text { Alpha }\end{array}$ & $\begin{array}{l}\text { CA - } \\
\text { Stand. }\end{array}$ \\
\hline \multirow{6}{*}{ Content } & \multirow{3}{*}{ Completeness } & Comp1 & 0.89 & 5.83 & \multirow{3}{*}{0.942} & \multirow{6}{*}{0.934} & \multirow{6}{*}{0.935} \\
\hline & & Comp2 & 0.96 & 5.78 & & & \\
\hline & & Comp3 & 0.91 & 5.82 & & & \\
\hline & \multirow{3}{*}{ Accuracy } & Accu1 & 0.75 & 5.69 & \multirow{3}{*}{0.870} & & \\
\hline & & Accu2 & 0.89 & 6.15 & & & \\
\hline & & Accu3 & 0.91 & 6.10 & & & \\
\hline \multirow{6}{*}{ Process } & \multirow{3}{*}{$\begin{array}{c}\text { Ease of Data } \\
\text { Entry }\end{array}$} & Ease1 & 0.73 & 6.14 & \multirow{3}{*}{0.894} & \multirow{6}{*}{0.862} & \multirow{6}{*}{0.872} \\
\hline & & Ease 2 & 0.91 & 6.20 & & & \\
\hline & & Ease3 & 0.94 & 6.19 & & & \\
\hline & \multirow{3}{*}{$\begin{array}{l}\text { Speed of } \\
\text { Data Entry }\end{array}$} & Spee1 & 0.75 & 5.37 & \multirow{3}{*}{0.839} & & \\
\hline & & Spee2 & 0.88 & 5.60 & & & \\
\hline & & Spee3 & 0.79 & 5.54 & & & \\
\hline \multirow{5}{*}{ Structure } & \multirow{3}{*}{ Flexibility } & Flex 1 & 0.74 & 5.05 & \multirow{3}{*}{0.729} & \multirow{5}{*}{0.867} & \multirow{5}{*}{0.871} \\
\hline & & Flex2 & 0.76 & 5.48 & & & \\
\hline & & Flex3 & 0.58 & 5.21 & & & \\
\hline & \multirow{2}{*}{$\begin{array}{l}\text { Utility of } \\
\text { Structure }\end{array}$} & Utill & 0.76 & 5.45 & \multirow{2}{*}{0.870} & & \\
\hline & & Util2 & 0.89 & 5.68 & & & \\
\hline
\end{tabular}




\begin{tabular}{|c|c|c|c|c|c|c|c|}
\hline Sub & Dimension & Item & $\begin{array}{c}\text { CFA } \\
\text { Loading }\end{array}$ & Mean & $\begin{array}{c}\text { Cronbach's } \\
\text { Alpha }\end{array}$ & $\begin{array}{c}\text { Cronbach's } \\
\text { Alpha }\end{array}$ & $\begin{array}{c}\text { CA - } \\
\text { Stand. }\end{array}$ \\
\hline & & Util3 & 0.85 & 5.57 & & & \\
\hline
\end{tabular}

Table 3 - Finalized items

\section{Descriptive Statistics}

We run our experiment through the Amazon Mechanical Turk and received 364 responses. First, we need to make sure that our collected data is of high quality. So, we cleaned the collected data by detecting and removing the corrupt datapoints. In order to do so, we consider two factors: timing and our Captcha item. As Qualtrics records the timing of each task, we knew how much time each participant spent on each task. To be consistent for different interfaces, we considered the time spent on our final survey (which was constant for all the participants). We wanted to figure out the minimum time required to spend on the survey. We asked three graduate students volunteers, who considered themselves fast-reader, to time themselves while reading and understanding the survey as fast as possible. Based on the result of this exercise, we figured that the minimum reasonable time to spend on the survey is 30 seconds. So, we dropped 42 responses, in which the participants spent less than 30 seconds, since they probably did not pay enough attention to the tasks. Further, as we mentioned in Chapter 2, we had one captcha item among the items of the speed of data entry dimension. Based on the nature of the items, it does not make sense if someone's response to this item is similar to his/her response to the other two items of this dimension. So, we assumed that those responses are given by participants who did not pay attention enough. So, we dropped those items too.

The final data set includes 242 responses. 124 participants $(51.2 \%)$ responded to the checking-in scenario (pre-flight), while the other 118 participants $(48.8 \%)$ responded to the on-plane experience scenario. Our participants include 145 (59.9\%) female and 97 (40.1\%) male MTurk workers, and they represent a wide range of age from 18 to over 55 years old. More than 83 percent of the participants hold at least a college degree. And more than 97 percent were native English 
speakers, so they did not have a language proficiency barrier to respond to the questions. The following table summarizes the descriptive statistics of our participants.

\begin{tabular}{|c|c|c|c|}
\hline \multirow{3}{*}{ Context } & Flight & 124 & $51.2 \%$ \\
\hline & Pre-flight & 118 & $48.8 \%$ \\
\hline & Total & 242 & $100.0 \%$ \\
\hline \multirow{3}{*}{ Gender } & Female & 145 & $59.9 \%$ \\
\hline & Male & 97 & $40.1 \%$ \\
\hline & Total & 242 & $100.0 \%$ \\
\hline \multirow{6}{*}{ Age } & $18-24$ years old & 28 & $11.6 \%$ \\
\hline & $25-34$ & 93 & $38.4 \%$ \\
\hline & $35-44$ & 53 & $21.9 \%$ \\
\hline & $45-54$ & 33 & $13.6 \%$ \\
\hline & 55 and over & 35 & $14.5 \%$ \\
\hline & Total & 242 & $100.0 \%$ \\
\hline \multirow{5}{*}{ Education } & College & 63 & $26.0 \%$ \\
\hline & Graduate & 48 & $19.8 \%$ \\
\hline & High School & 41 & $16.9 \%$ \\
\hline & Undergraduate & 90 & $37.2 \%$ \\
\hline & Total & 242 & $100.0 \%$ \\
\hline \multirow{4}{*}{$\begin{array}{l}\text { Language } \\
\text { Proficiency }\end{array}$} & Beginner & 1 & $0.4 \%$ \\
\hline & Native English speaker & 235 & $97.1 \%$ \\
\hline & $\begin{array}{l}\text { NOT native English } \\
\text { speaker, but proficient }\end{array}$ & 6 & $2.5 \%$ \\
\hline & Total & 242 & $100.0 \%$ \\
\hline
\end{tabular}

Table 4 - Descriptive statistics

As we mentioned earlier, we have designed three different interfaces for this experiment and each respondent was assigned to one of these interfaces. However, we wanted to make sure that the respondents are actually getting engaged with the task and sharing their experiences. For the structured format, where multiple questions were asked, each participant had to respond to all the questions, i.e. the system would not let you submit your responses unless the participant responses to all the questions. However, for the unstructured and semi-structured, the condition was different, because the participants may share very little about the experience. To control this situation, we added two more interfaces to the experiment: conditional structured and conditional semi- 
structured. Conditional structured (or Conditional semi-structured) interface was exactly similar to the regular structured (or semi-structured) interface, except that the participants' response was required to be at least 700 characters. The analyses of the final dataset show that even for the regular interfaces, where we did not imply any minimum character requirement, the average number of the character for received responses were around 700 characters. The following table shows the distribution of responses for each interface.

\begin{tabular}{|l|r|r|r|}
\hline Interface & Label & $\begin{array}{r}\text { Number of } \\
\text { responses }\end{array}$ & Percentage \\
\hline Highly Structured & HS & 69 & $28.5 \%$ \\
\hline Semi-structured (Minimum 700 characters) & SS & 33 & $13.6 \%$ \\
\hline Semi-structured (no-minimum characters applied) & SS & 46 & $19.0 \%$ \\
\hline Unstructured (Minimum 700 characters) & US & 42 & $17.4 \%$ \\
\hline Unstructured (no-minimum characters applied) & US & 52 & $21.5 \%$ \\
\hline Total & & $\mathbf{2 4 2}$ & $\mathbf{1 0 0 . 0 \%}$ \\
\hline
\end{tabular}

Table 5 - Response distribution for each interface

\section{Analyses}

To evaluate the differences between the interfaces, we compare the result of surveys that were submitted by participants after using each interface. We examine how data creators rate different aspects of each interface and investigate how different degrees of structure could affect data creators' perception of the quality of information collection. First, we looked at the mean and standard deviation of the dimensions. Table 6 summarizes the statistics for each interface.

\begin{tabular}{|c|c|c|c|c|c|c|c|}
\hline \multirow{2}{*}{$\begin{array}{c}\text { Sub- } \\
\text { construct }\end{array}$} & \multirow{2}{*}{ Dimension } & \multicolumn{6}{|c|}{ Unstructured } \\
\cline { 3 - 8 } & & $\mathbf{N}$ & Mean & Std. Dev & Std. Err & Min & Max \\
\hline \multirow{2}{*}{ Content } & Completeness & 94 & 6.18 & .892 & .092 & 2 & 7 \\
\cline { 2 - 8 } & Accuracy & 94 & 6.26 & .867 & .089 & 4 & 7 \\
\hline \multirow{3}{*}{ Process } & Ease of Data Entry & 94 & 6.18 & .927 & .096 & 2 & 7 \\
\cline { 2 - 8 } & Speed & 94 & 5.38 & 1.237 & .128 & 1 & 7 \\
\hline \multirow{2}{*}{ Structure } & Flexibility & 94 & 5.37 & 1.057 & .109 & 3 & 7 \\
\cline { 2 - 8 } & Utility of Structure & 94 & 5.74 & .961 & .099 & 2 & 7 \\
\hline
\end{tabular}




\begin{tabular}{|c|c|c|c|c|c|c|c|}
\hline \multirow{2}{*}{$\begin{array}{c}\text { Sub- } \\
\text { construct }\end{array}$} & \multirow{2}{*}{ Dimension } & \multicolumn{6}{|c|}{ Unstructured } \\
\hline & & $\mathbf{N}$ & Mean & Std. Dev & Std. Err & Min & Max \\
\hline & & \multicolumn{6}{|c|}{ Semi-structured } \\
\hline \multirow{2}{*}{ Content } & Completeness & 79 & 6.04 & .912 & .103 & 3 & 7 \\
\hline & Accuracy & 79 & 6.16 & .854 & .096 & 4 & 7 \\
\hline \multirow{2}{*}{ Process } & Ease of Data Entry & 79 & 6.13 & .939 & .106 & 3 & 7 \\
\hline & Speed & 79 & 5.49 & 1.108 & .125 & 2 & 7 \\
\hline \multirow{2}{*}{ Structure } & Flexibility & 79 & 5.29 & 1.027 & .116 & 3 & 7 \\
\hline & Utility of Structure & 79 & 5.82 & .944 & .106 & 4 & 7 \\
\hline & & \multicolumn{6}{|c|}{ Highly-structured } \\
\hline \multirow{2}{*}{ Content } & Completeness & 69 & 5.03 & 1.485 & .179 & 2 & 7 \\
\hline & Accuracy & 69 & 5.46 & 1.195 & .144 & 3 & 7 \\
\hline \multirow{2}{*}{ Process } & Ease of Data Entry & 69 & 6.25 & .775 & .093 & 4 & 7 \\
\hline & Speed & 69 & 5.70 & 1.019 & .123 & 3 & 7 \\
\hline \multirow{2}{*}{ Structure } & Flexibility & 69 & 4.94 & 1.174 & .141 & 1 & 7 \\
\hline & Utility of Structure & 69 & 5.07 & 1.321 & .159 & 2 & 7 \\
\hline
\end{tabular}

Table 6 - Statistics of each interface

As we can see from the table, dimensions associated with the content sub-construct in the unstructured interface has a higher score than the others. The mean of data creators' perceived completeness and accuracy of the content that they recorded using the unstructured interface are 6.18 and 6.26 (out of 7), respectively. If we take a look at the the mean of the same dimensions for the other two interfaces designs, we can see the mean score is dropping. Interestingly, the mean score for both perceived completeness and accuracy are the lowest for a highly structured interface design. The following chart shows this relationship. 


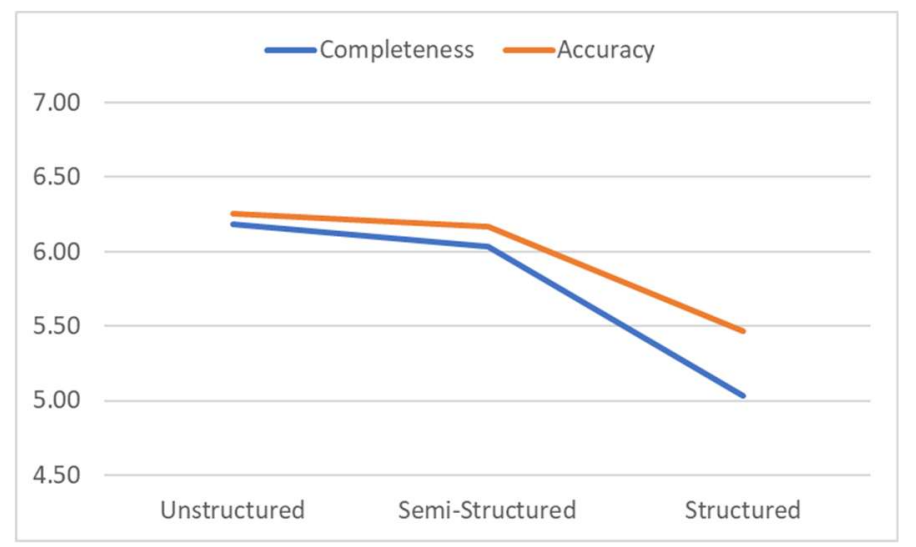

Figure 9 - Changes between interfaces - completeness \& accuracy

The mean score of the structure sub-construct also follows a similar pattern. As we can see, the statistics of the perceived flexibility and utility of structure are the highest for the unstructured interface (flexibility; mean: 5.37, std dev: 1.057 - utility of structure; mean: 5.74, std dev: 0.961). Meanwhile, the lowest score for perceived flexibility and utility of structure belongs to the highly structured interface (flexibility; mean: 4.94, std dev: 1.174 - utility of structure; mean: 5.07, std dev: 1.321). As the following chart shows, the less-structured format holds the highest score.

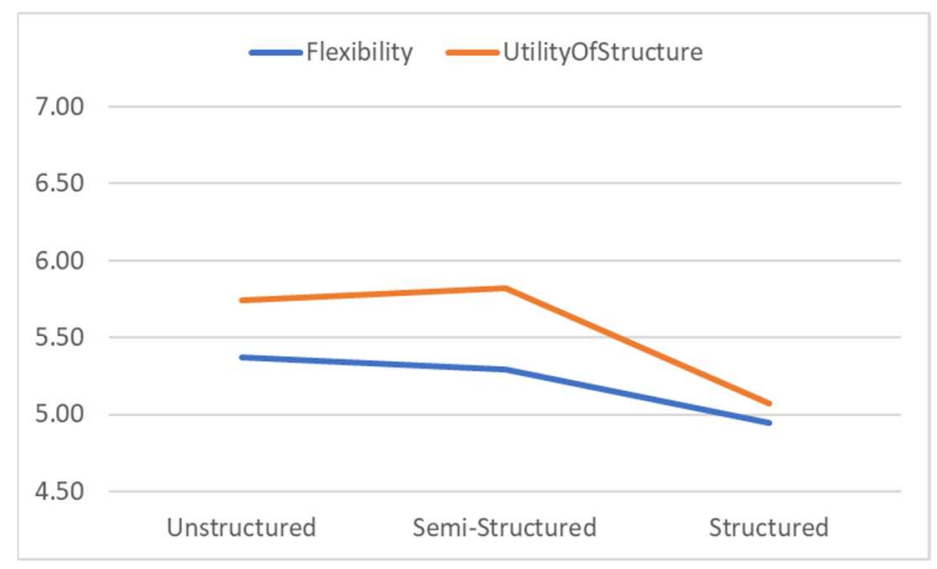

Figure 10 - Changes between interfaces - flexibility \& utility of structure

On the other hand, the dimensions for process sub-construct follows a different pattern. Although the mean for perceived ease of data entry and perceived speed of data entry for structured format 
are the highest (ease of data entry; mean: 6.25, std dev: 0.775 - speed of data entry; mean: 5.70, std dev: 1.019), no noticeable differences among the interfaces has been detected. As the following figure shows, the chart follows a more linear pattern than the other two charts.

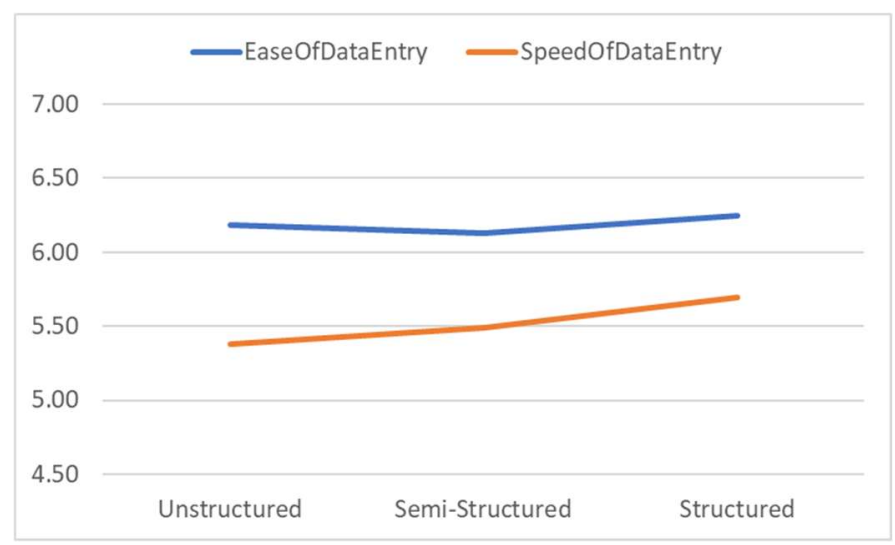

Figure 11 - Changes between interfaces - ease \& speed of data entry

The one-way analysis of variance (ANOVA) is used to determine whether there are any statistically significant differences among the three interfaces in terms of the perceived quality of information collection. Basically, the one-way ANOVA compares the means between the under-investigated groups and determines whether any of those means are statistically significantly different from each other. The following table summarizes our ANOVA test.

\begin{tabular}{|c|l|c|c|c|c|c|c|c|}
\hline Dimension & $\mathbf{N}$ & Mean & $\begin{array}{l}\text { Std. } \\
\text { Deviation }\end{array}$ & $\begin{array}{l}\text { Std. } \\
\text { Error }\end{array}$ & Min & Max & F & Sig. \\
\hline Completeness & 242 & 5.81 & 1.201 & .077 & 2 & 7 & 24.466 & .000 \\
\hline Accuracy & 242 & 6.00 & 1.023 & .066 & 3 & 7 & 15.002 & .000 \\
\hline Ease of Data Entry & 242 & 6.18 & .888 & .057 & 2 & 7 & .333 & .717 \\
\hline Speed of Data Entry & 242 & 5.51 & 1.139 & .073 & 1 & 7 & 1.516 & .222 \\
\hline Flexibility & 242 & 5.22 & 1.093 & .070 & 1 & 7 & 3.376 & .036 \\
\hline Utility of Structure & 242 & 5.58 & 1.114 & .072 & 2 & 7 & 10.893 & .000 \\
\hline
\end{tabular}

Table 7 - ANOVA results

As we can see in the table, we detect significant differences between interfaces for the data creators' perceived completeness and accuracy. The results show that the recorded perceived completeness 
$(5.81, \mathrm{p}<0.000)$ is significantly different from one interface to the other. Also, data creators' perception of accuracy $(6.00, \mathrm{p}<0.000)$ is significantly different while using differently designed interfaces, which provides support for our first hypothesis (H1a). This shows data creators perceive that using less-structured information collection interfaces results in recording more complete and accurate data than using more-structured information collection interfaces.

Examining the two dimensions of structure sub-construct, flexibility and utility of structure, also yields similar results. Using interfaces with various degrees of structure results in significantly different scores for both perceived flexibility $(5.22, \mathrm{p}<0.05)$ and utility of structure $(5.58, \mathrm{p}<$ 0.000). This finding supports our third hypotheses (H1c), where we propose data creators perceive that less-structured information collection interfaces are more flexible and let higher utilize of structure than more-structured information collection interfaces

As we could infer from the charts, no significant differences were detected for perceived ease of data entry $(6.18, \mathrm{p}=0.717)$ and the speed of data entry $(5.51, \mathrm{p}=0.222)$. In other words, the perception of the quality of information collection for participants who used the less-structured interface is not significantly different from that of participants who used the more-structured interface. This finding does not provide any support for our second hypotheses (H1b). In other words, we did not detect any difference in terms of ease or speed of data entry for using differently designed interfaces.

Since the ANOVA test determines whether we have overall significant differences among the interfaces, we carried a MANCOVA test with post hoc multiple comparisons using Tukey HSD, with alpha $=0.05$. The following is the result of the post hoc test. 


\begin{tabular}{|c|c|c|c|c|c|c|c|}
\hline \multirow{2}{*}{$\begin{array}{l}\text { Dependent } \\
\text { Variable }\end{array}$} & \multirow{2}{*}{$\begin{array}{l}\text { (I) } \\
\text { InterfaceID }\end{array}$} & \multirow[b]{2}{*}{$\begin{array}{l}\text { (J) } \\
\text { InterfaceID }\end{array}$} & \multirow{2}{*}{$\begin{array}{c}\text { Mean } \\
\text { Difference } \\
\text { (I-J) }\end{array}$} & \multirow[b]{2}{*}{$\begin{array}{l}\text { Std. } \\
\text { Error }\end{array}$} & \multirow[b]{2}{*}{ Sig. } & \multicolumn{2}{|c|}{ 95\% Confi. Interval } \\
\hline & & & & & & $\begin{array}{l}\text { Lower } \\
\text { Bound }\end{array}$ & $\begin{array}{l}\text { Upper } \\
\text { Bound }\end{array}$ \\
\hline \multirow{6}{*}{ Completeness } & \multirow{2}{*}{ US } & $\mathrm{SS}$ & .143 & .168 & .671 & -.25 & .54 \\
\hline & & $\mathrm{HS}$ & $1.152^{*}$ & .174 & .000 & .74 & 1.56 \\
\hline & \multirow{2}{*}{ SS } & US & -.143 & .168 & .671 & -.54 & .25 \\
\hline & & $\mathrm{HS}$ & $1.009^{*}$ & .181 & .000 & .58 & 1.44 \\
\hline & \multirow{2}{*}{ HS } & US & $-1.152^{*}$ & .174 & .000 & -1.56 & -.74 \\
\hline & & SS & $-1.009^{*}$ & .181 & .000 & -1.44 & -.58 \\
\hline \multirow{6}{*}{ Accuracy } & \multirow{2}{*}{ US } & $\mathrm{SS}$ & .091 & .148 & .812 & -.26 & .44 \\
\hline & & $\mathrm{HS}$ & $.792^{*}$ & .153 & .000 & .43 & 1.15 \\
\hline & \multirow{2}{*}{ SS } & US & -.091 & .148 & .812 & -.44 & .26 \\
\hline & & $\mathrm{HS}$ & $.701^{*}$ & .159 & .000 & .32 & 1.08 \\
\hline & \multirow{2}{*}{ HS } & US & $-.792^{*}$ & .153 & .000 & -1.15 & -.43 \\
\hline & & $\mathrm{SS}$ & $-.701^{*}$ & .159 & .000 & -1.08 & -.32 \\
\hline \multirow{6}{*}{$\begin{array}{l}\text { Ease of Data } \\
\text { Entry }\end{array}$} & \multirow{2}{*}{ US } & $\mathrm{SS}$ & .054 & .136 & .916 & -.27 & .37 \\
\hline & & $\mathrm{HS}$ & -.066 & .141 & .888 & -.40 & .27 \\
\hline & \multirow{2}{*}{ SS } & US & -.054 & .136 & .916 & -.37 & .27 \\
\hline & & $\mathrm{HS}$ & -.120 & .147 & .693 & -.47 & .23 \\
\hline & \multirow{2}{*}{ HS } & US & .066 & .141 & .888 & -.27 & .40 \\
\hline & & $\mathrm{SS}$ & .120 & .147 & .693 & -.23 & .47 \\
\hline \multirow{6}{*}{$\begin{array}{l}\text { Speed of } \\
\text { Data Entry }\end{array}$} & \multirow{2}{*}{ US } & $\mathrm{SS}$ & -.111 & .173 & .799 & -.52 & .30 \\
\hline & & $\mathrm{HS}$ & -.313 & .180 & .194 & -.74 & .11 \\
\hline & \multirow{2}{*}{ SS } & US & .111 & .173 & .799 & -.30 & .52 \\
\hline & & HS & -.202 & .187 & .528 & -.64 & .24 \\
\hline & \multirow{2}{*}{ HS } & US & .313 & .180 & .194 & -.11 & .74 \\
\hline & & $\mathrm{SS}$ & .202 & .187 & .528 & -.24 & .64 \\
\hline \multirow{6}{*}{ Flexibility } & \multirow{2}{*}{ US } & $\mathrm{SS}$ & .081 & .165 & .875 & -.31 & .47 \\
\hline & & $\mathrm{HS}$ & $.430^{*}$ & .172 & .034 & .03 & .84 \\
\hline & \multirow{2}{*}{ SS } & US & -.081 & .165 & .875 & -.47 & .31 \\
\hline & & $\mathrm{HS}$ & .349 & .178 & .125 & -.07 & .77 \\
\hline & HS & US & $-.430^{*}$ & .172 & .034 & -.84 & -.03 \\
\hline & חग & $\mathrm{SS}$ & -.349 & .178 & .125 & -.77 & .07 \\
\hline & & $\mathrm{SS}$ & -.078 & .163 & .882 & -.46 & .31 \\
\hline & US & $\mathrm{HS}$ & $.672^{*}$ & .170 & .000 & .27 & 1.07 \\
\hline Utility of & & US & .078 & .163 & .882 & -.31 & .46 \\
\hline Structure & SS & HS & $.750^{*}$ & .176 & .000 & .33 & 1.17 \\
\hline & & US & $-.672^{*}$ & .170 & .000 & -1.07 & -.27 \\
\hline & HS & $\mathrm{SS}$ & $-.750^{*}$ & .176 & .000 & -1.17 & -.33 \\
\hline
\end{tabular}

Table 8 - Post hoc results

As we can see, no significant difference was detected between unstructured and semi-structured interfaces in any dimension. In other words, participants deem that using unstructured or semistructured interface does not result in significantly different results in terms of completeness, 
accuracy, ease or speed of use, flexibility and utility of structure. This finding is not surprising to us, considering our definition of semi-structured. As we already described, the semi-structured interface is very similar to the unstructured format, and the only added feature is the hashtag requirement. On the other hand, when we compare a highly structured interface with either of the other two interfaces, we can see significant differences in terms of completeness, accuracy, flexibility and utility of structure. The only dimension that no significant differences were detected between highly structured and semi-structured format is perceived flexibility $(p=0.125)$. The following table summarizes the p-value results of the post hoc test.

\begin{tabular}{|c|c|c|c|c|}
\hline Dimension & Interface & US & SS & HS \\
\hline \multirow{3}{*}{ Completeness } & US & & .671 & .000 \\
\hline & SS & .671 & & .000 \\
\hline & HS & .000 & .000 & \\
\hline \multirow{3}{*}{ Accuracy } & US & & .812 & .000 \\
\hline & SS & .812 & & .000 \\
\hline & HS & .000 & .000 & \\
\hline \multirow{3}{*}{$\begin{array}{c}\text { Ease of Data } \\
\text { Entry }\end{array}$} & US & & .916 & .888 \\
\hline & SS & .916 & & .693 \\
\hline & HS & .888 & .693 & \\
\hline \multirow{3}{*}{$\begin{array}{c}\text { Speed of Data } \\
\text { Entry }\end{array}$} & US & & .799 & .194 \\
\hline & SS & .799 & & .528 \\
\hline & HS & .194 & .528 & \\
\hline \multirow{3}{*}{ Flexibility } & US & & .875 & .034 \\
\hline & SS & .875 & & .125 \\
\hline & HS & .034 & .125 & \\
\hline \multirow{3}{*}{$\begin{array}{l}\text { Utility of } \\
\text { Structure }\end{array}$} & US & & .882 & .000 \\
\hline & SS & .882 & & .000 \\
\hline & HS & .000 & .000 & \\
\hline
\end{tabular}

Table 9 - Summary results of the post hoc test

We also studied the control variables to detect any significant differences that appear. We run multivariate tests for the demographic statistics that we collected. We also counted the number of 
characters and words of the participants' responses in unstructured and semi-structured interface design. The following table shows the results of the test.

\begin{tabular}{|l|l|c|c|c|r|}
\hline Effect & & Value & F & \multicolumn{1}{c|}{ Sig. } & Partial Eta Squared \\
\hline \multirow{5}{*}{ Gender } & Pillai's Trace & .043 & $1.719^{\mathrm{b}}$ & .117 & .043 \\
\cline { 2 - 6 } & Wilks' Lambda & .957 & $1.719^{\mathrm{b}}$ & .117 & .043 \\
\cline { 2 - 6 } & Hotelling's Trace & .045 & $1.719^{\mathrm{b}}$ & .117 & .043 \\
\cline { 2 - 6 } & Roy's Largest Root & .045 & $1.719^{\mathrm{b}}$ & .117 & .043 \\
\hline \multirow{5}{*}{ Age } & Pillai's Trace & .054 & $2.178^{\mathrm{b}}$ & .046 & .054 \\
\cline { 2 - 6 } & Wilks' Lambda & .946 & $2.178^{\mathrm{b}}$ & .046 & .054 \\
\cline { 2 - 6 } & Hotelling's Trace & .057 & $2.178^{\mathrm{b}}$ & .046 & .054 \\
\cline { 2 - 6 } & Roy's Largest Root & .057 & $2.178^{\mathrm{b}}$ & .046 & .054 \\
\hline \multirow{5}{*}{ Education } & Pillai's Trace & .027 & $1.056^{\mathrm{b}}$ & .390 & .027 \\
\cline { 2 - 6 } & Wilks' Lambda & .973 & $1.056^{\mathrm{b}}$ & .390 & .027 \\
\cline { 2 - 6 } & Hotelling's Trace & .028 & $1.056^{\mathrm{b}}$ & .390 & .027 \\
\cline { 2 - 6 } & Roy's Largest Root & .028 & $1.056^{\mathrm{b}}$ & .390 & .39 \\
\hline
\end{tabular}

Table 10 - Multivariate test results

The following table shows the results of the test for each of the dimensions separately:

\begin{tabular}{|l|l|r|r|r|r|r|r|}
\hline \multirow{5}{*}{ Source } & $\begin{array}{c}\text { Type III Sum } \\
\text { of Squares }\end{array}$ & df & $\begin{array}{c}\text { Mean } \\
\text { Square }\end{array}$ & F & Sig. & $\begin{array}{c}\text { Partial Eta } \\
\text { Squared }\end{array}$ \\
\hline \multirow{5}{*}{ Gender } & Completeness & 1.303 & 1 & 1.303 & 1.097 & .296 & .005 \\
\cline { 2 - 8 } & Accuracy & 1.834 & 1 & 1.834 & 2.131 & .146 & .009 \\
\cline { 2 - 8 } & Ease of Data Entry & 6.608 & 1 & 6.608 & 9.298 & .003 & .038 \\
\cline { 2 - 8 } & Speed of Data Entry & 3.950 & 1 & 3.950 & 3.048 & .082 & .013 \\
\cline { 2 - 8 } & Flexibility & .643 & 1 & .643 & .571 & .451 & .002 \\
\cline { 2 - 8 } & Utility of Structure & 1.550 & 1 & 1.550 & 1.377 & .242 & .006 \\
\hline \multirow{5}{*}{ Age } & Completeness & .212 & 1 & .212 & .179 & .673 & .001 \\
\cline { 2 - 8 } & Accuracy & 1.265 & 1 & 1.265 & 1.470 & .227 & .006 \\
\cline { 2 - 8 } & Ease of Data Entry & .121 & 1 & .121 & .170 & .680 & .001 \\
\cline { 2 - 8 } & Speed of Data Entry & .094 & 1 & .094 & .072 & .788 & .000 \\
\cline { 2 - 8 } & Flexibility & 10.089 & 1 & 10.089 & 8.956 & .003 & .037 \\
\cline { 2 - 8 } & Utility of Structure & .458 & 1 & .458 & .407 & .524 & .002 \\
\hline \multirow{5}{*}{ Education } & Completeness & 1.071 & 1 & 1.071 & .901 & .343 & .004 \\
\cline { 2 - 8 } & Accuracy & 2.087 & 1 & 2.087 & 2.425 & .121 & .010 \\
\cline { 2 - 8 } & Ease of Data Entry & .021 & 1 & .021 & .030 & .863 & .000 \\
\hline
\end{tabular}




\begin{tabular}{|l|l|r|r|r|r|r|r|}
\hline Source & $\begin{array}{c}\text { Type III Sum } \\
\text { of Squares }\end{array}$ & df & $\begin{array}{c}\text { Mean } \\
\text { Square }\end{array}$ & F & Sig. & $\begin{array}{c}\text { Partial Eta } \\
\text { Squared }\end{array}$ \\
\hline \multirow{2}{*}{} & Speed of Data Entry & .064 & 1 & .064 & .049 & .824 & .000 \\
\cline { 2 - 8 } & Flexibility & 3.643 & 1 & 3.643 & 3.233 & .073 & .014 \\
\cline { 2 - 8 } & Utility of Structure & 1.305 & 1 & 1.305 & 1.159 & .283 & .005 \\
\hline
\end{tabular}

Table 11 - Test of between-subjects effect

Based on the tables, we can detect significant results in some of the conditions. For example, males and females' perception of the ease of data entry differs significantly $(\mathrm{P}<0.005)$. As the following descriptive table shows, sharing experience using the provided interfaces is deemed easier by female participants than male participants. On the other hand, older participants (over 55 years old) perceived the interfaces significantly less flexible compared to what the younger participants perceive $(\mathrm{p}<0.005)$.

\begin{tabular}{|c|c|c|c|c|c|c|c|c|}
\hline Variable & Category & No & 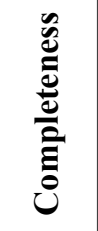 & 冚 & 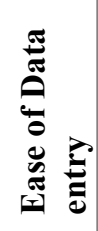 & 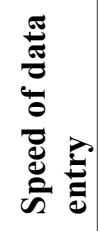 & 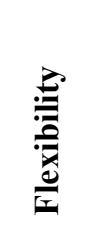 & 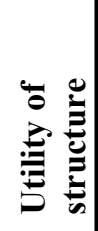 \\
\hline \multirow{2}{*}{ Gender } & Female & 145 & 5.87 & 6.07 & 6.31 & 5.61 & 5.26 & 5.63 \\
\hline & Male & 97 & 5.72 & 5.85 & 5.98 & 5.34 & 5.22 & 5.48 \\
\hline \multirow{5}{*}{ Age } & $18-24$ yo & 28 & 6.20 & 6.31 & 6.43 & 5.68 & 5.43 & 5.70 \\
\hline & $25-34$ yo & 93 & 5.67 & 5.92 & 6.08 & 5.35 & 5.45 & 5.51 \\
\hline & $35-44$ yo & 53 & 5.84 & 5.91 & 6.09 & 5.60 & 5.05 & 5.58 \\
\hline & $45-54$ yo & 33 & 5.88 & 6.06 & 6.32 & 5.52 & 5.24 & 5.75 \\
\hline & $55 \&$ over & 35 & 5.76 & 5.90 & 6.25 & 5.61 & 4.86 & 5.42 \\
\hline \multirow{4}{*}{ Education } & Highschool & 41 & 5.90 & 6.08 & 6.19 & 5.49 & 5.44 & 5.67 \\
\hline & College & 63 & 5.94 & 6.03 & 6.11 & 5.39 & 5.25 & 5.54 \\
\hline & Undergrad & 90 & 5.83 & 6.02 & 6.32 & 5.66 & 5.29 & 5.68 \\
\hline & Graduate & 48 & 5.51 & 5.76 & 6.00 & 5.38 & 4.99 & 5.31 \\
\hline
\end{tabular}

Table 12 - Statistics based on the control variables

In the next section, we examine the data consumers' feedback on the content recorded in this experiment. 


\section{Data consumers' view}

So far, we evaluated the data creators' perception of information quality. While using a certain interface to record the content, we ask data creators to assess their perception of the quality of the recorded content, the process of data collection, and the structure of the given interface. As we explained earlier, the content produced in online communities is usually inconclusive. Therefore, the person who created the content is a reasonable person to judge the effectiveness of the interface, in terms of its ability to exactly collect data creators intended-to-be-shared content. However, the other main stakeholder is data consumer. Even though the data creators might feel that they were able to record high-quality information, data consumers may not deem it high-quality. In this experiment, we assess data consumers' perception of the quality of the recorded content.

We have selected 131 responses from the previous experiment. These responses were collected by either the unstructured interface ( 73 responses) or the structured interface (58 responses). Out of the total 131, 67 responses are related to pre-flight experience, while the other 64 responses represent the flight experiences. Each response was shown to 5 different participants (on average), who were asked to evaluate the response. The evaluation process contains both quantitative and qualitative sections.

In the quantitative section, we asked participants 6 Likert-scaled questions about the content being complete, accurate, effortful, well-structured, useful, and data creators' sincerity. Our measurement instrument is different from the one that we used for data creators' assessment. Therefore, we are not able to statistically compare the results of these two experiments. However, it gives us a preliminary insight about the qualitative result. For example, the following charts represent the average of completeness perceived by data creators and data consumers in the unstructured interface format. As we expected, data creators' average score is higher than data consumers' rating, in most of the cases. 


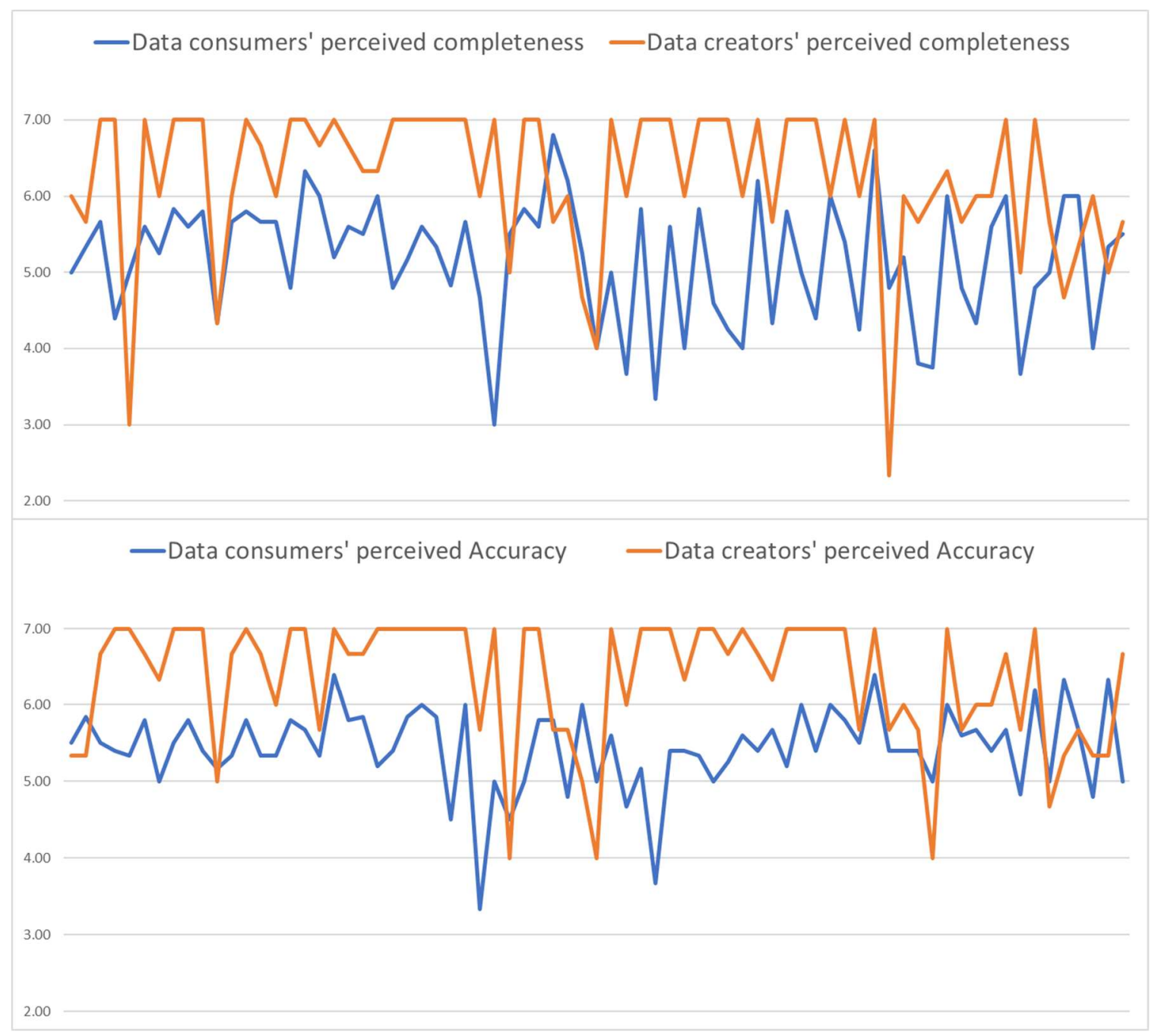

Figure 12 - Data creators' vs data consumers' perception of completeness \& accuracy - Unstructured

On the other hand, this comparison for content collected through the structured interface is different. The following charts represent perceived completeness and accuracy in the structured interface format. As we can see, data creators' average score for completeness is less than data consumers' average point, in most cases. This finding is really interesting and indicates that data consumers' trust in structured interfaces, more than data creators do. While data creators feel they were not able to create complete information, data consumers feel that the content, presented in the structured format, is relatively complete. 


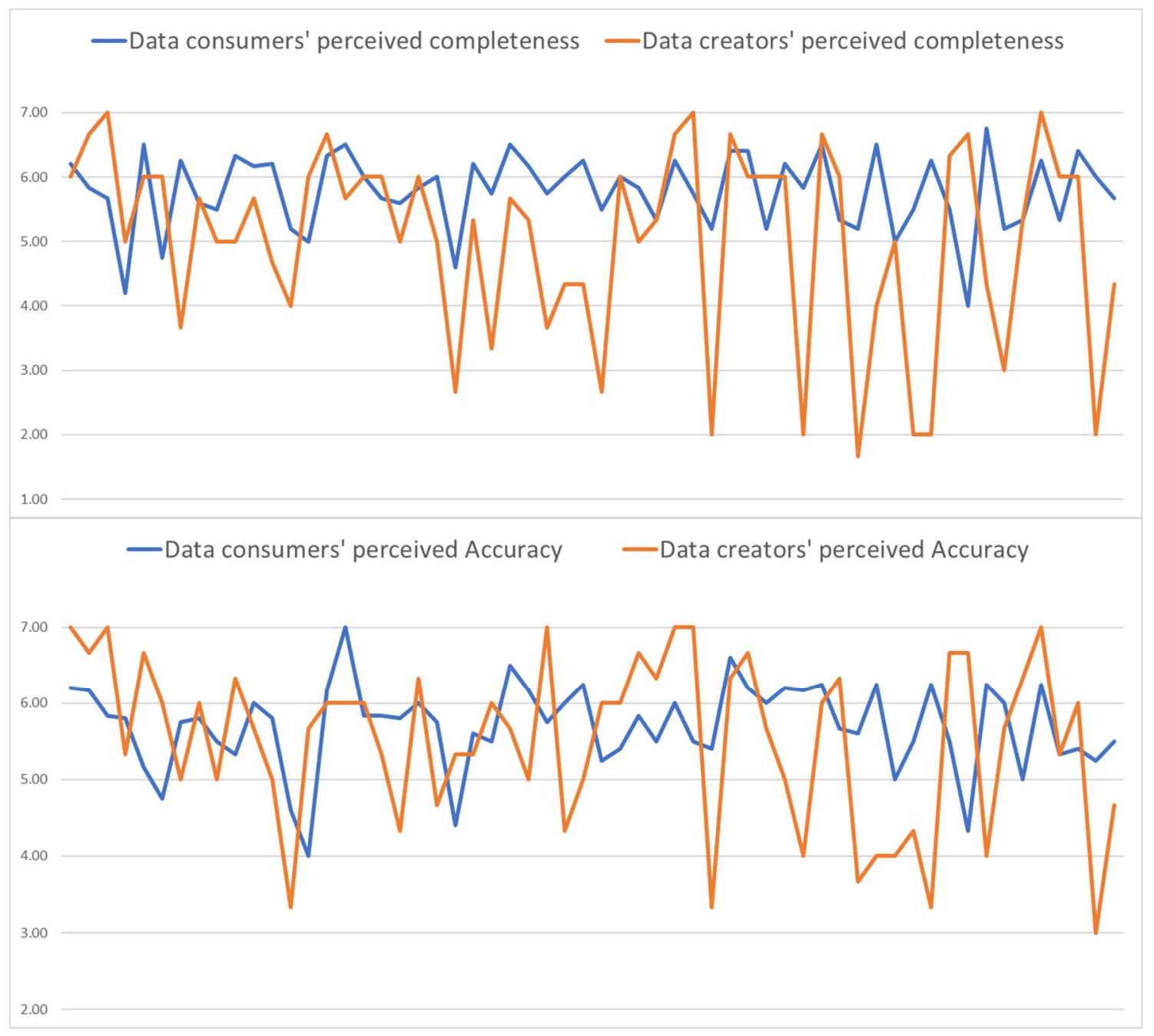

Figure 13 - Data creators' vs data consumers' perception of completeness \& accuracy - Structured

We also compare the data consumers' responses on usefulness and sincerity of the contributor. We assume that the more useful a data consumer find a piece of content, the more sincere he/she might perceive that the contributor is. The comparison partly supports our assumption. The following charts represent data consumers' perceived usefulness and data creators' sincerity perceived by data consumers. As we can see, the two dimensions follow the same pattern. 


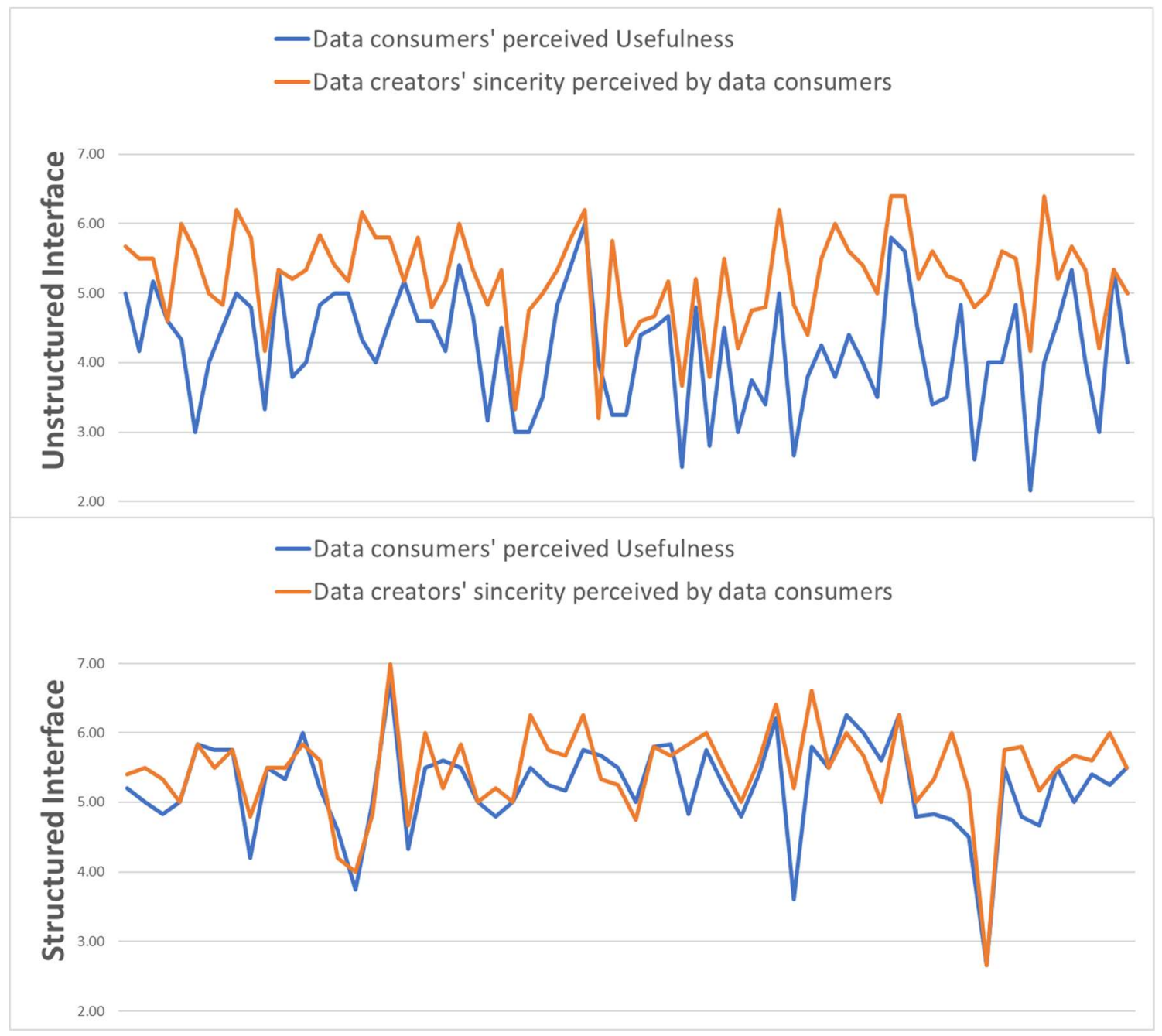

Figure 14 - Data consumers' perceived usefulness vs data creators' sincerity perceived by consumers

In the qualitative section, we asked participants to mention the possible omitted or inaccurate points. Moreover, we look for the participants' general idea about the data creator. Each participant provides a brief answer to these questions, based on the presented content. We read and analyzed the participants' responses. Accordingly, we were able to infer some general ideas about the features of each interface design.

Our findings show that data consumers assume some advantages and disadvantages for both structured and unstructured interfaces. For example, data consumers mentioned that an unstructured interface may collect responses beyond the demanded content. In other words, data creators using 
unstructured interface potentially may go beyond the expected topic and provide details that are not necessary. As a result, this result will increase the input for data analyses, making this process more complicated. Moreover, using unstructured information collection interface may eventually raise some questions for the data consumer. Furthermore, the unstructured interface gives the data creators the freedom to record whatever they wish in sentences or paragraphs format. However, not asking specific questions might result in neglecting to record some obvious details of the event. For example, data consumers mentioned that the data creator forgot to provide details on the timeline of the flight, in some instances. On the other hand, some examples show that unstructured interface provides the opportunity to record something unexpected and unique, as opposed to the structured format.

The results of analyzing structured interface were also interesting. Similar to the results of the quantitative part, most of the data consumers perceive that the provided content is complete. However, there are some cases that the data consumer mentions that the data is not complete. These cases are related to the reason for an unpleasant experience. For example, if a structured set of data shows that the respondent was not satisfied with a service, the content does not provide a reason. In other words, it seems that the structured interface fails to answer to the "why" question in some cases. Furthermore, the data consumers, for obvious reasons, have no complaints about any grammar or spelling error.

Finally, the responses to the sincerity question are also analyzed. Our findings indicate that facing unstructured content, data consumers are able to make more guesses about the personality and sincerity of the data creator, than facing structured content. It might not be necessarily true, however, data consumers feedback on this question implies that a detailed response in the form of sentences and paragraphs gives them more input to judge a person. While the responses to structured content experiment include being easy-going, having an acceptable experience, or 
overall satisfaction, data consumers' inference from unstructured content were more subjective and personal, e.g. sociable and friendly, appreciative, or generally happy.

\section{Discussion}

Previous research on information collection interfaces in UGC settings indicates that we have little understanding about the appropriate level of structure for collecting UGC. We approach this concern by focusing on interface design in a UGC setting. In this chapter, we investigate the differences in data creators' perception of the information collection interfaces, resulting from different interface designs. Particularly, we examine different degrees of structure for information collection interfaces and how data creators feel about each interface design.

Data creators are one of the major stakeholders of online communities. Online communities urge their users to contribute to the communities. Data creators are encouraged to promote the communities' goals by sharing their experiences and engaging in the discussions. To keep data creators engaged, an online community should ensure that they are satisfied and happy with the parts of the system with which they are dealing. For this reason, we first seek data creators' feedback to evaluate our information collection interfaces. Although a data creator's perception of having recorded complete and accurate information does not guarantee reaching a high-quality piece of information, we consider the data creator's perception very critical for one obvious reason: the data creators join the online communities to share data for a reason (e.g., share an experience or help others, ), and, in order to do that, they need a data collection interface that is able to collect that data in a way that is meant to be shared by the data creator.

We collected data from users who use differently structured interfaces to share their experience and asked them to assess their perception of the quality of information collection that was conducted by the provided interface. Our findings show that using differently-designed interfaces results in noticeable differences in perceptions of IQ. Specifically, data creators' perception of accuracy, 
completeness, flexibility, and utility of structure decreases for interfaces with highly structured formats compared to those with unstructured and semi-structured formats. In other words, data creators perceive that they are able to record more complete and accurate content while using a less-structured interface format. Similarly, data creators deem less-structured interfaces more flexible than highly structured interfaces. The results indicate that the highest results for IQ dimensions are consistently obtained when the data is entered in an unstructured format, which demonstrates peoples' appreciation of the value of unstructured data collection. This result is consistent with Proposition 1, where we proposed that collecting data through interfaces with different degrees of structure affects perceived information quality.

The insignificant findings for the ease of data entry and speed of data entry suggest that people perceive structured and unstructured interfaces to be generally comparable in the amount of expended effort. This notable finding implies that designers should not sacrifice a preferable degree of structure for an easier or faster way to collect data. In other words, data creators do not deem data creation that uses a certain degree of structure to be easier or faster than one that uses another degree of structure. Most importantly, this finding shows that while unstructured data collection brings advantages (for completeness, accuracy, flexibility, and utility of structure), these advantages are not gained at the expense of losing ease or speed of data entry.

The other main stakeholders of the online communities are data consumers. They are a part of the community that uses the content (and, of course, the user-generated content) for a purpose (e.g.., to take an action or to use in a decision-making process). The recorded content should be usable for analyses and action to keep data consumers satisfied with the platform. Thus, we think that data consumers' perception of the information quality of the outcome should be analyzed, too. Although there was some overlap between data consumers and creators' perception of the quality, data consumers welcome the unstructured interface for unexpected and unique incidents. Overall, our 
results indicate the need to measure both data creators' and data consumers' perceived IQ to gain a comprehensive perspective on the impact of the variables of interest on information quality.

The preliminary findings, based on perceived IQ, are of great significance to the theory and practice of UGC and information quality. They show the value of unstructured interfaces in data collection in online communities. In particular, they suggest that when more rigid formats are used to capture UGC, people may feel that they are not able to fully express themselves. This may have a negative impact on the overall experience of people with the platform for which data collection took place. Furthermore, and equally important, organizations may begin to make inappropriate decisions as a result of the analysis of UGC data, given that users perceive some deficiencies regarding completeness and accuracy when the wrong format is chosen. 


\section{CHAPTER 4: Nature of shared content and its effect on PQoIC}

\section{Introduction}

Over the past 20 years, we have experienced a rapid growth in appearance of different online communities. Whether an online community is devoted to health consultation, travel-experience sharing, or other purposes, the data creators have a simple expectation from the platform: they would like to be given an interface that enables them to easily share whatever they wish to share. However, too many online examples, as well as previous research (Huang and Benyoucef 2013), indicate that this expectation is not fully met. We argue that the design of the provided information collection interface in online communities may not be aligned with users' expectations. In the previous chapter, we studied information collection interface in terms of degree of structure, and we showed that data creators' perception of completeness and accuracy of the recorded content increases when they use unstructured formats of interfaces. In this chapter, we focus on the users' expectation component and integrate it with the findings of the previous chapter.

Online community users are usually either data creators or data consumers within the platform. When playing data creators' role, participants record the content using a given interface. The content that they are recording stems from either their previous personal experiences or their knowledge about an issue. Either way, this content usually comes from data creators' memory. From psychology studies, we know that different types of memory are stored and managed differently in human memory, and that they are retrieved accordingly. We suggest that the degree of structure of the provided interface to collect a certain piece of information should be aligned with the memory structure of the data contributor.

Examining some of the current online interfaces reveals that they are designed with no regard to the origin of the to-be-shared content. As we discuss further in this chapter, human brain treats memories associated to personal experiences different from memories associated to general knowledge. However, we have not identified this differentiation in most of the interface designs. 
For example, online users of PatientsLikeMe, an online health community, are given a similar interface design to share their own experience of a disease as well as their knowledge about the disease. We posit that designing interfaces with sensitivity to the human memory structure may result in improvements in the IQ of UGC.

In this chapter, we argue that the interface design to collect the UGC should be aligned with the memory structure of the contributor. In other words, we propose that different content should be collected differently, with consideration of how they were stored in human memory.

\section{Literature review}

Considering different aspects of human memory in designing the information systems has been studied for years. Laske (1978) considered the information processing feature of human memory in designing an interface for computer music. Sutcliffe (1988) highlighted the importance of understanding human reasoning and memory in human-computer interaction designs. As Zhang et al. (2016) mentioned, data creators deal with memory recall and information processing.

However, it seems that the mismatch between users' thinking process and provided interface still exists. There are many cases of user frustration from misalignment between users' thinking process and provided interface. For instance, an MD in Kansas City, MO criticized his hospital's platform by saying "the designers of the software did not design the system to communicate in the manner that doctors use to communicate efficiently and effectively... [They] seem to labor under the delusion that to have more data is equivalent to having more useful and actionable information... I still have to hand-enter how many pills will be dispensed." The doctor even complaints about using the data by mentioning "systems don't search strings of text efficiently. It would be great, for example, if I wanted to learn what patient's normal vital sign was, I could type the search term "vital signs" and then the system would offer me choices, the way Google does" (Green 2015). In this example, our employed user, with a level of high incentive for participation, has little option 
but to vent his frustration with complaints. However, a voluntary participant, with a much lower incentive to participate, might simply walk away when presented with an interface which does not allow appropriate self-expression.

We suggest that these problems arise due to a misalignment between the interface and the users' memory. To approach this issue, we think that in the UGC setting, interface designers should consider the factor of users' thinking- the content in users' mind. Intuitively, if we are designing platforms to collect what is in people's minds, we should consider the nature of to-be-shared content, and we should design the interface based on the Nature of Shared Content (NSC).

As we mentioned earlier, the shared content in online communities is related to either experience or general knowledge. In this study, we study the possible differences between collecting experiences and collecting knowledge in terms of the perceived quality of information collection. In other words, we seek to answer the following research question:

- Does designing an interface, with consideration of whether an experience or a general knowledge is being recorded, make any differences in data creators' Perceived Quality of Information Collection?

The answer to this research question will show whether using a certain interface design to collect a certain type of content results in higher perceived information quality.

\section{Theoretical background}

In this section, we describe the theoretical foundation of our study. With the given introduction, the research question that we raised wants to improve the information quality of outcome (performance), by providing the appropriate interface (technology), based on the type of to-beshared content (task). Essentially, with the keywords that we used, we are following the theory of Task-Technology Fit (TTF). 
Task-Technology Fit Theory is about the correspondence between task requirements, users' abilities, and the functionality of the technology (Goodhue and Thompson 1995). Based on this theory, a higher level of performance should result from a better match between task's, technology's and involved individual's characteristics (Tremblay et al. 2007). Although this theory has been applied mostly at the organizational level (Aljukhadar et al. 2014; Iyer et al. 2009), its potential implications at the individual level have been indicated by researchers (Aljukhadar et al. 2014). It also has been used to study online users. For example, Aljukhadar et al. (2014) extended the task-technology theory to examine the drivers and consequences of task completion by online users. In simple words, Task-Technology Fit model seeks whether task fits technology, while usercentered design seeks whether task fit users' abilities. What we feel that is missing in UGC interface design is if the task fits how users think. In other words, users' thoughts that originated from their mind will be the resulted UGC as their opinions, posts, comments, and so on. We suggest that the nature of these thoughts that are going to be the UGC should be considered in designing the information collection interface.

In order to follow this theory, we translate each element of task-technology fit into the borders of our study. In this study, the user that we are talking about is the data creator in online communities. The technology, that needs to match the task characteristics, is actually the appropriate interface design, that needs to match the nature of to-be-shared content. The TTF outcome would be a positive impact on the performance, in which our case is the perceived quality of information collection. The following table summarizes our elements. 


\begin{tabular}{|l|l|}
\hline TTF Dimensions & Equivalent in this study \\
\hline User & Data Creator \\
\hline Capabilities of IT & Interface (Degree of Structure) \\
\hline Task & Human memory (To-be-shared content) \\
\hline Positive impact on performance & $\begin{array}{l}\text { Impact on the perceived quality of information } \\
\text { collection }\end{array}$ \\
\hline
\end{tabular}

Table 13 - TTF dimensions

We already discussed the perceived quality of information collection in Chapter 2. In the following sections, we examine interface design and human memory.

\section{Information systems and Interface Design}

Information systems are supposed to facilitate the business processes within an organization. Designing a productive information system (IS) has been a trending topic in information systems research for decades. As Wand and Weber (Wand and Weber 1990, 1995) described, designers should simulate the real-world components and relationships within the system. Many other studies tried to investigate IS design principles in different contexts. Wand and Weber (1993) focused on the ontological expressiveness of information system design models. They provide a representational view of information systems analysis and design methodologies, which helps to develop a systematic IS design. Turoff et al. (2004) examined system design in the context of emergency response management information systems and developed a set of general design principles for information systems. Arazy et al. (2010) tried to link theory and system design and proposed a methodology for theory-driven design. Their work is one of the few studies that used behavioral theories in system design.

Previous research highlighted the importance of considering users capabilities in designing the system. Shneiderman and Plaisant(1987) considered determining users' skill levels as a very critical principle in interface design. User-centered design, introduced by Norman and Draper (1986), considers a design process where end-users can influence how a design takes shape. This 
perspective has been utilized in terms of consulting users about their needs, considering their expectations (Abras et al. 2004) or users physical abilities (Holzinger 2002). Simply, the usercentered design seeks an output design where the task fits users' abilities. While this is important, it does not consider whether the task fits how users think. Collecting feedbacks in an interactive iterative process is critical in designing a user-centered interface. Preece et al. (2007) suggested some techniques to involve users in design. Interviews focus groups and on-site observations can be used in the early stage of the design cycle.

In an attempt to further consider users in system design, some researchers also considered the cultural factor in designing the platform. For example, Marcus and West-Gould (2000) studied different dimensions of culture and considered their effects on interface design. They posit that usually complex interplay of user, business, system, and marketing requirements leads to the interface design. However, the element of users' culture is being ignored in the process. For example, considering Hofstede's (1990) cultural dimensions, they suggest that power distance, which is the extent to which less powerful members expect and accept unequal power distribution within a culture, may influence some aspects of system or user interface design. In their study, Reinecke and Bernstein (2011) took this to another level and linked perceived usability and aesthetics to users' cultural background. They proposed a personalized interface based on cultural preferences. They argued that the influence of cultural dimensions is obvious and cannot be ignored. The study shows that accuracy and efficiency of the outcome and user experience will increase by considering cultural elements. Kramer et al. (2000) emphases the importance of capturing needs and values of end users in designing the system interface. They suggest that using the appropriate personalization will result in an efficient system.

Even though the mentioned studies focused on considering users capabilities in system design, they did not examine users' memory. Even the user-centered design approach mostly focuses on users' skills, physical capabilities, and feedback. Moreover, the other studies that promote considering 
users in designing the system mostly focus on users' preferences and motivational factors (Stoeck1 et al. 2007). Nonetheless, some studies investigated the users' thinking process.

As we mentioned earlier, some researchers have considered aspects of human memory in designing the information systems (Laske 1978; Zhang et al. 2016). As Zhang et al. (2016) mentioned, data creators dealing with memory recall and information processing. Laske (1978) considered the information processing feature of human memory in designing interface for computer music. Also in his book, Sutcliffe (1988) highlighted the importance of understanding human reasoning and memory in human-computer interaction designs. The importance of designing the interface according to the users' information processing capabilities has been mentioned by several researchers (Dix 2009; Jacko 2012). According to human information-processing approach in psychology, the humans' mind performance is a function of several processing stages, with the central metaphor of "a human is like a computer" (Jacko 2012; Lachman et al. 1979). Besides, human-processing analyses are used to develop computational models to characterize human information processing when interacting with computers (Dix 2009). These studies imply the potential similarities between the human mind and information systems.

Despite the previous efforts on considering the human thinking process in designing the information systems, it seems that this important topic needs more attention. As we focus on the online communities in this study, a big part of the information system is the online platform where users interact with each other. And the big part of the online platform that data creators deal with, is the information collection interface. What appears to us is that the factor of users' thinking - the content in the users' mind - needs more scrutinization. Intuitively, if we are designing platforms to collect what is in people's minds, we should design the interface based on the type of information that is supposed to be recorded as UGC. The next section discusses human cognitive memory considerations in more details. 


\section{Cognitive memory structure}

Clearly, the UGC created by data creators in online communities is originated in their memory. We want to briefly take a look at the human memory structure. Studies of human memory have categorized human memory in a generic hierarchy. As Cowan (Cowan 2000) classified, the human memory three distinct systems are sensory, short-term, and long-term system. The sensory system temporarily stores inputs from senses and pass the visual and auditory inputs to the short-term memory (Herz and Brunk 2017). Holding little amount of information for a brief period of time, short-term memory gradually transfers the relevant information to long-term memory. Long-term memory is usually divided into two types: the declarative memory and the nondeclarative. Declarative memory, which is referred to as explicit or conscious memory, involves representations of facts and events that are subject to conscious recollection (Squire and Zola 1998) (Eichenbaum 1997). The user-generated content that we are dealing with on online communities, is generally users' opinion about something. The generated content is a way for users to declare themselves. This type of content is associated with human declarative memory. Based on Tulving's (1972) theory of memory, declarative memory can be divided into semantic memory and episodic memory. The following figure summarizes the human memory categorization.

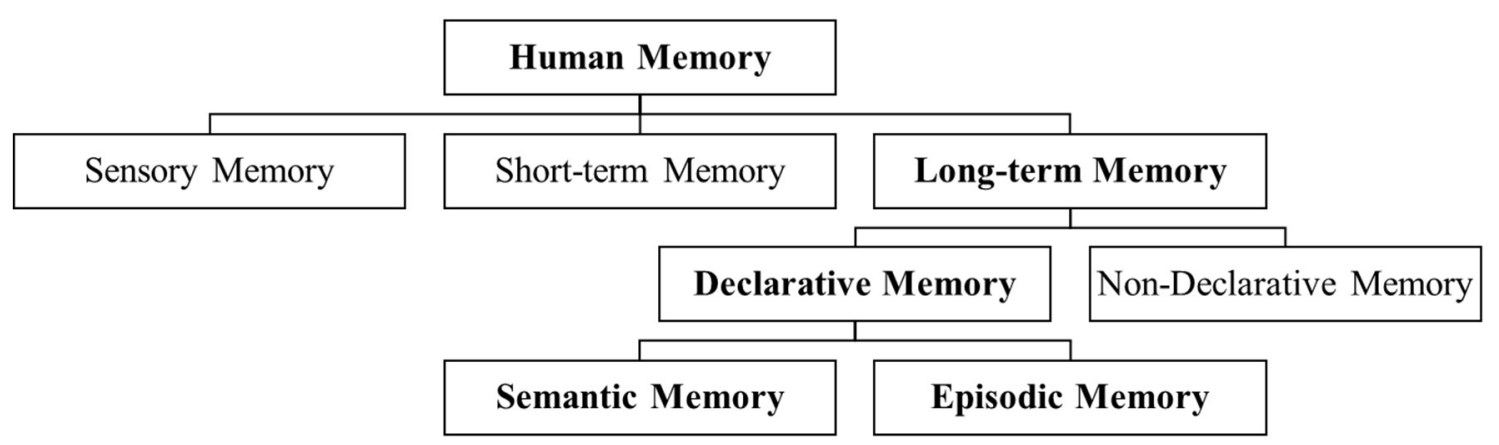

Figure 15 - Memory hierarchy, adapted from Herz and Brunk (2017) 


\section{Theories of memory}

Semantic memory are facts about the world, while episodic memory is the capacity to re-experience an event in the context similar to the context it originally occurred (Larry 2004). In fact, in this categorization, we are distinguishing two types of memory based on the type of information remembered (Goldstein 2010). However, Gardiner (2001) suggested that these two types of memory can be distinguished based on the type of experience associated with each. According to Tulving (1972), episodic and semantic memory systems differs from each other in different ways, including in terms of the nature of stored information. Besides, semantic memory information can be stored indirectly and gradually, as opposed to episodic memory information, which must be stored directly. Also, episodic memory is more forgettable and changeable than semantic memory. To better differentiate the two types of memory, we can say that the defining property of the experience of episodic memory is that it involved the experience of traveling back in time to restore the events that happened in the past (Goldstein 2010). However, the experience of semantic memory involves reaching knowledge about the world that does not have to be related to a personal experience. For example, the fact that I know there is a Starbucks on my college campus is a semantic type of memory, while my memory about going to the Starbucks on my college campus with my friend and talking about last weekend's party is an episodic kind of memory. Goldstein (2010b) gives another example of the Pacific Ocean. Remembering "sitting in the car, seeing the ocean and saying Wow! to my wife who was sitting next to me" is an episodic type, while knowing "where the Pacific Ocean located or that it is big" is considered semantic memory. Since the introduction of semantic and episodic memory by Tulving (1972), there have been many research and debates on their characteristics, features, the way human brain treats them and their storage in psychology literature (Bonnici et al. 2016; Butters et al. 1987; Greenberg and Verfaellie 2010; McClelland and Rumelhart 1985; Squire and Zola 1998; Takashima et al. 2017; Tulving 2002a). These studies show that the human brain differentiates between experience and knowledge. 
The previous research on the representation of different types of memory in mind (Goldstein 2010; McClelland and Rogers 2003; Rogers and McClelland 2004) inspired us to connect this topic to represent the types of memory in designing information systems for user-generated content. Since these are the two major type of content that online users generate in online communities, we propose that interface designers should also consider this difference in their design. That is why we suggest considering a new construct, Nature of Shared Content (NSC).

As explained earlier, the content that online community users share in an online platform is associated with either their personal experiences or their general knowledge. We call this classification the Nature of Shared Content (NSC):

- Content related to episodic memory; information that comes from re-experiencing an event in the context similar to the context it originally occurred (Larry 2004). Simply, episodic information is information related to users' personal experience.

- Content related to semantic memory; knowledge about the world that does not have to be related to personal experience. Simply, semantic information is the general facts and knowledge that a person might know.

\section{Research design and hypotheses development}

To the best of our knowledge, there is no previous study in IS discipline that considers the nature of to-be-shared content in designing the interface. We argue that not only the design of interface (Jacko 2012), but also the process of data collection in online platforms should be in accordance with users' information processing capabilities. Specifically, we propose that understanding the Nature of Shared Content (NSC), whether a piece of information is experience or knowledge, could help designers to improve the information collection interfaces.

By utilizing concepts from psychology on human memory, we examine the possible customization of interface design based on the nature of to-be-shared content. In the previous chapter, we show 
that using differently designed interfaces to collect UGC results in the different perceived quality of information collections. Given the characteristics of semantic and episodic memory, we posit that the nature of shared content, whether a personal knowledge or a general fact, can moderate the effect of interface design on perceived quality of information collection. Since findings of Chapter 3 showed that some interface designs might result in different outcome in terms of quality, we suggest that this effect can be influenced by the nature of to-be-shared content. The following figure shows our conceptual model.

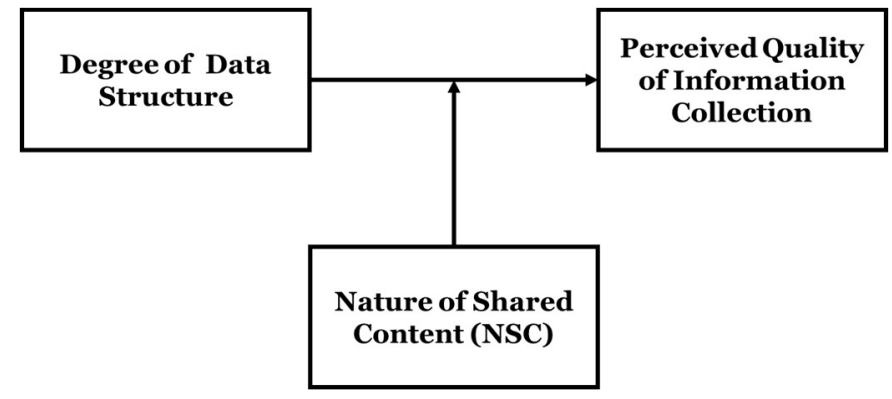

Figure 16 - Conceptual model

We develop our conceptual model to explore the moderating effect of Nature of Shared Content, that could be either semantic or episodic, on the relationship between the degree of structure and PQoIC. As we discussed in Chapter 3, our degree of structure construct is represented by three different designs; structured, semi-structured and unstructured format. Furthermore, following Chapter 2, we assess the perceived quality of information collection in terms of content, process, and structure of the interface. The following is the expanded version of our conceptual model. 


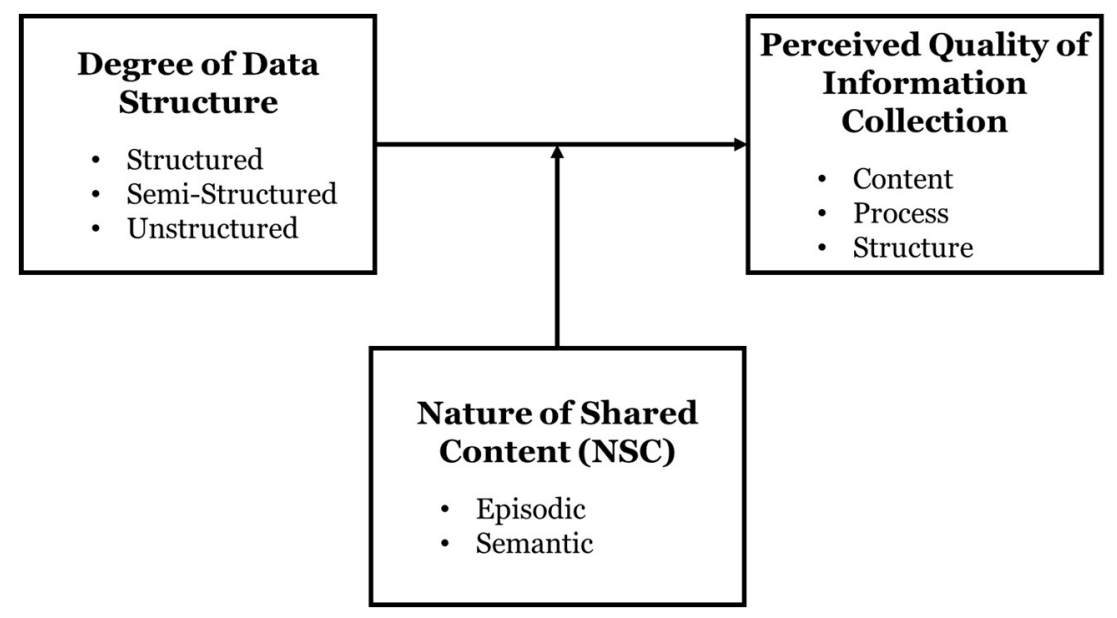

Figure 17 - Detailed conceptual model

To study the moderating effect of nature of shared content, we investigate different combinations of NSC and the degree of structure. The following figure represents our research model.

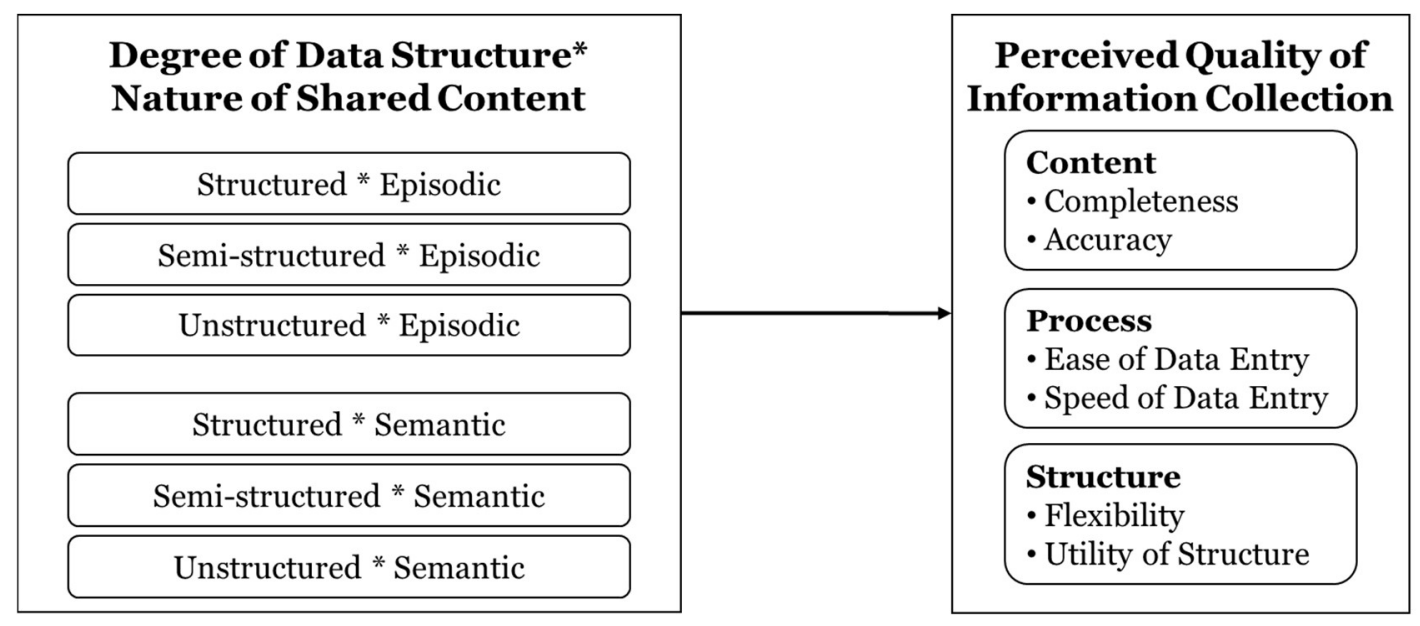

Figure 18 - Research model

In the UGC setting, we deal with information provided by online users. Given that much of the produced UGC originated in the declarative memory of the contributors, we posit that designing interfaces with sensitivity to the human memory structure may result in improvements in IQ of UGC. As mentioned earlier, we are using the episodic vs semantic classification of human memory 
to include the nature of shared content. Episodic memory is about temporally dated events and the temporal-spatial relations of the events (Burianova et al. 2010; Tulving 1972). Episodic data in the human mind is stored as a perceptual event in terms of its autobiographical reference to other similar contents and is quite susceptible to transformation and loss of information. This kind of memory is describable in terms of their perceptible dimensions, and its retrieval is related to the knowledge of the individual of his or her personal identity (Mitchell 1989; Tulving 1985). As Tulving (1972) stated: "since information in episodic memory is always temporally dated, and since it can only be retrieved if its temporal date is sufficiently accurately specified by the retrieval cue, interference with temporal coding may render access to the to-be-retrieved material difficult or impossible (Tulving 1972)." Tulving's description of episodic information features and its comparison to semantic information implies less structure and organization in storing the information for the episodic type of content. To be able to enhance the quality of episodic information in the UGC setting, we propose the following:

- Proposition 2 - For episodic data, using information collection interface with a lower degree of structure will result in a higher Perceived Quality of Information Collection than using the information collection interface with a higher degree of structure.

- $\mathrm{H} 2 \mathrm{a}$ - While attempting to record episodic data, data creators perceive that using lessstructured information collection interfaces results in recording more complete and accurate data than using more-structured information collection interfaces.

- $\mathrm{H} 2 \mathrm{~b}$ - While attempting to record episodic data, data creators perceive that using lessstructured information collection interfaces is easier and faster than using morestructured information collection interfaces.

$\circ \mathrm{H} 2 \mathrm{c}$ - While attempting to record episodic data, data creators perceive that lessstructured information collection interfaces are more flexible and let higher utilize of structure than more-structured information collection interfaces. 
On the other hand, Tulving (Tulving 1985, 2002b)_referred to semantic memory as an organized knowledge that an individual possesses about verbal symbols and their meaning or referents. Semantic memory is much less vulnerable to be changed or be forgotten than episodic memory (Burianova et al. 2010; Greenberg and Verfaellie 2010). According to Tulving (1972), semantic information is "always referred to an existing cognitive structure, that is, they always have some cognitive reference...". Semantic memory information usually represents objects, concepts, facts and so on, which all are detached from their autobiographical reference. Also, Tulving mentioned: "information in semantic memory, on the other hand, is usually encoded as part of, or assimilated into, a rich multi-dimensional structure of concepts and their relations, and such embeddedness protects the stored information from interference by other inputs (Tulving 1972)." Considering the features of semantic memory and how semantic information is stored and treated in the human mind, we examine the way it should be stored as UGC in online platforms. We propose the following about the appropriate degree of structure to store semantic information.

- Proposition 3 - For semantic data, using information collection interface with a higher degree of structure will result in a higher Perceived Quality of Information Collection than using the information collection interface with a lower degree of structure.

- $\mathrm{H} 3 \mathrm{a}-$ While attempting to record semantic data, data creators perceive that using morestructured information collection interfaces results in recording more complete and accurate data than using less-structured information collection interfaces.

$\circ \mathrm{H} 3 \mathrm{~b}$ - While attempting to record semantic data, data creators perceive that using morestructured information collection interfaces is easier and faster than using lessstructured information collection interfaces.

$\circ \mathrm{H} 3 \mathrm{c}$ - While attempting to record semantic data, data creators perceive that morestructured information collection interfaces are more flexible and let higher utilize of structure than less-structured information collection interfaces. 
The following table summarizes the experiment design and our hypotheses:

\begin{tabular}{|c|c|c|c|c|c|c|c|}
\hline \multirow{3}{*}{$\begin{array}{l}\text { Nature of } \\
\text { Shared } \\
\text { Content }\end{array}$} & \multirow{3}{*}{$\begin{array}{l}\text { Degree of Data } \\
\text { Structure } \\
\text { (Interface Design) }\end{array}$} & \multicolumn{6}{|c|}{ Perceived Quality of Information Collection } \\
\hline & & \multicolumn{2}{|c|}{ Content } & \multicolumn{2}{|c|}{ Process } & \multicolumn{2}{|c|}{ Structure } \\
\hline & & Completeness & Accuracy & $\begin{array}{c}\text { Ease of Data } \\
\text { Entry }\end{array}$ & $\begin{array}{l}\text { Speed of } \\
\text { Data Entry }\end{array}$ & Flexibility & $\begin{array}{l}\text { Utility of } \\
\text { Structure }\end{array}$ \\
\hline \multirow{3}{*}{$\begin{array}{l}\frac{\underline{0}}{\mathrm{o}} \\
\frac{\mathrm{m}}{2}\end{array}$} & Structured & & & & & & \\
\hline & Semi-Structured & & & & & & \\
\hline & Unstructured & & & & & & \\
\hline \multirow{3}{*}{ 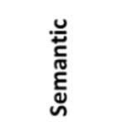 } & Structured & & & & & & \\
\hline & Semi-Structured & & & & & & \\
\hline & Unstructured & & & & & & \\
\hline
\end{tabular}

Figure 19 - Experiment design

\section{Methodology}

An experimental methodology is used to study the moderating effect of NSC on the relationship between the degree of data structure and the perceived quality of information collection in online communities. Similar to the previous experiment, we examine the perception of both data creators and data consumers. For data creators' point of view, we designed a completed randomized experiment where participants used differently designed interfaces and evaluated their data recording experience for each experiment. For data consumers' point of view, we run another experiment to evaluate the data consumers' perception of the quality of the outcome. The following sections describe our experiment designs.

\section{Experiment design - Data creators}

We want to investigate whether designing an interface, with consideration of whether an experience or a general knowledge is being recorded, make any differences in data creators' perception of Information Quality. So, we decided to run an experiment where the participants are given differently designed interfaces and are asked to record whether semantic or episodic information. To run the experiment, we used the three different interfaces that we developed in the previous experiment. We also prepared two different scenarios: one that asks for information that is 
associated with participants' semantic memory, and the other one that asks for information that is associated with participants' episodic memory. The participants are randomly assigned to one of the interfaces to respond to one of the scenarios, that is also randomly assigned. After responding to the selected scenario's question(s) - using the assigned interface - the participants are given a survey to assess their perception of the quality of information collection based on the provided interface. The items in the survey are measured by a 7-point Likert type scale, with values ranging from 1 (very unimportant or strongly disagree) to 7 (very important or strongly agree). The experiment is conducted via Amazon Mechanical Turk.

Before beginning the experiment, the participants are presented with a brief description of the experiment and research. When they consent to participate in the study, they are presented with a short demographic survey, which asks about their gender, age range, education, and English language proficiency. Since some participants are assigned to an interface that requires writing their experience, we think that not being proficient in the English language might affect the responses. So, we decide to control this variable as well.

\section{Scenario}

We decide to design this experiment in the healthcare context. We chose this context for several reasons. First, to effectively engage participants in the experiment, we need to evoke their emotion and attention. Healthcare is a field that people care about and are willing to help to improve it. Second, almost everyone has some experience in this field. We hardly can find someone who never had any health-related problem or never had a relative with the health-related problem. So, this topic is appreciable to almost every participant in our study. Third, we are working on improving the quality of UGC. One of the major fields that deal with a huge amount of UGC is healthcare. People share their opinion or experience in healthcare in so many websites, forums, social networks 
and so on. So, it is better to design our experience within a context that actually could benefit from our work.

We needed to design two scenarios: one that asks for semantic information and one that asks for episodic information. So, we needed to consider a topic that not only the potential participants have experience in, but also have knowledge about. After reviewing different topics in healthcare, we selected Influenza. Influenza (the Flu) is a common infectious disease with a wide range of symptoms. Besides, it is a known disease that people may read about in magazines or other informational outlets. For the episodic scenario, we could ask the participants to share their last catching Flu experience. While for the semantic scenario, we could ask them to share their knowledge about the disease.

Before running the experiment, we make sure that whether each scenario actually asks for semantic or episodic information. First, there are a lot of examples of semantic or episodic memory in psychology literature on human memory. We adopt our scenarios based on the examples in the literature. So, with a good chance, we can label them as either semantic or episodic. Second, to validate our scenarios, we consult with two researchers, faculty members in the Psychology Department, experts on the human memory field. We show the scenarios and related questions to the experts, and they both confirmed that each assignment is, in fact, looking for the intended type of memory (either episodic or semantic). Furthermore, we run a simple task with a group of Business students (who were not psychology experts). We briefly describe the human memory hierarchy and provide a short and simple explanation om semantic and episodic memory. Then we show them the designed scenarios and ask them to label each scenario as either episodic, semantic, or "I cannot decide". The results were significantly according to our expectations.

The following are two examples of our scenarios for the unstructured format. The full version of the tasks is provided in Appendix D. 
- Remember the last time (or a memorable time) you got sick (cold, the flu...). We want you to share your experience throughout the sickness period as much as you remember. Let's consider "the sickness period" the moment the first vague, general symptoms showed up (onset phase) to the moment that you felt completely fine (all symptoms were gone). Your experience during this sickness period can be related to the onset phase, illness phase, convalescence phase, the duration of each phase, symptoms, severity of each symptom in each period, medicines that you took, people who you consulted with, places that you visited for treatment, the money that you spend on treatment, everything you did to accelerate the treatment process and so on ...

- We want you to describe the Influenza disease. Based on your general knowledge, share whatever you know about this disease. Try to mention all the facts that you know about Influenza. This can include the types of Influenza, causes of disease, its symptoms, its different phases, its duration, suggested medicine, suggested lifestyle changes, suggested eating habits, its possible consequences, ways to control the disease and so on...

Even though it might seem that episodic and semantic memory cannot be separated easily, we need to understand that they differ in the "kind of conscious experience they involve" (Greenberg and Verfaellie 2010). As we mentioned earlier, episodic requires the conscious recollection of a personal experience, while semantic memory does not. So, you may be asked about something that you have prior experience with, as well as a general knowledge about. Even though it may be hard to say, but you actually use one of the two memories to answer the question. One way to push the person to use a specific memory is the words that we use in the question statement. As in our example, stating "remember the last time you caught Flu" pushes the respondent to use his/her episodic memory to respond. 
Before starting the episodic task, we ask participants if they remember the last time (or a memorable time) that they caught Flu. For the semantic task, we ask participants if they are familiar with the Influenza disease.

\section{Information Collection Interface}

The information collection interfaces that we used for this experiment are similar to the ones that we used in Chapter 3.

- The unstructured (flexible) format which Comes in a variety of formats and contains no explicit structuring information; In our experiment, the unstructured format represents with open box field, where users can write their answers in the form of sentences or paragraphs.

- The semi-structured format in which data might be interpreted with structural information supplied as tags, therefore the structural regularity across data items is gone; As we mentioned earlier, there are too many possible conditions for a semi-structured format. For the sake of simplicity and in order to see if we could figure out a pattern for different conditions, our semi-structured format is similar to the unstructured format with one big difference. The unstructured open box field is accompanied by three hashtag fields, and the participants are required to create at least two hashtags. They can create a hashtag by typing \# following by a term. This term can be a keyword or an important point of the answer.

- The structured (fixed) format which is organized in a highly regular way and the regularity applies to all the data in the dataset; This interface has to result in a totally structured outcome. So, we let participants record content only by selecting answers from a pre-defined list. This interface contains a list of multiple-choice questions. One important point in designing this interface was to make sure that we have a comprehensive list of questions. In other words, a participant who uses unstructured format 
is free to write whatever they want regarding the experience. For example, while talking about catching the Flu, he/she can talk about the medicines that he/she took. However, in a structured format, participants do not have the freedom to write down their experiences and they are only allowed to answer the given questions by choosing from a list of answers. So, we had to make sure that the given questions cover as much as the possible experiences that the participants wanted to share. Therefore, we interviewed 6 who caught the Flu recently or had a memorable Flu experience. We also interviewed 6 different volunteers who did not remember the last time they caught Flu but were familiar with the disease. The interviewees were 5 male and 7 females ranging from 23 years old to 51 years old. The interviews were unstructured, and we ask volunteers to talk about their experience or knowledge about the Flu. Based on the results of these interviews, we came up with a list of questions that covers all the responses of the interviewees. Even though there could be always a very rare and unique piece of experience, we think that our list of questions for structured format could potentially cover almost all the experiences or knowledge that our future participants are willing to share.

\section{PQoIC instrument}

The instrument that we use to measure the perceived quality of information collection (PQoIC) is the same instrument that we used and validated in Chapter 3. As we described in Chapter 2, our instrument has three sub-constructs, each of which contains two dimensions: perceived completeness and accuracy for content sub-construct, perceived ease and speed of data entry for process sub-construct, and perceived flexibility and utility of structure for structure sub-construct. In our survey instrument, each item is measured by a 7-point Likert type scale, with values ranging from 1 (very unimportant or strongly disagree) to 7 (very important or strongly agree). A higher value represents greater importance or agreement perceived by the respondents. 
The following table summarizes the experiment conditions.

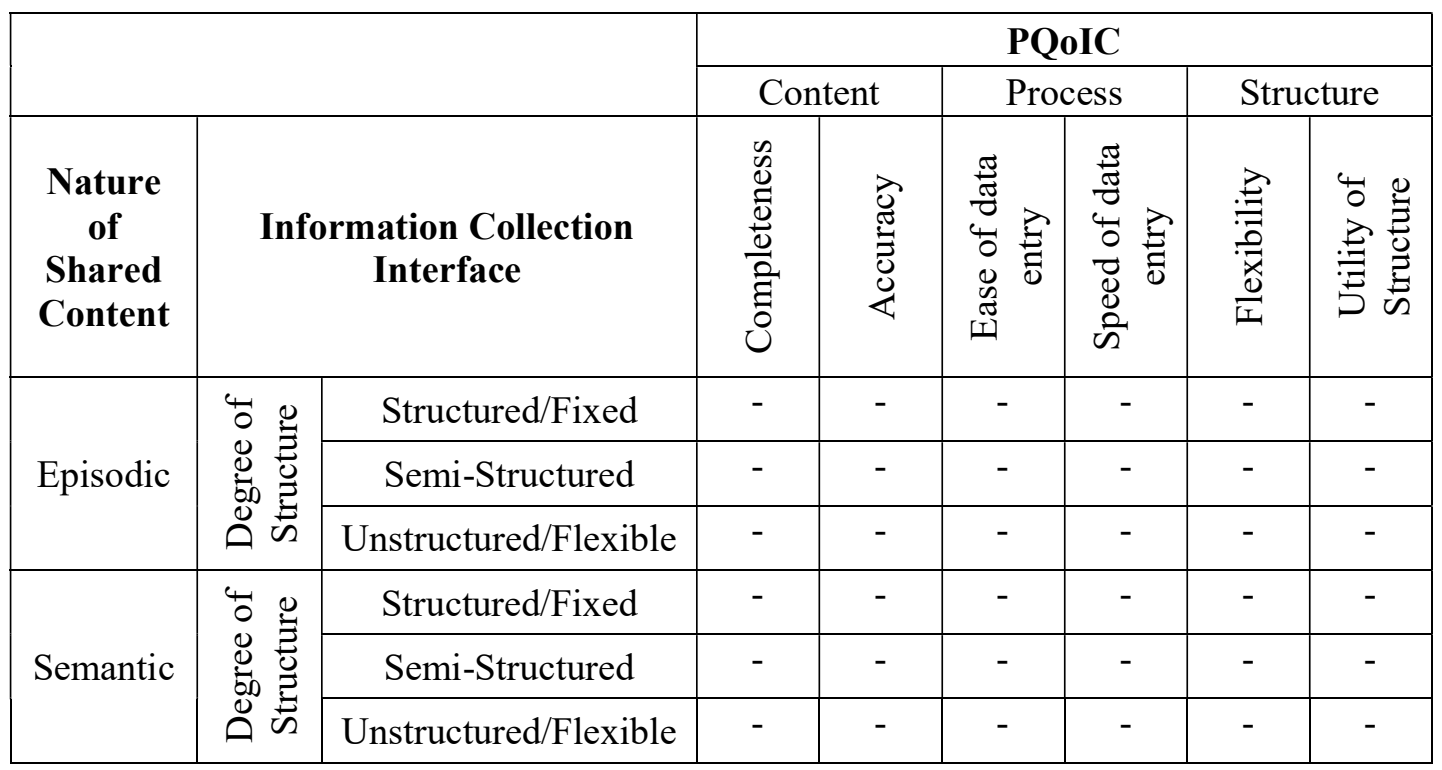

Table 14 - Experiment conditions

Similar to the previous experiment, we think the fact that how well the participants remember details of the experience (for the episodic scenario) or how much they know about the topic (for the semantic scenario) could affect the response. Therefore, we consider the participants' perception of their familiarity/remembrance. So, we ask participants to rate their perception on a 7point Likert scale. Furthermore, we use the same measures (from Chapter 3 experiment) to assess participants' involvement with the task.

A complete list of questions and tasks of this experiment is provided in Appendix D.

\section{Experiment design - Data consumers}

As a follow-up study, we run another experiment to assess the data consumers' perceived quality of information collection. The recorded information from the first set of experiments was shown to the independent participants of a new study. Similar to the previous experiment, we measure data consumers perception of the quality of the content that is recorded using each one of the interfaces. 
The participants will be asked to assess the quality of recorded information and make inferences about the person who provided this information based on the information provided. Each participant is randomly given either an unstructured content or a structured content. The unstructured content is shown as a text box, whereas structured content is shown as a brief table. The following figure provides an example of a piece of content collected through an unstructured interface.

About a month ago I got the cold, it started out with me sneezing that made me feel like I was getting bad allergic reactions. My headache came later. The headache wasn't so bad, so I did my usual routine. Since I didn't know that I was getting a cold I was powering it thru. I took some echinacea and vitamin $\mathrm{C}$ for prophylaxis. When the fever came in, it finally came with all the symptoms. I couldn't leave the bed. My throat was on fire, weakness, tiredness. I took a homeopathic cough syrup. Also, I used ibuprofen for the weakness and to decrease my fever. In a couple of days after drinking lots and lots of fluids my situation got better. I stayed in bed for a week in total. This cold was not so bad. Just the dry leaking nose and sore throat made the symptoms feel 10 times

worse.

\section{Figure 20 - A sample of unstructured content}

Figure 21 provides an example of an episodic piece of content collected through a structured interface. 


\begin{tabular}{|c|c|c|c|c|c|c|c|c|c|c|c|c|c|c|}
\hline \multicolumn{10}{|c|}{ * Answers in GREEN. / "Other" indicates answers that are not listed. } & \multicolumn{5}{|c|}{ ID: F.T6.HS.E.243 } \\
\hline \multicolumn{3}{|c|}{$\begin{array}{l}\text { Which one best describes } \\
\text { your sickness? }\end{array}$} & \multicolumn{2}{|c|}{ Common cold } & \multicolumn{2}{|c|}{$\begin{array}{c}\text { Seasonal Flu } \\
\text { (Influenza) }\end{array}$} & \multicolumn{3}{|c|}{$\begin{array}{c}\text { Other kinds of } \\
\text { Flu }\end{array}$} & \multicolumn{2}{|c|}{ Not Sure } & \multicolumn{3}{|c|}{ Other } \\
\hline \multicolumn{3}{|c|}{$\begin{array}{l}\text { When did this sickness } \\
\text { happen to you? }\end{array}$} & \multicolumn{2}{|c|}{$\begin{array}{l}\text { Within last } \\
\text { year }\end{array}$} & \multicolumn{2}{|c|}{$1-2$ years ago } & \multicolumn{3}{|c|}{$3-4$ years ago } & \multicolumn{2}{|c|}{$5-6$ years ago } & \multicolumn{3}{|c|}{$\begin{array}{l}\text { More than } 6 \\
\text { years ago }\end{array}$} \\
\hline \multicolumn{3}{|c|}{$\begin{array}{l}\text { Which of the following } \\
\text { treatments did you use? }\end{array}$} & Nothing & \multicolumn{2}{|c|}{$\begin{array}{l}\text { Taking } \\
\text { Medicine }\end{array}$} & \multicolumn{2}{|c|}{$\begin{array}{l}\text { Taking } \\
\text { Supplements }\end{array}$} & \multicolumn{2}{|c|}{$\begin{array}{l}\text { Physical } \\
\text { therapy }\end{array}$} & \multicolumn{2}{|c|}{$\begin{array}{l}\text { Using an } \\
\text { equipment }\end{array}$} & \multicolumn{2}{|c|}{ Exercise } & Other \\
\hline \multicolumn{2}{|c|}{$\begin{array}{l}\text { Who did you consult } \\
\text { with for treatment? }\end{array}$} & \multicolumn{2}{|l|}{\begin{tabular}{|l} 
No \\
one
\end{tabular}} & \multicolumn{2}{|c|}{$\begin{array}{l}\text { A friend (who is } \\
\text { not a health } \\
\text { expert) }\end{array}$} & \multicolumn{3}{|c|}{$\begin{array}{l}\text { A family member } \\
\text { (who is not a health } \\
\text { expert) }\end{array}$} & $\begin{array}{l}\text { A } \\
\text { healt } \\
\text { exper }\end{array}$ & $\begin{array}{l}\text { An } \\
\text { hez } \\
\text { cor }\end{array}$ & $\begin{array}{l}\text { online } \\
\text { alth } \\
\text { nmunit }\end{array}$ & & Oth & \\
\hline $\begin{array}{l}\text { Where did you vi } \\
\text { treatment? }\end{array}$ & sit for & Now & here & $\begin{array}{l}\text { A pharmacy } \\
\text { buy drugs }\end{array}$ & & $\begin{array}{l}\text { Emergency } \\
\text { room }\end{array}$ & & $\begin{array}{l}\text { Joctor } \\
\text { ice }\end{array}$ & & A hos & pital & $\begin{array}{l}\text { Urger } \\
\text { care }\end{array}$ & & Other \\
\hline $\begin{array}{l}\text { Did you take any } \\
\text { medicine? How o } \\
\text { you acquire it? }\end{array}$ & lid & $\begin{array}{l}\text { o. I did } \\
\text { ke any } \\
\text { edicin }\end{array}$ & & $\begin{array}{l}\text { Yes. I alre } \\
\text { had the } \\
\text { medicine. }\end{array}$ & & $\begin{array}{l}\text { Yes. Som } \\
\text { friend/fa } \\
\text { gave it to }\end{array}$ & $\begin{array}{l}\text { ne } \\
\text { amily } \\
\text { o me. }\end{array}$ & & $\begin{array}{l}\text { s. I bo } \\
\text { jer th } \\
\text { unter }\end{array}$ & $\begin{array}{l}\text { ought it } \\
\text { o. }\end{array}$ & $\begin{array}{l}\text { Yes. I } \\
\text { (pres } \\
\text { drug) } \\
\end{array}$ & $\begin{array}{l}\text { I bough } \\
\text { scribed } \\
\text { i. }\end{array}$ & d it & Other \\
\hline If you took any $\mathrm{m}$ & nedicine & & I did & not take any & & Pills / T & Tablet & Cap & psule & Sup & positor & & Solut & tion \\
\hline which item(s) de & scribe th & hem? & Syru & Ointr & ment & Ampul & & Spra & & Seru & & & Othe & \\
\hline $\begin{array}{l}\text { How did you } \\
\text { change your }\end{array}$ & $\begin{array}{l}\text { Nothin } \\
\text { for me. }\end{array}$ & g chan & & $\begin{array}{l}\text { I took some } \\
\text { off from my }\end{array}$ & $\begin{array}{l}\text { days/h } \\
\text { work. }\end{array}$ & \begin{tabular}{l|l} 
hours & I re \\
\end{tabular} & est mor & e thar & an usu & & $\begin{array}{l}\text { tried } t \\
\text { normal }\end{array}$ & $\begin{array}{l}\text { to redi } \\
\text { I physi }\end{array}$ & $\begin{array}{l}\text { uce } m \\
\text { ical ac }\end{array}$ & $\begin{array}{l}\text { ly } \\
\text { ctivity. }\end{array}$ \\
\hline $\begin{array}{l}\text { lifestyle during } \\
\text { the illness? }\end{array}$ & $\begin{array}{l}\text { I tooks } \\
\text { shower }\end{array}$ & $\begin{array}{l}\text { several } \\
\text { rs. }\end{array}$ & & I stopped sm & noking. & & $\begin{array}{l}\text { mebody } \\
\text { re of } \mathrm{me}\end{array}$ & $\begin{array}{l}\text { y help } \\
\text { e. }\end{array}$ & $\mathrm{ped} / \mathrm{t}$ & & Dther & & & \\
\hline $\begin{array}{l}\text { How did you } \\
\text { change your }\end{array}$ & $\begin{array}{l}\text { Nothir } \\
\text { for me }\end{array}$ & $\begin{array}{l}\text { ng cha } \\
\text { e. }\end{array}$ & nged & $\begin{array}{l}\text { I drank mor } \\
\text { than usual. }\end{array}$ & re wate & \begin{tabular}{l|l} 
er & I const \\
and fru
\end{tabular} & $\begin{array}{l}\text { sumed ju } \\
\text { ruit mor }\end{array}$ & $\begin{array}{l}\text { juice, } f \\
\text { re tha }\end{array}$ & $\begin{array}{l}\text { fresh } \\
\text { an usi }\end{array}$ & $\begin{array}{l}\text { i vegetak } \\
\text { ual. }\end{array}$ & ples & $\begin{array}{l}\text { I avoid } \\
\text { Alcoho }\end{array}$ & $\begin{array}{l}\text { led / r } \\
\text { ol. }\end{array}$ & reduced \\
\hline nutrition / diet? & $\begin{array}{l}\text { I avoid } \\
\text { reduce }\end{array}$ & $\begin{array}{l}\text { ded / } \\
\text { ed caff }\end{array}$ & eine. & $\begin{array}{l}\text { I avoided / } \\
\text { fried food. }\end{array}$ & reduce & \begin{tabular}{l|l} 
ed & Other \\
\end{tabular} & & & & & & & & \\
\hline $\begin{array}{l}\text { How much mone } \\
\text { total out of pock }\end{array}$ & $\begin{array}{l}y \text { did yo } \\
\text { et for th }\end{array}$ & $\begin{array}{l}\text { Ju spe } \\
\text { is dise }\end{array}$ & $\begin{array}{l}\text { nd in } \\
\text { ase? }\end{array}$ & $0 \$$ & $10 \$$ & $11-25 \$$ & $25-50$ & & $50-1$ & $100 \$$ & $100-2$ & $200 \$$ & & $>200 \$$ \\
\hline What was the fir & st symp & tom th & & Fever & Runr & ny nose & Sore th & roat & & ausea & Diarr & rrhea & $\mathrm{Hea}$ & adache \\
\hline $\begin{array}{l}\text { appeared that } m \\
\text { you were in the }\end{array}$ & $\begin{array}{l}\text { ade you } \\
\text { onset ph }\end{array}$ & $\begin{array}{l}\text { realiz } \\
\text { nase? }\end{array}$ & & Coughing & & atigue & Wheez & zing & & somnia & Dizzir & iness & & $\begin{array}{l}\text { Iuscle } \\
\text { pain }\end{array}$ \\
\hline How long did eac & h perio & d take & & $0-1$ day & & -3 days & $4-5 \mathrm{da}$ & & & 7 days & & $>7$ & & $N / A$ \\
\hline $\begin{array}{l}\text { Onset phase (Vag } \\
\text { symptoms) }\end{array}$ & gue, gen & neral & & & & & & & & & & & & \\
\hline $\begin{array}{l}\text { Illness phase (mo } \\
\text { symptoms) }\end{array}$ & st sever & re sign & & & & & & & & & & & & \\
\hline $\begin{array}{l}\text { Declination phas } \\
\text { and symptoms) }\end{array}$ & e (declir & ning si & & & & & & & & & & & & \\
\hline $\begin{array}{l}\text { How severe was } \\
\text { phase? }\end{array}$ & each syr & mpton & duri & ng the illness & & None & & Mild & & Mo & derate & & Sev & vere \\
\hline & & ver & & & & & & & & & & & & \\
\hline & Runn & y nose & & & & & & & & & & & & \\
\hline & Sore & throat & & & & & & & & & & & & \\
\hline & $\mathrm{Nat}$ & usea & & & & & & & & & & & & \\
\hline & Diar & rrhea & & & & & & & & & & & & \\
\hline & Heac & dache & & & & & & & & & & & & \\
\hline & Cou: & ghing & & & & & & & & & & & & \\
\hline & Fat & igue & & & & & & & & & & & & \\
\hline & Whe & ezing & & & & & & & & & & & & \\
\hline & Inso & mnia & & & & & & & & & & & & \\
\hline & Dizz & iness & & & & & & & & & & & & \\
\hline & Musc & le pain & & & & & & & & & & & & \\
\hline
\end{tabular}

Figure 21 - A sample of episodic content presented in a structured format

Figure 22 provides an example of a semantic piece of content collected through a structured interface. 


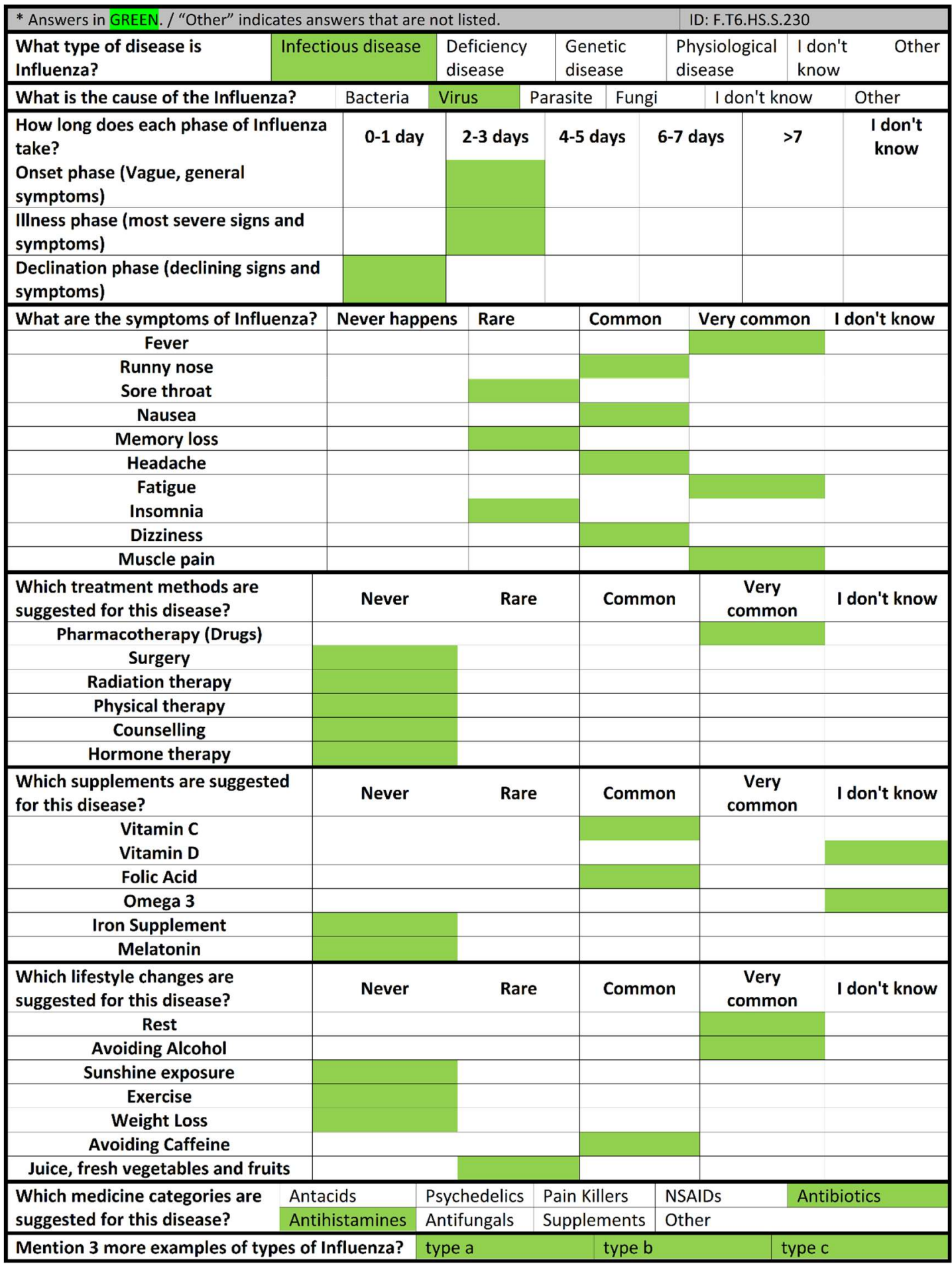

Figure 22 - A sample of semantic content presented in a structured format

Similar to the previous experiment, each participant is randomly assigned to one of the recorded contents (it could be either structured or unstructured, also either episodic or semantic). Then, the 
participant is given the exact short survey which we used for the data consumers section of the previous experiment. We follow a qualitative approach for this experiment to explore data consumers perception about each type of content.

\section{Data collection}

As MTurk is becoming widely accepted in business research (Deng et al. 2016; Kees et al. 2017), we used MTurk to recruit our participants for this experiment as well. As our theory is based on general memory systems, we conducted experiments with the general population. We recruit MTurk workers ages 18 to 60 living in the United States, to participate in the experiments. Similar to the previous experiment, we designed our experiment on Qualtrics and put a hyperlink on the MTurk task. So, MTurk workers who decided to participate in our study are directed to the Qualtrics experiment using a hyperlink. To minimize the bias in our study, we follow a between-subject design. So, each participant is allowed to take part in the experiment only once. Moreover, to decrease the risk of receiving corrupted data, we needed to make sure that the participants are actually sharing their own experience by using the given interface. So, using an HTML code, we disabled the copy/paste feature on the page of the experiment.

\section{Analyses and results}

\section{Descriptive Statistics}

We run our experiment through MTurk and received 352 responses. We need to make sure that our collected data is of high quality. So, we cleaned the collected data by following the same steps that we followed to clean the collected data for the experiment in Chapter 3. The final data set includes 273 responses. 133 participants responded to our episodic scenario, while the other 140 participants responded to the semantic scenario. Similar to the previous experiment, we have provided 3 differently designed interfaces. The following table summarizes the number of participants for each interface and scenario. 


\begin{tabular}{|c|c|c|c|c|}
\hline \multirow{2}{*}{\multicolumn{2}{|c|}{ Interface Design }} & \multicolumn{2}{|c|}{ NSC } & \multirow{3}{*}{$\begin{array}{c}\text { Total } \\
109\end{array}$} \\
\hline & & \multirow{2}{*}{$\begin{array}{c}\text { Episodic } \\
50\end{array}$} & \multirow{2}{*}{$\frac{\text { Semantic }}{59}$} & \\
\hline 40 & Unstructured & & & \\
\hline 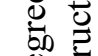 & Semi-structured & 52 & 50 & 102 \\
\hline 0 & Highly Structured & 31 & 31 & 62 \\
\hline & Total & 133 & 140 & 273 \\
\hline
\end{tabular}

Table 15 - Response distribution for each condition

The following table shows the percentage of each condition.

\begin{tabular}{|c|c|c|c|c|}
\hline \multirow{2}{*}{\multicolumn{2}{|c|}{ Interface Design }} & \multicolumn{2}{|c|}{ NSC } & \multirow{3}{*}{$\begin{array}{c}\text { Total } \\
39.93 \%\end{array}$} \\
\hline & & \multirow{2}{*}{$\frac{\text { Episodic }}{18.32 \%}$} & \multirow{2}{*}{$\frac{\text { Semantic }}{21.61 \%}$} & \\
\hline 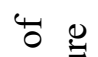 & Unstructured & & & \\
\hline$\tilde{\omega}_{0}$ & Semi-structured & $19.05 \%$ & $18.32 \%$ & $37.36 \%$ \\
\hline ๑ & Highly Structured & $11.36 \%$ & $11.36 \%$ & $22.71 \%$ \\
\hline & Total & $48.72 \%$ & $51.28 \%$ & $100.00 \%$ \\
\hline
\end{tabular}

Table 16 - Response distribution percentage for each condition

Based on the collected demographic information, our participants include 187 (68.5\%) female and $86(31.5 \%)$ male MTurk workers, and they represent a wide range of age from 18 to over 55 years old. More than 80 percent of the participants hold at least a college degree. And more than 97 percent were native English speakers, so they did not have a language proficiency barrier to respond to the questions. The following table summarizes the descriptive statistics of our participants.

\begin{tabular}{|l|l|r|r|}
\hline \multirow{3}{*}{ Gender } & Female & 187 & $68.5 \%$ \\
\cline { 2 - 4 } & Male & 86 & $31.5 \%$ \\
\hline \multirow{6}{*}{ Age } & $18-24$ years old & 26 & $9.5 \%$ \\
\cline { 2 - 4 } & $25-34$ & 92 & $33.7 \%$ \\
\cline { 2 - 4 } & $35-44$ & 57 & $20.9 \%$ \\
\cline { 2 - 4 } & $45-54$ & 38 & $13.9 \%$ \\
\cline { 2 - 4 } & 55 and over & 60 & $22.0 \%$ \\
\hline
\end{tabular}




\begin{tabular}{|c|l|r|r|}
\hline \multirow{3}{*}{ Education } & College & 93 & $34.1 \%$ \\
\cline { 2 - 4 } & Graduate & 50 & $18.3 \%$ \\
\cline { 2 - 4 } & High School & 54 & $19.8 \%$ \\
\cline { 2 - 4 } & Undergraduate & 76 & $27.8 \%$ \\
\hline \multirow{3}{*}{$\begin{array}{c}\text { Language } \\
\text { Proficiency }\end{array}$} & Limited proficiency & 1 & $0.4 \%$ \\
\cline { 2 - 4 } & Native English speaker & 265 & $97.1 \%$ \\
\cline { 2 - 4 } & $\begin{array}{l}\text { NOT native English } \\
\text { speaker, but proficient }\end{array}$ & 7 & $2.6 \%$ \\
\hline
\end{tabular}

Table 17 - Descriptive statistics

The following table provides detailed information about the participants for the episodic type of content. The mean score of each dimension for the groups is provided.

\begin{tabular}{|c|c|c|c|c|c|c|c|c|c|}
\hline NSC & Variable & Category & No & 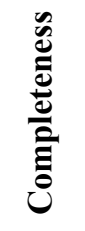 & 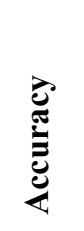 & 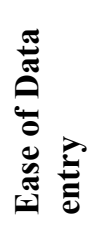 & 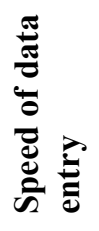 & 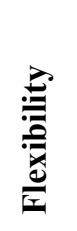 & 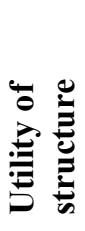 \\
\hline \multirow{11}{*}{$\begin{array}{l}\frac{U}{0} \\
\frac{0}{0} \\
\frac{0}{2} \\
\frac{1}{x}\end{array}$} & \multirow{2}{*}{ Gender } & Female & 91 & 6.04 & 6.00 & 6.33 & 5.64 & 5.44 & 5.79 \\
\hline & & Male & 42 & 5.92 & 5.91 & 6.04 & 5.53 & 5.42 & 5.78 \\
\hline & \multirow{5}{*}{ Age } & $18-24$ уо & 9 & 6.41 & 6.48 & 6.59 & 6.00 & 5.37 & 5.78 \\
\hline & & $25-34$ yo & 52 & 5.90 & 5.93 & 6.17 & 5.50 & 5.50 & 5.85 \\
\hline & & $35-44$ yo & 33 & 5.99 & 5.90 & 6.19 & 5.56 & 5.34 & 5.71 \\
\hline & & $45-54$ yo & 17 & 5.96 & 5.90 & 6.39 & 5.71 & 5.45 & 5.80 \\
\hline & & $55 \&$ over & 22 & 6.12 & 6.02 & 6.20 & 5.68 & 5.44 & 5.76 \\
\hline & \multirow{4}{*}{ Education } & Highschool & 19 & 6.16 & 6.30 & 6.40 & 5.86 & 5.42 & 6.05 \\
\hline & & College & 43 & 5.90 & 5.98 & 6.08 & 5.53 & 5.51 & 5.72 \\
\hline & & Undergrad & 43 & 6.04 & 5.84 & 6.30 & 5.69 & 5.32 & 5.85 \\
\hline & & Graduate & 28 & 6.00 & 5.93 & 6.27 & 5.40 & 5.51 & 5.62 \\
\hline
\end{tabular}

Table 18 - Control variables statistics for episodic content

The following table provides detailed information about the participants for the semantic type of content. The mean score of each dimension for the groups is provided. 


\begin{tabular}{|c|c|c|c|c|c|c|c|c|c|}
\hline NSC & Variable & Category & No & 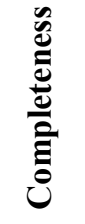 & 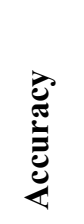 & 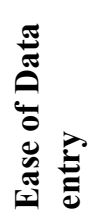 & 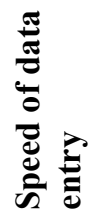 & 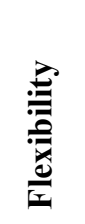 & 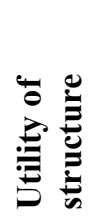 \\
\hline \multirow{11}{*}{ 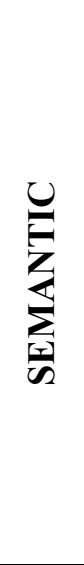 } & \multirow{2}{*}{ Gender } & Female & 96 & 6.14 & 6.03 & 6.30 & 5.76 & 5.27 & 5.75 \\
\hline & & Male & 40 & 5.92 & 5.89 & 6.02 & 5.64 & 5.45 & 5.63 \\
\hline & \multirow{5}{*}{ Age } & $18-24$ yo & 17 & 5.88 & 5.73 & 6.00 & 5.35 & 5.18 & 5.31 \\
\hline & & $25-34$ yo & 40 & 6.12 & 6.14 & 6.20 & 5.73 & 5.60 & 5.88 \\
\hline & & $35-44$ yo & 24 & 5.96 & 6.00 & 6.32 & 5.97 & 5.08 & 5.60 \\
\hline & & $45-54$ уо & 21 & 6.03 & 5.65 & 6.22 & 5.65 & 5.17 & 5.68 \\
\hline & & $55 \&$ over & 38 & 6.20 & 6.11 & 6.25 & 5.75 & 5.34 & 5.82 \\
\hline & \multirow{4}{*}{ Education } & Highschool & 35 & 5.98 & 5.98 & 6.07 & 5.70 & 5.13 & 5.42 \\
\hline & & College & 50 & 5.96 & 5.97 & 6.22 & 5.62 & 5.43 & 5.83 \\
\hline & & Undergrad & 33 & 6.15 & 6.00 & 6.36 & 5.74 & 5.47 & 6.02 \\
\hline & & Graduate & 22 & 6.35 & 6.00 & 6.21 & 5.94 & 5.17 & 5.45 \\
\hline
\end{tabular}

Table 19 - Control variables statistics for episodic content

\section{Stage 1 - degree of structure vs PQoIC}

In this experiment, we want to investigate whether considering the nature of shared content affects data creators' perceived quality of information collection for differently designed interfaces. However, before considering the nature of shared content, we examine the relationship between the degree of structure and PQoIC. We already investigated this relationship in Chapter 3. Using the new set of data, we re-examine that relationship to make sure that we end up with consistent results. First, we looked at the mean and standard deviation of the dimensions in each interface. The following table summarizes the statistics for each interface.

\begin{tabular}{|l|l|r|r|r|r|}
\hline \multicolumn{1}{|c|}{ Interface } & \multicolumn{5}{c|}{ Unstructured } \\
\hline PIQ Dimension & N & \multicolumn{1}{c|}{ Mean } & Std.Dev & Min & Max \\
\hline Completeness & 109 & 6.25 & 0.747 & 3 & 7 \\
\hline Accuracy & 109 & 6.16 & 0.784 & 3 & 7 \\
\hline Ease of Data Entry & 109 & 6.32 & 0.731 & 4 & 7 \\
\hline Speed of Data Entry & 109 & 5.80 & 0.998 & 3 & 7 \\
\hline Flexibility & 109 & 5.48 & 0.929 & 4 & 7 \\
\hline Utility of Structure & 109 & 5.90 & 1.036 & 2 & 7 \\
\hline
\end{tabular}




\begin{tabular}{|l|r|r|r|r|r|}
\hline \multicolumn{1}{|c|}{ Interface } & \multicolumn{5}{c|}{ Unstructured } \\
\hline & \multicolumn{5}{c|}{ Semi-Structured } \\
\hline Completeness & 102 & 6.07 & 0.836 & 3 & 7 \\
\hline Accuracy & 102 & 6.06 & 0.818 & 4 & 7 \\
\hline Ease of Data Entry & 102 & 6.19 & 0.817 & 3 & 7 \\
\hline Speed of Data Entry & 102 & 5.52 & 1.031 & 3 & 7 \\
\hline Flexibility & 102 & 5.43 & 0.990 & 2 & 7 \\
\hline Utility of Structure & 102 & 5.76 & 0.946 & 3 & 7 \\
\hline & \multicolumn{5}{|c|}{ Highly Structured } \\
\hline Completeness & 62 & 5.61 & 1.092 & 2 & 7 \\
\hline Accuracy & 62 & 5.66 & 0.809 & 4 & 7 \\
\hline Ease of Data Entry & 62 & 6.18 & 0.736 & 3 & 7 \\
\hline Speed of Data Entry & 62 & 5.65 & 0.749 & 3 & 7 \\
\hline Flexibility & 62 & 5.11 & 0.907 & 3 & 7 \\
\hline Utility of Structure & 62 & 5.50 & 0.937 & 3 & 7 \\
\hline
\end{tabular}

Table 20 - Statistics of each condition

To evaluate the differences between the interfaces, we compare the result of surveys that were submitted by participants after using each interface. The table shows the statistics of PQoIC for each interface design. However, the following chart depicts the changes in the mean score of the content dimensions from unstructured to structured format. Similar to the findings of Chapter 3 , the mean score for both perceived completeness and accuracy are the lowest for highly structured interface design. 


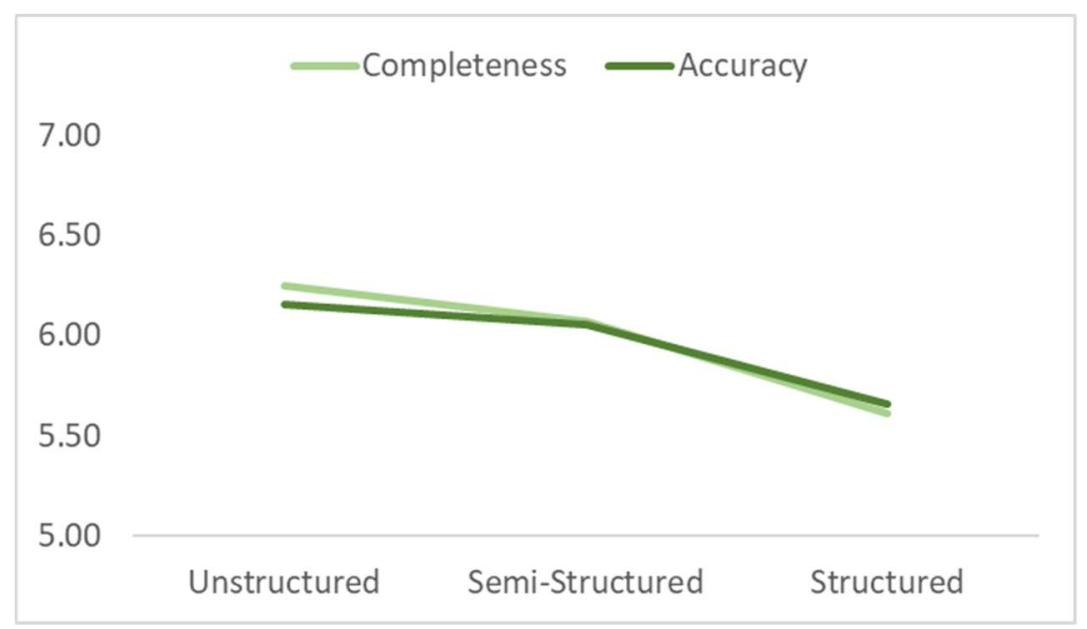

Figure 23 - Changes between interfaces - completeness \& accuracy

The same thing happens for the structure dimensions. We can see the mean score is dropping, from unstructured to structured format. As the following chart shows, the less-structured format holds the highest score.

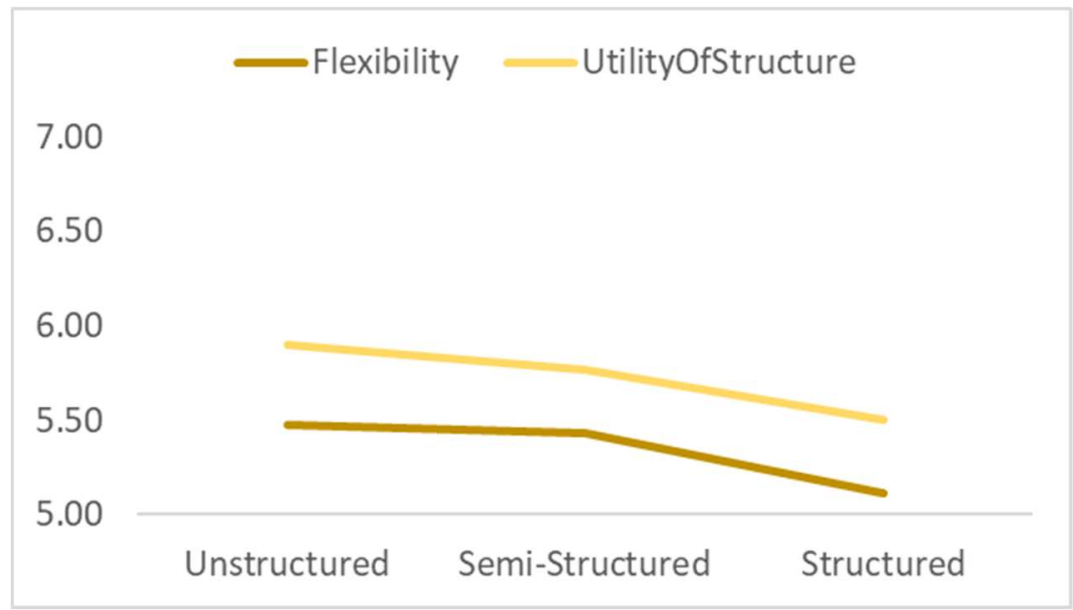

Figure 24 - Changes between interfaces - flexibility \& utility of structure

Similar to the previous experiment, the only sub-construct that does not follow this pattern is the process sub-construct. As the following figure shows, the chart follows a more linear pattern than the other two charts. 


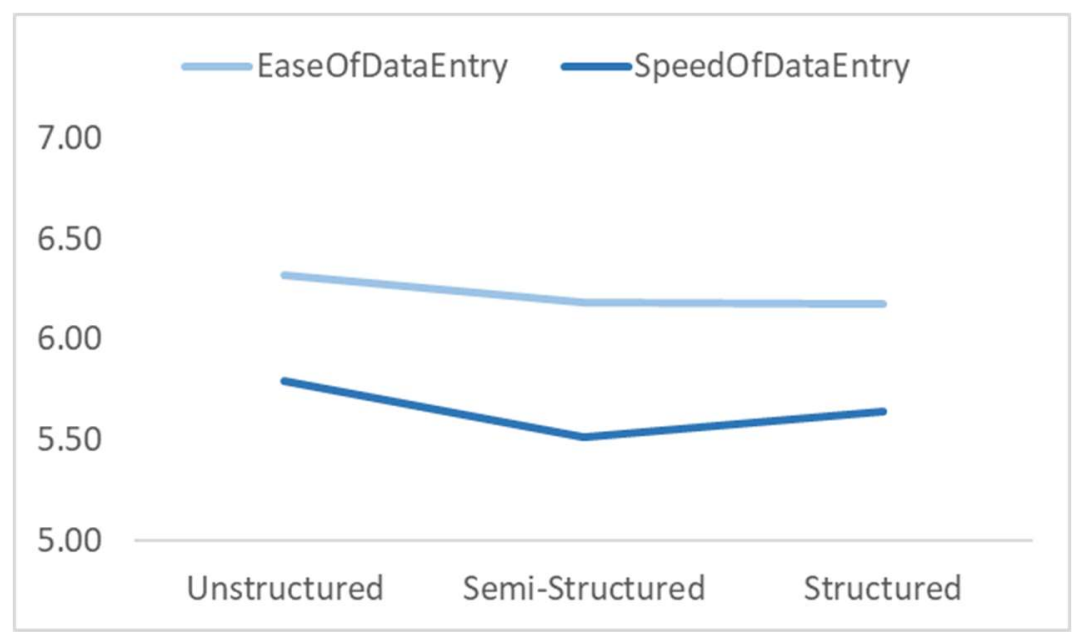

Figure 25 - Changes between interfaces - ease \& speed of data entry

We also run the one-way analysis of variance (ANOVA) to determine whether there are any statistically significant differences among the three interfaces in terms of PQoIC. The following table summarizes our ANOVA test.

\begin{tabular}{|l|l|r|r|r|r|r|r|}
\hline PIQ Dimension & N & \multicolumn{1}{|c|}{ Mean } & Std.Dev & \multicolumn{1}{|c|}{ Min } & Max & \multicolumn{1}{c|}{ F } & \multicolumn{1}{c|}{ Sig. } \\
\hline Completeness & 273 & 6.04 & 0.899 & 2 & 7 & 10.673 & 0.000 \\
\hline Accuracy & 273 & 6.01 & 0.822 & 3 & 7 & 7.843 & 0.000 \\
\hline Ease of Data Entry & 273 & 6.24 & 0.766 & 3 & 7 & 1.069 & 0.345 \\
\hline Speed of Data Entry & 273 & 5.66 & 0.965 & 3 & 7 & 2.224 & 0.110 \\
\hline Flexibility & 273 & 5.38 & 0.955 & 2 & 7 & 3.184 & 0.043 \\
\hline Utility of Structure & 273 & 5.76 & 0.989 & 2 & 7 & 3.275 & 0.039 \\
\hline
\end{tabular}

Table 21 - ANOVA results

Interestingly, the results of this ANOVA test are very consistent with the results of the ANOVA test in Chapter 3. We detect significant differences between interfaces for the data creators' perceived completeness and accuracy. The results show that the recorded perceived completeness $(6.04, \mathrm{p}<0.000)$ is significantly different from one interface to the other. Also, data creators' perception of accuracy $(6.01, \mathrm{p}<0.000)$ is significantly different while using differently designed interfaces. The results on flexibility and utility of structure are also similar to the experiment in 
Chapter 3. Using interfaces with various degrees of structure results in significantly different scores for both perceived flexibility $(5.38, \mathrm{p}<0.043)$ and utility of structure $(5.76, \mathrm{p}<0.039)$. Finally, we did not detect any significant differences for perceived ease of data entry $(6.24, \mathrm{p}=0.345)$ and speed of data entry $(5.66, \mathrm{p}=0.110)$.

Since the ANOVA test determines whether we have overall significant differences among the interfaces, we carried a MANCOVA test with post hoc multiple comparisons using Tukey HSD, with alpha $=0.05$. The following is the result of the post hoc test. 


\begin{tabular}{|c|c|c|c|c|c|c|c|}
\hline \multirow{2}{*}{$\begin{array}{l}\text { Dependent } \\
\text { Variable }\end{array}$} & \multirow{2}{*}{$\begin{array}{l}\text { (I) } \\
\text { InterfaceID }\end{array}$} & \multirow{2}{*}{$\begin{array}{l}\text { (J) } \\
\text { InterfaceID }\end{array}$} & \multirow{2}{*}{$\begin{array}{c}\text { Difference } \\
(\mathbf{I}-J)\end{array}$} & \multirow{2}{*}{$\begin{array}{l}\text { Std. } \\
\text { Error }\end{array}$} & \multirow{2}{*}{ Sig. } & \multicolumn{2}{|c|}{ 95\% Conf. } \\
\hline & & & & & & Lower & Upper \\
\hline \multirow{6}{*}{ Completeness } & \multirow{2}{*}{ US } & $\mathrm{SS}$ & 0.179 & 0.120 & 0.294 & -0.10 & 0.46 \\
\hline & & HS & $.635^{*}$ & 0.138 & 0.000 & 0.31 & 0.96 \\
\hline & \multirow{2}{*}{$\mathrm{SS}$} & US & -0.179 & 0.120 & 0.294 & -0.46 & 0.10 \\
\hline & & HS & $.456^{*}$ & 0.140 & 0.004 & 0.13 & 0.79 \\
\hline & \multirow{2}{*}{ HS } & US & $-.635^{*}$ & 0.138 & 0.000 & -0.96 & -0.31 \\
\hline & & $\mathrm{SS}$ & $-.456^{*}$ & 0.140 & 0.004 & -0.79 & -0.13 \\
\hline \multirow{6}{*}{ Accuracy } & \multirow{2}{*}{ US } & $\mathrm{SS}$ & 0.097 & 0.111 & 0.654 & -0.16 & 0.36 \\
\hline & & HS & $.495^{*}$ & 0.128 & 0.000 & 0.19 & 0.80 \\
\hline & \multirow{2}{*}{ SS } & US & -0.097 & 0.111 & 0.654 & -0.36 & 0.16 \\
\hline & & HS & $.398^{*}$ & 0.129 & 0.007 & 0.09 & 0.70 \\
\hline & \multirow{2}{*}{ HS } & US & $-.495^{*}$ & 0.128 & 0.000 & -0.80 & -0.19 \\
\hline & & SS & $-.398^{*}$ & 0.129 & 0.007 & -0.70 & -0.09 \\
\hline \multirow{6}{*}{$\begin{array}{l}\text { Ease of Data } \\
\text { Entry }\end{array}$} & \multirow{2}{*}{ US } & $\mathrm{SS}$ & 0.135 & 0.105 & 0.409 & -0.11 & 0.38 \\
\hline & & HS & 0.144 & 0.122 & 0.466 & -0.14 & 0.43 \\
\hline & \multirow{2}{*}{$\mathrm{SS}$} & US & -0.135 & 0.105 & 0.409 & -0.38 & 0.11 \\
\hline & & HS & 0.009 & 0.123 & 0.997 & -0.28 & 0.30 \\
\hline & \multirow{2}{*}{ HS } & US & -0.144 & 0.122 & 0.466 & -0.43 & 0.14 \\
\hline & & $\mathrm{SS}$ & -0.009 & 0.123 & 0.997 & -0.30 & 0.28 \\
\hline \multirow{6}{*}{$\begin{array}{l}\text { Speed of } \\
\text { Data Entry }\end{array}$} & \multirow{2}{*}{ US } & $\mathrm{SS}$ & 0.279 & 0.132 & 0.091 & -0.03 & 0.59 \\
\hline & & HS & 0.153 & 0.153 & 0.577 & -0.21 & 0.51 \\
\hline & \multirow{2}{*}{ SS } & US & -0.279 & 0.132 & 0.091 & -0.59 & 0.03 \\
\hline & & $\mathrm{HS}$ & -0.126 & 0.155 & 0.696 & -0.49 & 0.24 \\
\hline & \multirow{2}{*}{ HS } & US & -0.153 & 0.153 & 0.577 & -0.51 & 0.21 \\
\hline & & SS & 0.126 & 0.155 & 0.696 & -0.24 & 0.49 \\
\hline \multirow{6}{*}{ Flexibility } & \multirow{2}{*}{ US } & $\mathrm{SS}$ & 0.046 & 0.131 & 0.935 & -0.26 & 0.35 \\
\hline & & HS & $.364^{*}$ & 0.151 & 0.043 & 0.01 & 0.72 \\
\hline & \multirow{2}{*}{$\mathrm{SS}$} & US & -0.046 & 0.131 & 0.935 & -0.35 & 0.26 \\
\hline & & HS & 0.318 & 0.153 & 0.094 & -0.04 & 0.68 \\
\hline & HS & US & $-.364^{*}$ & 0.151 & 0.043 & -0.72 & -0.01 \\
\hline & HD & $\mathrm{SS}$ & -0.318 & 0.153 & 0.094 & -0.68 & 0.04 \\
\hline & US & $\mathrm{SS}$ & 0.134 & 0.135 & 0.581 & -0.18 & 0.45 \\
\hline & US & $\mathrm{HS}$ & $.399^{*}$ & 0.156 & 0.030 & 0.03 & 0.77 \\
\hline Utility of & SS & US & -0.134 & 0.135 & 0.581 & -0.45 & 0.18 \\
\hline Structure & SS & HS & 0.265 & 0.158 & 0.216 & -0.11 & 0.64 \\
\hline & $H \mathrm{~S}$ & US & $-.399^{*}$ & 0.156 & 0.030 & -0.77 & -0.03 \\
\hline & Пग & $\mathrm{SS}$ & -0.265 & 0.158 & 0.216 & -0.64 & 0.11 \\
\hline
\end{tabular}

Table 22 - Post hoc results

The following table summarizes the p-value results of the post hoc test. 


\begin{tabular}{|c|c|c|c|c|}
\hline Dimension & Interface & US & SS & HS \\
\hline \multirow{3}{*}{ Completeness } & $\mathbf{U S}$ & & .294 & .000 \\
\hline & SS & .294 & & .004 \\
\hline & HS & .000 & .004 & \\
\hline \multirow{3}{*}{ Accuracy } & $\mathbf{U S}$ & & .654 & .000 \\
\hline & SS & .654 & & .007 \\
\hline & HS & .000 & .007 & \\
\hline \multirow{3}{*}{$\begin{array}{c}\text { Ease of Data } \\
\text { Entry }\end{array}$} & $\mathbf{U S}$ & & .409 & .466 \\
\hline & SS & .409 & & .997 \\
\hline & HS & .466 & .997 & \\
\hline \multirow{3}{*}{$\begin{array}{c}\text { Speed of } \\
\text { Data Entry }\end{array}$} & $\mathbf{U S}$ & & .091 & .577 \\
\hline & SS & .091 & & .696 \\
\hline & HS & .577 & .696 & \\
\hline \multirow{3}{*}{ Flexibility } & $\mathbf{U S}$ & & .935 & .043 \\
\hline & SS & .935 & & .094 \\
\hline & HS & .043 & .094 & \\
\hline \multirow{3}{*}{$\begin{array}{l}\text { Utility of } \\
\text { Structure }\end{array}$} & US & & .581 & .030 \\
\hline & SS & .581 & & .216 \\
\hline & HS & .030 & .216 & \\
\hline
\end{tabular}

Table 23 - Summary results of the post hoc test

This stage was conducted to validate our findings from Chapter 3. The results are similar to those findings in different ways and consistently confirms our previous findings. Our findings show data creators perceive that using less-structured information collection interfaces results in recording more complete and accurate data than using more-structured information collection interfaces. Also, data creators perceive that less-structured information collection interfaces are more flexible and let higher utilize of structure than more-structured information collection interfaces. Now, we take into account the Nature of Shared Content (NSC) in stage 2.

\section{Stage 2 - Effect of Nature of Shared Content (NSC)}

In this stage, we consider the nature of shared content and investigate the differences in data creators' PQoIC. We have categories six different conditions that comes from two types of content, 
semantic (S) vs episodic (E), and three interface designs (US: Unstructured, SS: Semi-Structured, HS: Highly Structured). The following table summarizes descriptive statistics for each condition.

\begin{tabular}{|l|c|c|r|r|r|r|r|r|r|}
\hline \multicolumn{1}{|c|}{ Interaction } & \multicolumn{4}{c|}{ US-E } & \multicolumn{4}{c|}{ SS-E } & \multicolumn{3}{c|}{ HS-E } \\
\hline PIQ Dimension & $\mathbf{N}$ & Mean & Std.Dev & N & Mean & Std.Dev & N & Mean & Std.Dev \\
\hline Completeness & 50 & 6.34 & 0.688 & 52 & 6.08 & 0.860 & 31 & 5.35 & 1.082 \\
\hline Accuracy & 50 & 6.16 & 0.866 & 52 & 6.19 & 0.715 & 31 & 5.35 & 0.798 \\
\hline Ease of Data Entry & 50 & 6.36 & 0.722 & 52 & 6.23 & 0.731 & 31 & 6.13 & 0.806 \\
\hline Speed of Data Entry & 50 & 5.78 & 1.075 & 52 & 5.52 & 1.111 & 31 & 5.45 & 0.888 \\
\hline Flexibility & 50 & 5.78 & 0.887 & 52 & 5.44 & 0.895 & 31 & 5.03 & 0.875 \\
\hline Utility of Structure & 50 & 6.00 & 1.143 & 52 & 5.87 & 0.886 & 31 & 5.29 & 0.902 \\
\hline & \multicolumn{3}{|c|}{ US-S } & \multicolumn{5}{|c|}{ SS-S } & \multicolumn{4}{|c|}{ HS-S } \\
\hline \multicolumn{1}{|c|}{ PIQ Dimension } & $\mathbf{N}$ & Mean & Std.Dev & N & Mean & Std.Dev & N & Mean & Std.Dev \\
\hline Completeness & 59 & 6.17 & 0.791 & 50 & 6.06 & 0.818 & 31 & 5.87 & 1.056 \\
\hline Accuracy & 59 & 6.15 & 0.715 & 50 & 5.92 & 0.900 & 31 & 5.97 & 0.706 \\
\hline Ease of Data Entry & 59 & 6.29 & 0.744 & 50 & 6.14 & 0.904 & 31 & 6.23 & 0.669 \\
\hline Speed of Data Entry & 59 & 5.81 & 0.937 & 50 & 5.52 & 0.953 & 31 & 5.84 & 0.523 \\
\hline Flexibility & 59 & 5.22 & 0.892 & 50 & 5.42 & 1.090 & 31 & 5.19 & 0.946 \\
\hline Utility of Structure & 59 & 5.81 & 0.937 & 50 & 5.66 & 1.002 & 31 & 5.71 & 0.938 \\
\hline
\end{tabular}

Table 24 - Statistics of the six conditions

We depict the changes in the mean score of each dimension in the following charts. The first three charts represent the mean score of responses for episodic scenarios, while the other three charts represent the mean score of responses for semantic scenarios. 


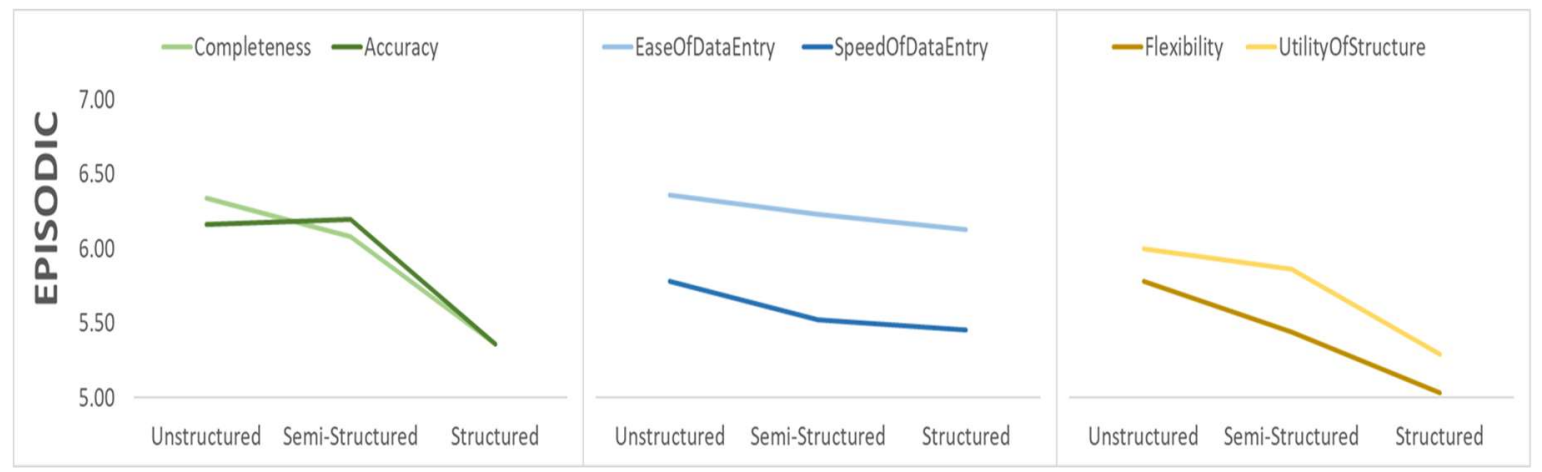

Figure 26 - Line charts for episodic content

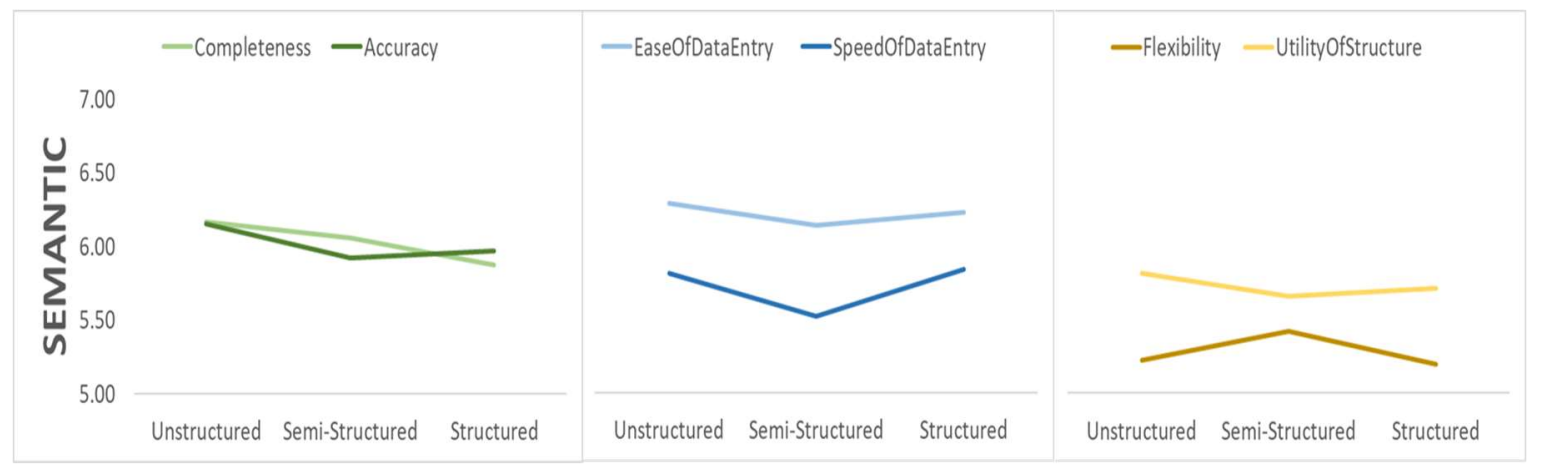

Figure 27 - Line charts for semantic content

In order to better understand the significant difference between the conditions, we need to run the appropriate statistical test. However, visually, we can infer that the charts from the episodic scenario are similar to the charts of stage 1 . However, the charts related to the semantic scenario does not seem to follow a similar pattern.

We run the one-way analysis of variance (ANOVA) to determine whether there are any statistically significant differences among the different groups. We examine the interaction of the degree of structure and nature of shared content. So, we compare the PQoIC results of the six groups. The following table summarizes our ANOVA test. 


\begin{tabular}{|l|c|r|r|r|r|r|r|l|}
\hline PIQ Dimension & N & Mean & Std.Dev & $\begin{array}{c}\text { Std. } \\
\text { Error }\end{array}$ & Min & Max & F & Sig. \\
\hline Completeness & 273 & 6.04 & 0.899 & 0.054 & 2 & 7 & 5.650 & 0.000 \\
\hline Accuracy & 273 & 6.01 & 0.822 & 0.050 & 3 & 7 & 5.726 & 0.000 \\
\hline Ease of Data Entry & 273 & 6.24 & 0.766 & 0.046 & 3 & 7 & 0.592 & 0.706 \\
\hline Speed of Data Entry & 273 & 5.66 & 0.965 & 0.058 & 3 & 7 & 1.397 & 0.226 \\
\hline Flexibility & 273 & 5.38 & 0.955 & 0.058 & 2 & 7 & 3.341 & 0.006 \\
\hline Utility of Structure & 273 & 5.76 & 0.989 & 0.060 & 2 & 7 & 2.313 & 0.044 \\
\hline
\end{tabular}

Table 25 - ANOVA test results

The initial results of our ANOVA test show that we have significant differences among the six conditions for some of the dimensions. The recorded perceived completeness $(6.04, \mathrm{p}<0.000)$ and accuracy $(6.01, \mathrm{p}<0.000)$ differs among the six groups significantly. Moreover, we detected significant differences for perceived flexibility $(5.38, \mathrm{p}<0.05)$ and utility of structure $(5.76, \mathrm{p}<$ 0.05). Similar to the previous experiment, no significant differences were identified for perceived ease of data entry $(6.24, p=0.706)$ and speed of data entry $(5.66, p<0.226)$. However, these findings just reveal significant differences between some of the conditions. So, we need to run a post hoc analysis to compare the conditions one by one. The following table summarizes the pvalue results of our post hoc Tukey test. 


\begin{tabular}{|c|c|c|c|c|c|c|c|}
\hline Dim & & US-E & SS-E & HS-E & US-S & SS-S & HS-S \\
\hline \multirow{6}{*}{ 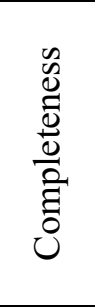 } & US-E & & 0.639 & 0.000 & 0.908 & 0.584 & 0.167 \\
\hline & SS-E & 0.639 & & 0.004 & 0.993 & 1.000 & 0.900 \\
\hline & HS-E & 0.000 & 0.004 & & 0.000 & 0.005 & 0.176 \\
\hline & US-S & 0.908 & 0.993 & 0.000 & & 0.986 & 0.625 \\
\hline & SS-S & 0.584 & 1.000 & 0.005 & 0.986 & & 0.930 \\
\hline & HS-S & 0.167 & 0.900 & 0.176 & 0.625 & 0.930 & \\
\hline \multirow{6}{*}{ 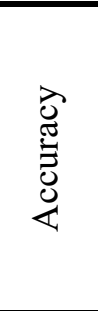 } & US-E & & 1.000 & 0.000 & 1.000 & 0.651 & 0.894 \\
\hline & SS-E & 1.000 & & 0.000 & 1.000 & 0.505 & 0.809 \\
\hline & HS-E & 0.000 & 0.000 & & 0.000 & 0.023 & 0.029 \\
\hline & US-S & 1.000 & 1.000 & 0.000 & & 0.643 & 0.898 \\
\hline & SS-S & 0.651 & 0.505 & 0.023 & 0.643 & & 1.000 \\
\hline & HS-S & 0.894 & 0.809 & 0.029 & 0.898 & 1.000 & \\
\hline \multirow{6}{*}{ 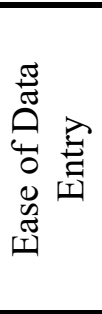 } & US-E & & 0.958 & 0.777 & 0.997 & 0.708 & 0.973 \\
\hline & SS-E & 0.958 & & 0.992 & 0.999 & 0.991 & 1.000 \\
\hline & HS-E & 0.777 & 0.992 & & 0.938 & 1.000 & 0.996 \\
\hline & US-S & 0.997 & 0.999 & 0.938 & & 0.917 & 0.999 \\
\hline & SS-S & 0.708 & 0.991 & 1.000 & 0.917 & & 0.997 \\
\hline & HS-S & 0.973 & 1.000 & 0.996 & 0.999 & 0.997 & \\
\hline \multirow{6}{*}{ 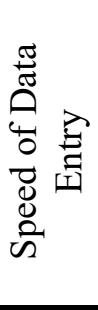 } & US-E & & 0.745 & 0.668 & 1.000 & 0.755 & 1.000 \\
\hline & SS-E & 0.745 & & 000 & 0.593 & 1.000 & 0.687 \\
\hline & HS-E & 0.668 & 1.000 & & 0.535 & 1.000 & 0.609 \\
\hline & US-S & 1.000 & 0.593 & 0.535 & & 0.607 & 1.000 \\
\hline & SS-S & 0.755 & 1.000 & 1.000 & 0.607 & & 0.696 \\
\hline & HS-S & 1.000 & 0.687 & 0.609 & 1.000 & 0.696 & \\
\hline \multirow{6}{*}{ 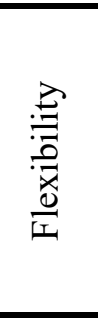 } & US-E & & 0.453 & 0.007 & 0.025 & 0.389 & 0.070 \\
\hline & SS-E & 0.453 & & 0.385 & 0.813 & 1.000 & 0.850 \\
\hline & HS-E & 0.007 & 0.385 & & 0.945 & 0.459 & 0.984 \\
\hline & US-S & 0.025 & 0.813 & 0.945 & & 0.877 & 1.000 \\
\hline & SS-S & 0.389 & 1.000 & 0.459 & 0.877 & & 0.897 \\
\hline & HS-S & 0.070 & 0.850 & 0.984 & 1.000 & 0.897 & \\
\hline \multirow{6}{*}{ 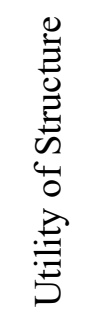 } & US-E & & 0.982 & 0.020 & 0.920 & 0.507 & 0.785 \\
\hline & SS-E & 0.982 & & 0.102 & 1.000 & 0.896 & 0.982 \\
\hline & HS-E & 0.020 & 0.102 & & 0.155 & 0.563 & 0.540 \\
\hline & US-S & 0.920 & 1.000 & 0.155 & & 0.964 & 0.997 \\
\hline & SS-S & 0.507 & 0.896 & 0.563 & 0.964 & & 1.000 \\
\hline & HS-S & 0.785 & 0.982 & 0.540 & 0.997 & 1.000 & \\
\hline
\end{tabular}

Table 26 - Summary results of post hoc test

This table shows the comparison between each two conditions. And the highlighted cells in the table shows the significance. As the ANOVA test reveals, we did not detect any significant 
differences in terms of perceived ease and speed of data entry among the six conditions. However, the perceived completeness mean score for using a highly structured format to collect episodic content is significantly lower than using unstructured or semi-structured format. The same results also gained for the perceived accuracy dimension. Moreover, the perceived flexibility and utility of structure for the unstructured-episodic condition is significantly higher than the unstructuredsemantic condition.

To better understand the differences, we show the results of the post hoc test based on the degree of structure in design. The following table is episodic vs semantic comparison within each interface:

\begin{tabular}{|c|c|c|c|c|c|c|}
\hline \multicolumn{7}{|c|}{ Unstructured - Episodic vs. Semantic } \\
\hline $\begin{array}{l}\text { PIQ } \\
\text { Dimension }\end{array}$ & Completeness & Accuracy & $\begin{array}{l}\text { Ease of } \\
\text { Data } \\
\text { Entry }\end{array}$ & $\begin{array}{l}\text { Speed } \\
\text { of Data } \\
\text { Entry }\end{array}$ & Flexibility & $\begin{array}{l}\text { Utility of } \\
\text { Structure }\end{array}$ \\
\hline US-E & 6.34 & 6.16 & 6.36 & 5.78 & 5.78 & 6.00 \\
\hline US-S & 6.17 & 6.15 & 6.29 & 5.81 & 5.22 & 5.81 \\
\hline \multicolumn{7}{|c|}{ Semi-structured - Episodic vs. Semantic } \\
\hline $\begin{array}{l}\text { PIQ } \\
\text { Dimension }\end{array}$ & Completeness & Accuracy & $\begin{array}{l}\text { Ease of } \\
\text { Data } \\
\text { Entry }\end{array}$ & \begin{tabular}{|l|} 
Speed \\
of Data \\
Entry \\
\end{tabular} & Flexibility & $\begin{array}{l}\text { Utility of } \\
\text { Structure }\end{array}$ \\
\hline SS-E & 6.08 & 6.19 & 6.23 & 5.52 & 5.44 & 5.87 \\
\hline SS-S & 6.06 & 5.92 & 6.14 & 5.52 & 5.42 & 5.66 \\
\hline \multicolumn{7}{|c|}{ Highly structured - Episodic vs. Semantic } \\
\hline $\begin{array}{l}\text { PIQ } \\
\text { Dimension }\end{array}$ & Completeness & Accuracy & $\begin{array}{l}\text { Ease of } \\
\text { Data } \\
\text { Entry }\end{array}$ & \begin{tabular}{|l|} 
Speed \\
of Data \\
Entry \\
\end{tabular} & Flexibility & $\begin{array}{l}\text { Utility of } \\
\text { Structure }\end{array}$ \\
\hline HS-E & 5.35 & 5.35 & 6.13 & 5.45 & 5.03 & 5.29 \\
\hline HS-S & 5.87 & 5.97 & 6.23 & 5.84 & 5.19 & 5.71 \\
\hline
\end{tabular}

Table 27 - Episodic vs semantic comparison

This table indicated that data creators have different perceptions of flexibility based on whether they record episodic or semantic content. Specifically, while using the unstructured interface, data creators' perception of flexibility is significantly higher for episodic data than for semantic data. The following chart Depicts how each dimension changes between semantic and episodic content 
in the unstructured interface. The only dimension that significantly drops is perceived flexibility which is represented by the bold purple line.

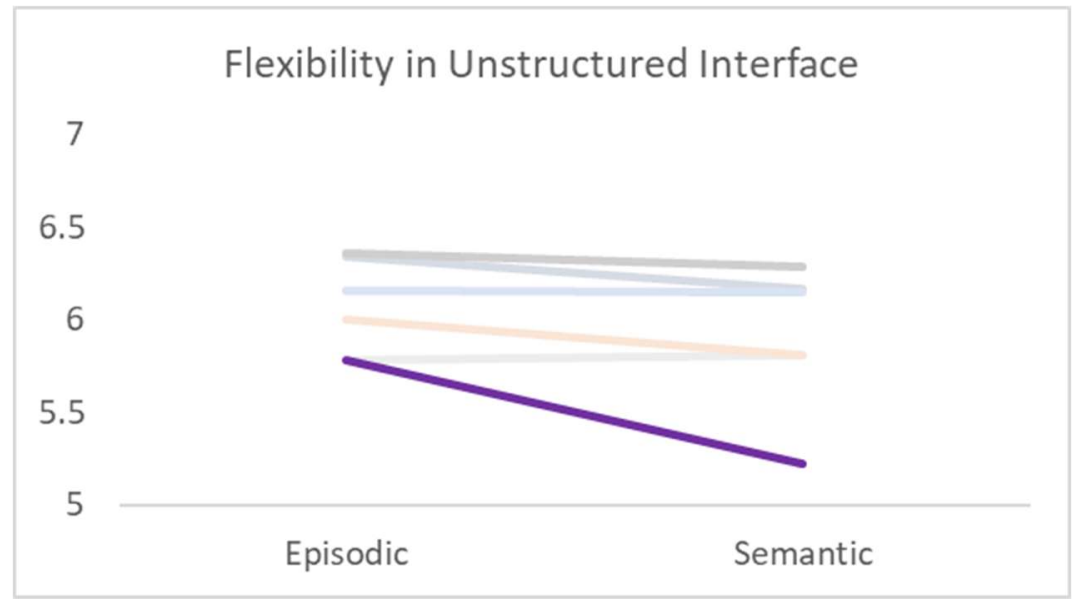

Figure 28 - Mean score - flexibility in unstructured interface

Moreover, the table indicates that data creators have different perceptions of accuracy based on whether they record episodic or semantic content. Specifically, while using a highly structured interface, data creators' perception of accuracy is significantly higher for semantic data than for episodic data. The following chart Depicts how each dimension changes between semantic and episodic content in a structured interface. The only dimension that significantly increases is perceived accuracy which is represented by the bold purple line. 


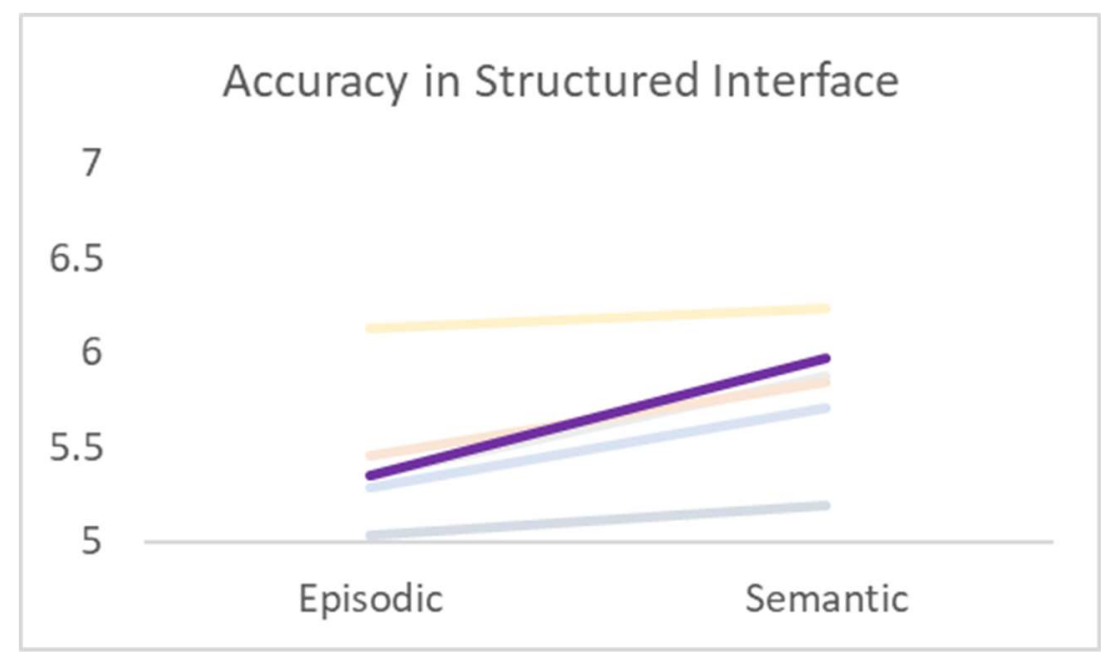

Figure 29 - Mean score - accuracy in structured interface

We also run the ANOVA test for episodic content and semantic content separately. First, we only consider episodic content. These contents were recorded using either unstructured, semi-structured or structured interface. So, we run the test to investigate any significant difference among the interfaces. The following table summarizes the results. The findings are very similar to the experiment in Chapter 3. The unstructured format was able to collect episodic content with significantly higher completeness $(6.34, \mathrm{p}<0.000)$ and accuracy $(6.16, \mathrm{p}<0.000)$, supporting our $\mathrm{H} 2 \mathrm{a}$ hypothesis. The results for perceived flexibility $(5.78, \mathrm{p}<0.005)$ and utility of structure $(6.00$, $\mathrm{p}<0.05)$ are also significant, which supports our $\mathrm{H} 2 \mathrm{c}$ hypothesis. Again, there is no significant difference detected for perceived ease $(p=0.383)$ and speed of data entry $(p=0.305)$. Similar to Chapter 3, our hypotheses for perceived ease and speed of data entry (H2b) is not supported. 


\begin{tabular}{|l|r|r|l|r|r|r|}
\hline & & & $\begin{array}{l}\text { Ease of } \\
\text { Data } \\
\text { PIQ Dimension }\end{array}$ & $\begin{array}{l}\text { Speed } \\
\text { of Data } \\
\text { Entry }\end{array}$ & Flexibility & $\begin{array}{l}\text { Utility of } \\
\text { Structure }\end{array}$ \\
\hline US-E & 6.34 & 6.16 & 6.36 & 5.78 & 5.78 & 6.00 \\
\hline SS-E & 6.08 & 6.19 & 6.23 & 5.52 & 5.44 & 5.87 \\
\hline HS-E & 5.35 & 5.35 & 6.13 & 5.45 & 5.03 & 5.29 \\
\hline F - value & 12.852 & 12.760 & 0.966 & 1.199 & 6.847 & 5.178 \\
\hline Sig. & 0.000 & 0.000 & 0.383 & 0.305 & 0.001 & 0.007 \\
\hline
\end{tabular}

Table 28 - Interface comparison for episodic content

We run the same test for semantic content too. These contents were recorded using either unstructured, semi-structured or structured interface. The following table summarizes the results. The findings are very different from episodic content (and the experiment in Chapter 3). We did not detect any significant differences between groups for any dimension. The results of comparison for perceived completeness $(p=0.301)$, accuracy $(p=0.273)$, ease of data entry $(p=0.622)$, speed of data entry $(p=0.146)$, flexibility $(p=0.479)$, and utility of structure $(p=0.698)$ were not significant. The results do not support our hypotheses for semantic content (H3a, H3b, and H3c).

\begin{tabular}{|l|r|r|l|l|r|r|}
\hline & & & $\begin{array}{l}\text { Ease of } \\
\text { Data } \\
\text { PIQ Dimension }\end{array}$ & $\begin{array}{l}\text { Speed } \\
\text { of Data } \\
\text { Entry }\end{array}$ & Flexibility & $\begin{array}{l}\text { Utility of } \\
\text { Structure }\end{array}$ \\
\hline US-S & 6.17 & 6.15 & 6.29 & 5.81 & 5.22 & 5.81 \\
\hline SS-S & 6.06 & 5.92 & 6.14 & 5.52 & 5.42 & 5.66 \\
\hline HS-S & 5.87 & 5.97 & 6.23 & 5.84 & 5.19 & 5.71 \\
\hline F - value & 1.210 & 1.309 & 0.476 & 1.949 & 0.740 & 0.360 \\
\hline Sig. & 0.301 & 0.273 & 0.622 & 0.146 & 0.479 & 0.698 \\
\hline
\end{tabular}

Table 29 - Interface comparison for semantic content

Similar to the experiment in Chapter 3, We also studied the control variables to detect any significant differences. We run multivariate tests for the demographic statistics. The following table shows the results of the test. 


\begin{tabular}{|l|l|r|r|r|r|}
\hline \multirow{4}{*}{ Source } & Dependent Variable & $\begin{array}{r}\text { Mean } \\
\text { Square }\end{array}$ & \multicolumn{1}{|c|}{ F } & Sig. & $\begin{array}{c}\text { Partial Eta } \\
\text { Squared }\end{array}$ \\
\hline \multirow{5}{*}{ Gender } & Completeness & 0.486 & 0.811 & 0.369 & 0.003 \\
\cline { 2 - 6 } & Accuracy & 0.049 & 0.094 & 0.759 & 0 \\
\cline { 2 - 6 } & Ease of Data Entry & 3.57 & 7.305 & 0.007 & 0.027 \\
\cline { 2 - 6 } & Speed of Data Entry & 0.073 & 0.085 & 0.770 & 0 \\
\cline { 2 - 6 } & Flexibility & 1.192 & 1.505 & 0.221 & 0.006 \\
\cline { 2 - 6 } & Utility of Structure & 0.155 & 0.177 & 0.675 & 0.001 \\
\hline \multirow{5}{*}{ Age } & Completeness & 0.689 & 1.149 & 0.285 & 0.004 \\
\cline { 2 - 6 } & Accuracy & 0.004 & 0.008 & 0.928 & 0 \\
\cline { 2 - 6 } & Ease of Data Entry & 0.04 & 0.082 & 0.775 & 0 \\
\cline { 2 - 6 } & Speed of Data Entry & 0.025 & 0.029 & 0.866 & 0 \\
\cline { 2 - 6 } & Flexibility & 0.571 & 0.721 & 0.397 & 0.003 \\
\cline { 2 - 6 } & Utility of Structure & 0 & 0 & 0.995 & 0 \\
\hline \multirow{5}{*}{ Education } & Completeness & 4.622 & 7.708 & 0.006 & 0.029 \\
\cline { 2 - 6 } & Accuracy & 0.008 & 0.015 & 0.903 & 0 \\
\cline { 2 - 6 } & Ease of Data Entry & 0.739 & 1.513 & 0.220 & 0.006 \\
\cline { 2 - 6 } & Speed of Data Entry & 0.227 & 0.263 & 0.608 & 0.001 \\
\cline { 2 - 6 } & Flexibility & 0.876 & 1.106 & 0.294 & 0.004 \\
\cline { 2 - 6 } & Utility of Structure & 0.04 & 0.046 & 0.830 & 0 \\
\hline \multirow{5}{*}{} & & & & & \\
\hline
\end{tabular}

Table 30 - Test of between-subjects effect

We detected significant differences in the perceived ease of data entry between male and female participants. Similar to the previous experiments, the process of data creation is perceived significantly easier $(\mathrm{p}<0.05)$ for our female participants compared to our male participants. Finally, we detect a significant difference in perceived completeness among participants with different levels of education.

\section{Data consumers' view}

In the previous section, we evaluated the perceived quality of information collection (PQoIC) from data creators' view. In this section, we assess the recorded content from data consumers' view. By evaluating the two major components of online communities, we could better understand the quality of the recorded outcome. 
We have selected 171 responses from the previous experiment. These responses were collected by either the unstructured interface (109 responses) or the structured interface (62 responses). Our data set includes 81 episodic responses and 90 semantic responses. Each response was shown to 5 different participants (on average), who were asked to evaluate the response. Similar to the experiment in Chapter 3, our evaluation process contains both quantitative and qualitative sections. The following table summarizes the distributions of the presented responses.

\begin{tabular}{|c|c|c|c|c|}
\hline \multirow{2}{*}{\multicolumn{2}{|c|}{ Interface Design }} & \multicolumn{2}{|c|}{ NSC } & \multirow{3}{*}{$\begin{array}{r}\text { Total } \\
109\end{array}$} \\
\hline & & \multirow{2}{*}{$\begin{array}{c}\text { Episodic } \\
50\end{array}$} & \multirow{2}{*}{$\frac{\text { Semantic }}{59}$} & \\
\hline $\begin{array}{ll}\text { 范 } \\
0\end{array}$ & Unstructured & & & \\
\hline 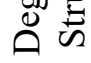 & Highly Structured & 31 & 31 & 62 \\
\hline & Total & 81 & 90 & 171 \\
\hline
\end{tabular}

Table 31 - Distribution of responses used in this experiment

The survey that we used in this experiment was similar to the experiment in Chapter 3. We asked participants six 7-point Likert-scaled questions about the content being complete, accurate, effortful, well-structured, useful, and data creators' sincerity. As we are not able to statistically compare the results of these two experiments, we visually compare the recorded results using line charts. The following chart shows the data creators and data consumers' average score of perceived completeness in the unstructured interface. We present the chart for episodic and semantic content separately. As it appears in the chart, the lines are relatively closer together in the episodic content, compared to in the semantic content. This implies that data consumers' perceived completeness is closer to data creators' perceived completeness when the episodic content is recorded. In other words, data consumers seem not satisfied with the recorded content related to a general fact or knowledge. In our particular example, data consumers assume that a person's experience of having Flu, shared in an unstructured format, is fairly complete (and their assumption is almost similar to 
the data creator's assumption). However, a person's description of the Flu as a common disease, recorded in an unstructured format, is not deemed as complete (and there is a gap between data creators and data consumers' assumptions in this case).

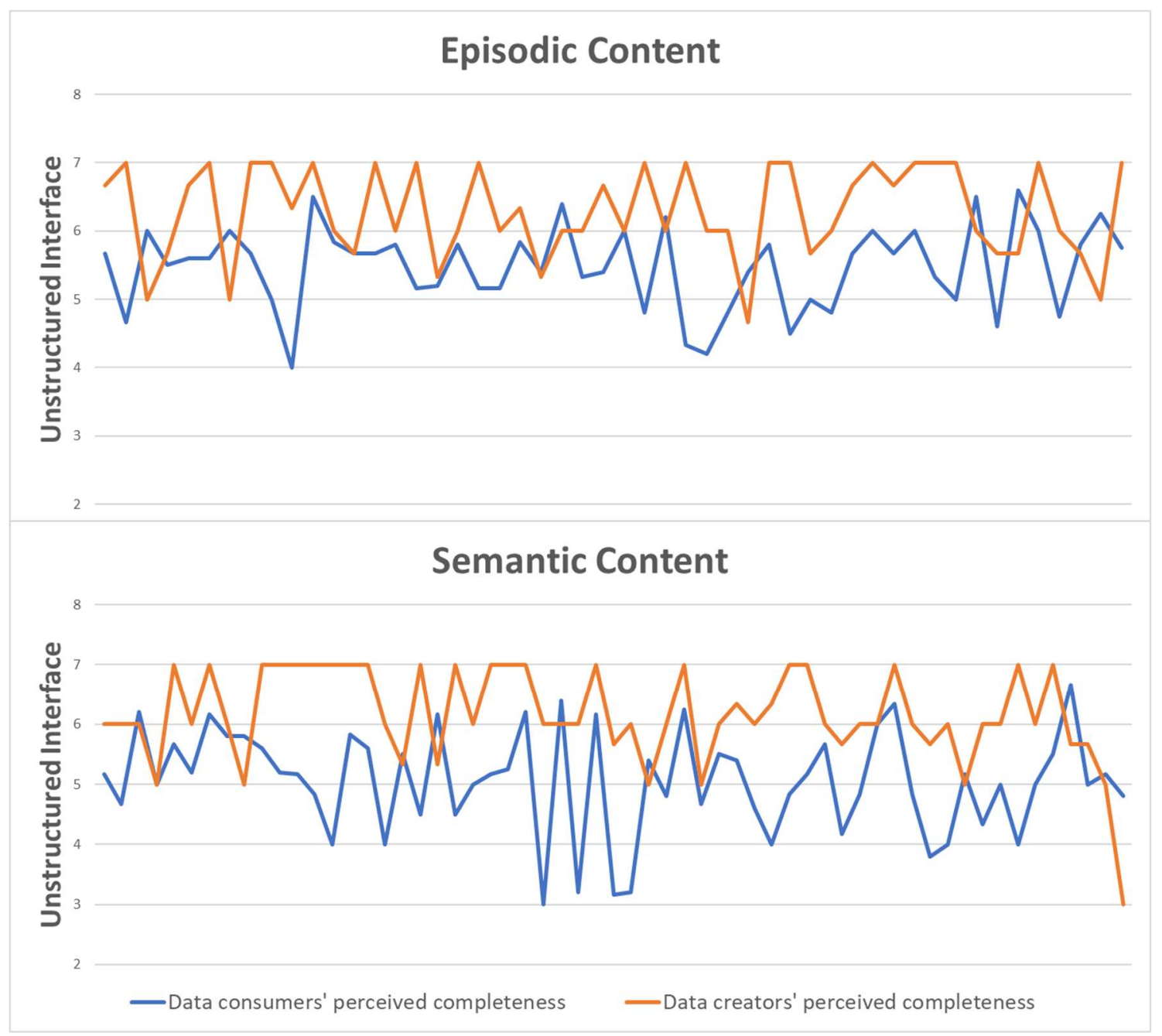

Figure 30 - Data creators vs data consumers' perception of completeness- Unstructured

We also provide a similar line chart for perceived accuracy. As we can see in the following chart, no particular trend has been detected in the accuracy chart. The difference between these two dimensions (completeness and accuracy) indicates that despite episodic or semantic content is being recorded, data creators and data consumers have a similar perception about the accuracy. 
However, the completeness, or data creators' expectation of the potential content, differs according to the nature of shared content (NSC).

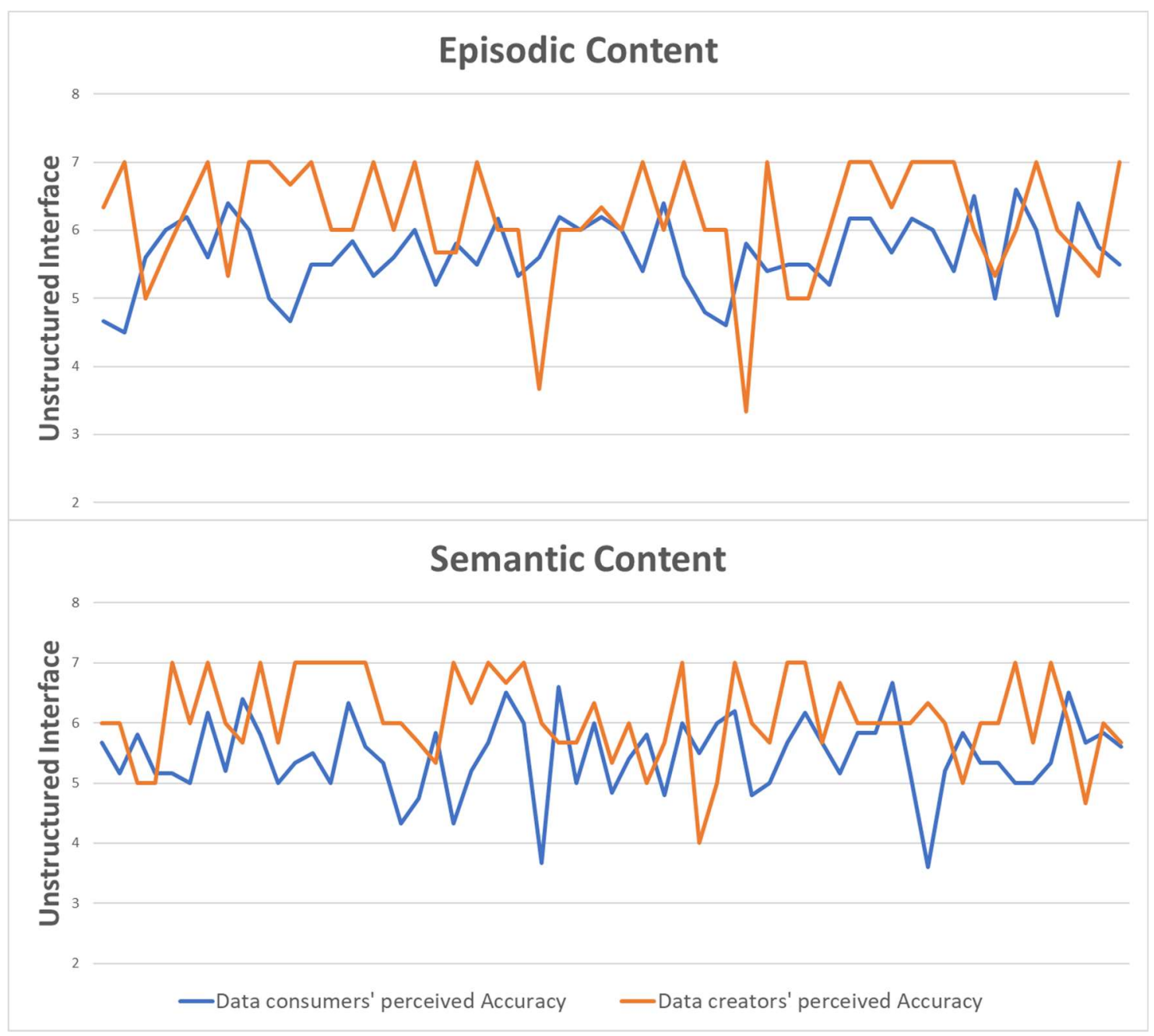

Figure 31 - Data creators vs data consumers' perception of accuracy - Unstructured

We also run the same analyses for the structured interface. The following chart shows the data creators and data consumers' average score of perceived completeness in the structured interface. Similar to the findings of Chapter 3, data consumers' perception of completeness in the structured format is generally higher than unstructured format. When the content is recorded in the structured format, data consumers feel that the completeness is relatively high. However, data creators' 
perception of completeness is relatively low for episodic content, reconfirming our findings from the previous section.

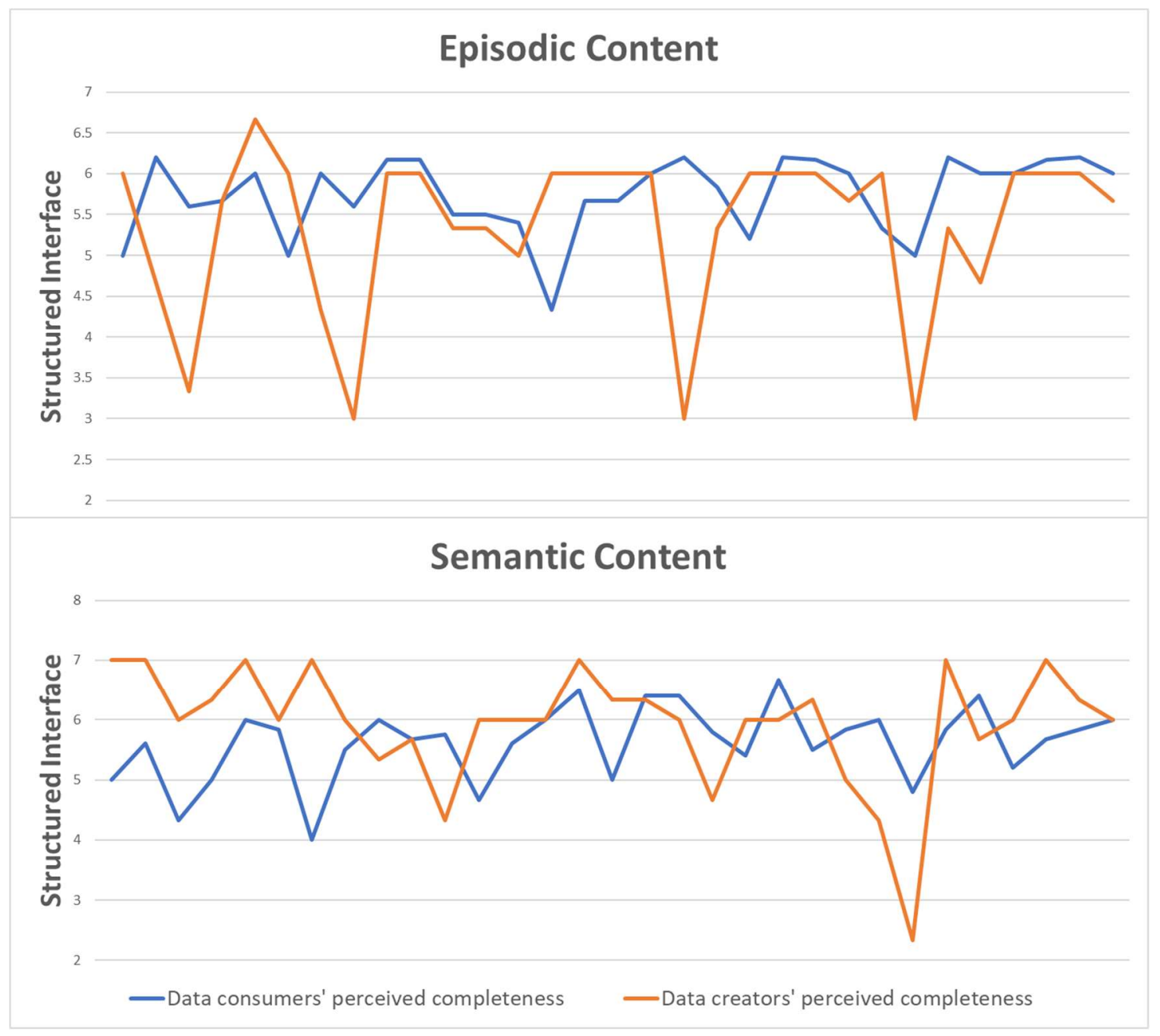

Figure 32 - Data creators vs data consumers' perception of completeness- Structured

The following chart presents data creators and data consumers perception of accuracy in the structured format. As we can see, there is no noticeable pattern is detected. 


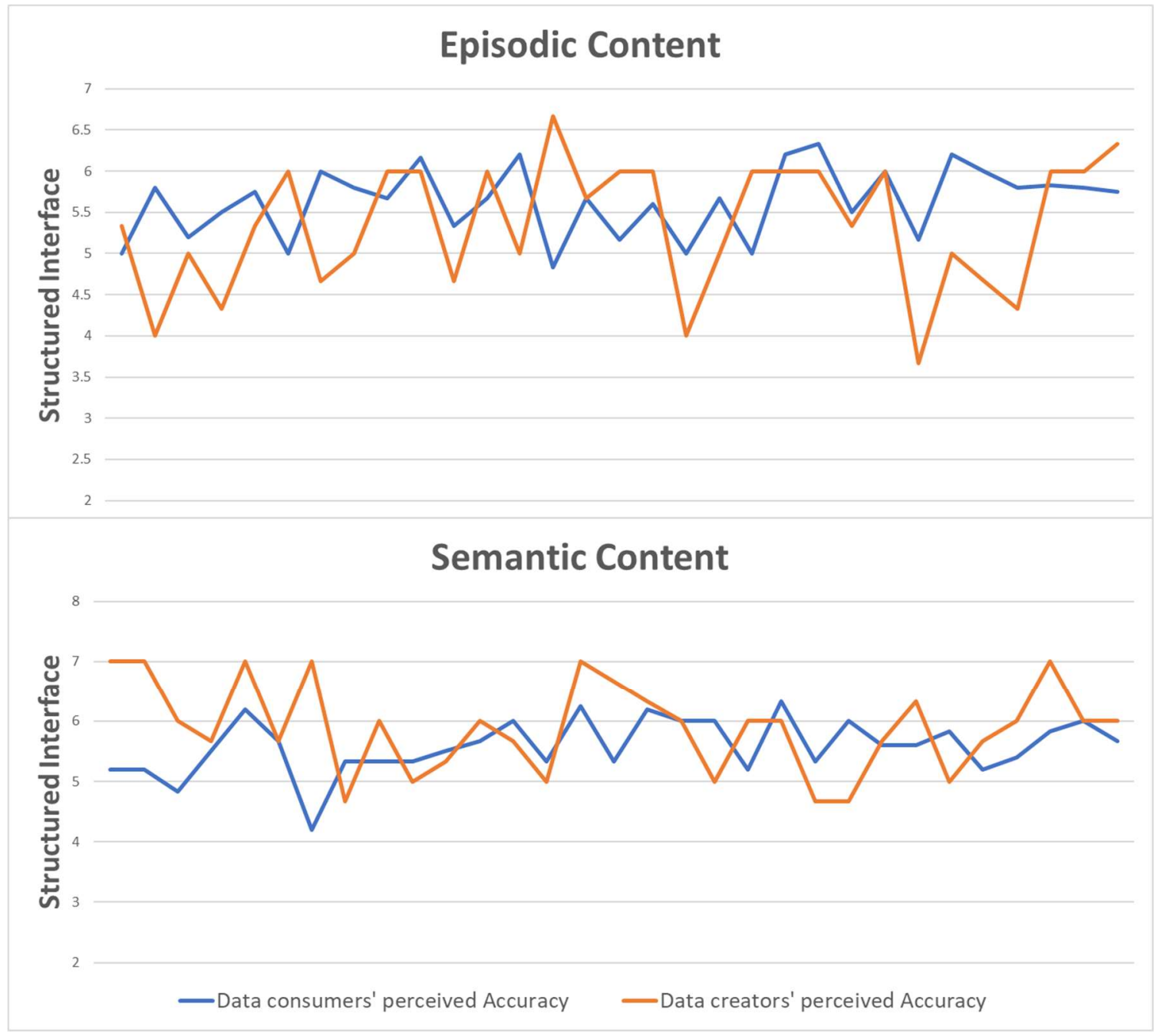

Figure 33 - Data creators vs data consumers' perception of accuracy - Structured

We also compare the data consumers' responses on usefulness and sincerity of the contributor. Similar to the finding of Chapter 3, these two dimensions follow almost the same pattern. However, if we look at the unstructured interface chart, we can identify a difference between the right and the left side of the chart. The right side represents the episodic responses, while the left side represents the semantic content. As we can see, the differences between data creators and data consumers' perception are greater in semantic content than in episodic content. In other words, even though the data consumer perceive that the semantic content recorded through unstructured format is not very useful, they did not question data creators' sincerity. The following chart presents this relationship. 


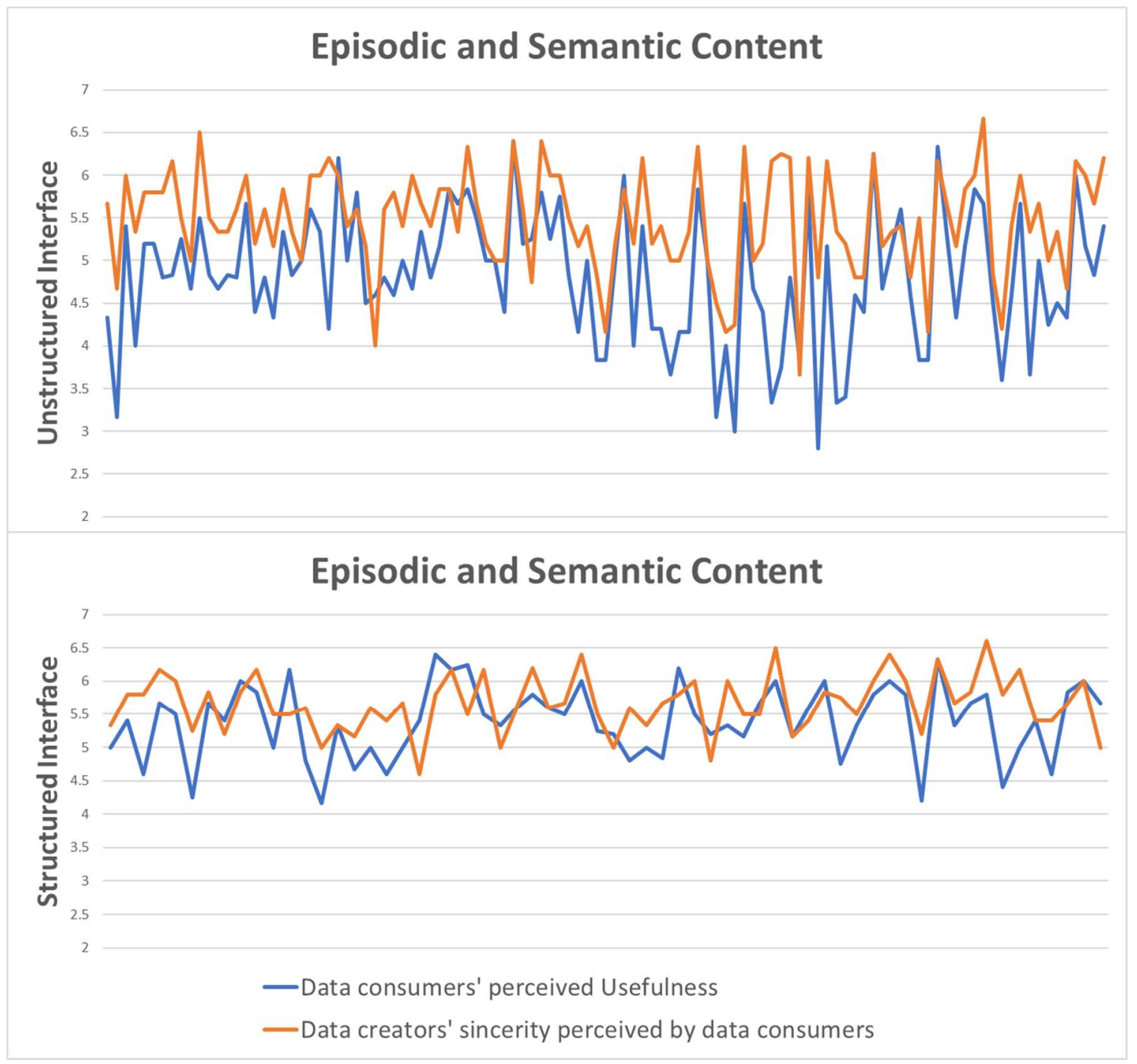

Figure 34 - Data consumers' perceived usefulness vs data creators' sincerity perceived by consumers

Furthermore, we analyzed data consumers' responses to our qualitative questions. Generally, our findings are very similar to the findings of the experiment in Chapter 3. From data consumers' point of view, an unstructured interface is able to catch some unexpected details that may be ignored in the structured format. However, the unstructured format is vulnerable in collecting some obvious details of the topic. Moreover, the unstructured format gives the data creator ability to exaggerate or to go beyond the topic. Furthermore, the unstructured interface is more likely to give the data 
consumer the power to judge the data creator. In some cases, the data consumers deem the creator dishonest, insincere or emotional.

In this section, we empirically compare data creators versus data consumers' perception of information quality and determine if people's perceptions of quality agree with objective measures. Generally, we argue that our findings are consistent with the findings of data creators' experiments. The comparison between the two major components of online communities stands to further contribute to the theory of information quality. Our results indicate the benefits of measuring both data creators and consumers point of view on perceived IQ to gain a comprehensive perspective on the impact of the variables of interest on information quality.

\section{Discussion}

We show that using differently-designed interfaces results in noticeable differences in perceptions of IQ. In other words, data creators feel differently when they are asked to create content using differently-designed interfaces. This finding directs interface designers' attention to the importance of the appropriate degree of structure in interface design.

Our research demonstrates a connection between information system design and human memory an obvious, but thus far neglected IQ factor. Indeed, especially in UGC settings, much of the content produced originated in the memory of the contributors. Consequently, it is reasonable to posit that a greater sensitivity to the memory structures of humans, may result in improvements in IQ - a proposition that has already been supported by our findings. Further, this study will extend the literature by enhancing our understanding of the structure-degree of different kinds of UGC. The results of this study can be used by researchers to further discuss the role of an appropriate degree of structure to collect data effectively and efficiently. Furthermore, findings of this research enrich the IQ literature by empirically comparing perceived IQ by data creators and data consumersanother common issue that has been consistently understudied in previous research. 
Data creators perceive that they are able to record more complete and accurate content while using a less-structured interface format. However, this is not always true. Our findings show that data creators' perception depends on the nature of shared content. In other words, data creators do perceive that they are able to record more complete and accurate content while using less-structured interface format, but only for episodic content. Therefore, data creators appreciate the value of unstructured interface while sharing their personal experiences, not while sharing general facts or knowledge. This finding could be helpful in designing interfaces in online communities. If an interface is intended to collect users' experiences, it should be designed in a less-structured format to let the user feel happier and more productive. On the other hand, data creators' perception of IQ for an interface intended to collect semantic content does not depend on the interface's degree of structure.

Our work is expected to help practitioners improve the design of UGC platforms and support the adoption of UGC by organizations. First, providing appropriate data-entry interface helps to enhance users' self-expression. In UGC context, especially in social media, users are willing to express their opinions. If users have something to share and could not find the appropriate medium or a convenient format to share, they get discouraged and may abandon the platform or provide distorted data. The findings of this study will lead to new design principles that improve users' ability to express themselves online. Second, providing a more effective data-entry interface improves the quality of UGC. It results in a more complete and accurate data for data consumers who are increasingly seeking to use UGC in their analysis and decision-making. 


\section{CHAPTER 5: Conclusion}

Our findings support our propositions on the importance of the Nature of Shared Content (NSC). When we compared the datasets based on the type of recorded information, our results were significant. We find it interesting that semantic content and episodic content are treated differently within a certain interface. While using a highly structured interface, data creators' perception of accuracy is significantly higher for semantic data than for episodic data. In fact, data creators who used the structured interface perceive that they are able to produce more accurate content when they are recording content related to knowing something, as opposed to recording content related to remembering something. Moreover, using an unstructured interface, data creators' perception of flexibility is significantly higher for episodic data than for semantic data.

The comparison between the two sides of perceived IQ stands to further contribute to the theory of information quality. Our results indicate the need to measure both data creators and consumers point of view on perceived IQ to gain a comprehensive perspective on the impact of the variables of interest on information quality.

Our findings, based on perceived IQ, are of potential significance to theory and practice of UGC and information quality. They show the value of unstructured data, especially for storing episodic information. In particular, they suggest that when more rigid formats are used to capture UGC, people may feel that they were not able to fully express themselves. This may have a negative impact on the overall experience of people with the platform where data collection took place. Furthermore, and also equally important, considering that users perceive some deficiencies for completeness and accuracy when the wrong format is chosen, it means that when organizations begin to analyze such UGC, these deficiencies may result in inappropriate decisions being made based on such data. Further, our findings support our propositions on the importance of Nature of Shared Content (NSC). In certain conditions, our results were significant, when we compared the 
data sets based on the type of recorded information. This finding encourages us to consider more detailed future work to see the users' response to record different types of information.

Our work is expected to help practitioners improve the design of UGC platforms and to support the adoption of UGC by organizations. First, providing appropriate data-entry interfaces helps to enhance users' self-expression. In the UGC context, especially in social media, users are willing to express their opinions. If users have something to share and cannot find the appropriate medium or a convenient format for sharing, they can be discouraged and might abandon the platform or provide distorted data. The findings of this study will lead to new design principles that improve users' ability to express themselves online. At this stage, our proposed principles could include:

- Identifying the nature of to-be-shared content. Prior to recording content, the data creators could be given a very simple question that asks about the nature of the content. The question could simply ask whether the to-be-shared content is associated with data creators' personal experience or his/her knowledge about something.

- Specifying the topic of to-be-shared content. Depending on the context, usually, the possible topics are predictable. For example, in a specific forum of an online healthcare community that is meant to discuss a particular disease, symptoms, drugs, side effects, treatments, lifestyles, and physicians are the possible topics. Data creators could help to specify the topic of to-be-shared content, by responding to a single multiple-choice question.

- Recognizing potentially noteworthy points in a specific topic. If all of the most-rated previous comments on the topic of side effects have talked about a severe headache, the system could ask the data creator about a possible headache or suggest talking about headaches. Using text mining, designers could use previous content to create a potential structured data collection interface for different topics. 
- Assigning a suitable interface to collect the information. Previous steps enabled the system to recognize the nature of to-be-shared content and to be equipped with differently designed interfaces. Perhaps the most notable design guideline originating in our findings is that different kinds of information should be collected using different interfaces. Specifically, we see that episodic information is best collected using unstructured interfaces, while structured ones are better suited to semantic information. Now, the system is able to provide a customized information collection interface based on the data creators' responses.

The other implication of this research is the ability to customize the interface design based on the type of to-be-shared content. The findings of this research indicate that both the degree of structure and nature of to-be-shared content could affect data creators' perception of information quality. Consequently, if the system could specify the type of to-be-shared content before sharing it, the system could offer the appropriate interface to collect the content in a more satisfying way to users. This provides a more effective data-entry interface that improves the quality of UGC. Both at the individual and the organization level, it results in more complete and accurate data for data consumers, who are increasingly seeking to use UGC in their analysis and decision-making. 


\section{REFERENCES}

Abdel-Hamid, T. K. 1988. “The Economics of Software Quality Assurance: A Simulation-Based Case Study," MIS Quarterly, pp. 395-411.

Abras, C., Maloney-Krichmar, D., and Preece, J. 2004. "User-Centered Design," Bainbridge, W. Encyclopedia of Human-Computer Interaction. Thousand Oaks: Sage Publications (37:4), pp. 445-456.

Agmon, N., and Ahituv, N. 1987. “Assessing Data Reliability in an Information System,” Journal of Management Information Systems, pp. 34-44.

Ali, A. L., Schmid, F., Al-Salman, R., and Kauppinen, T. 2014. "Ambiguity and Plausibility: Managing Classification Quality in Volunteered Geographic Information," SIGSPATIAL, pp. 1-10.

Aljukhadar, M., Senecal, S., and Nantel, J. 2014. "Is More Always Better? Investigating the Task-Technology Fit Theory in an Online User Context," Information \& Management (51:4), pp. 391-397.

Alonso, O., and Mizzaro, S. 2012. "Using Crowdsourcing for TREC Relevance Assessment," Information Processing \& Management (48:6), pp. 1053-1066.

Arazy, O., and Kopak, R. 2011. “On the Measurability of Information Quality,” Journal of the American Society for Information Science and Technology (62:1), pp. 89-99.

Arazy, O., Kumar, N., and Shapira, B. 2010. "A Theory-Driven Design Framework for Social Recommender Systems," Journal of the Association for Information Systems (11:9), pp. 455-490.

Arazy, O., Nov, O., Patterson, R., and Yeo, L. 2011. "Information Quality in Wikipedia: The Effects of Group Composition and Task Conflict," Journal of Management Information Systems (27:4), pp. 71-98.

Asur, S., and Huberman, B. 2010. Predicting the Future with Social Media., presented at the Web Intelligence and Intelligent Agent Technology (WI-IAT), IEEE.

Baars, H., and Kemper, H.-G. 2008. "Management Support with Structured and Unstructured Data - an Integrated Business Intelligence Framework," Information Systems Management (25:2), pp. 132-148.

Ballou, D. P., and Pazer, H. L. 1995. "Designing Information Systems to Optimize the AccuracyTimeliness Tradeoff," Information Systems Research (6:1), p. 51.

Ballou, D. P., and Pazer, H. L. 2003. "Modeling Completeness versus Consistency Tradeoffs in Information Decision Contexts," Knowledge and Data Engineering, IEEE Transactions On (15:1), pp. 240-243. 
Batini, C., and Scannapieca, M. 2006. Data Quality: Concepts, Methodologies and Techniques, Springer.

Behrend, T., Sharek, D., Meade, A., and Wiebe, E. 2011. "The Viability of Crowdsourcing for Survey Research,” Behavior Research Methods (43:3), pp. 800-813.

Ben-Zion, R., Pliskin, N., and Fink, L. 2014. "Critical Success Factors for Adoption of Electronic Health Record Systems: Literature Review and Prescriptive Analysis," Information Systems Management (31:4), pp. 296-312.

Bhatt, G. D., and Stump, R. L. 2001. "An Empirically Derived Model of the Role of IS Networks in Business Process Improvement Initiatives,” Omega (29:1), pp. 29-48.

Bidgoli, H. 2014. MIS 5, Cengage learning.

Blueside. 2004. "Problem with User Data Entry Into a Control." (http://forums.ni.com/t5/LabVIEW/Problem-with-User-Data-Entry-Into-a-Control/td$\mathrm{p} / 136185)$.

Blumberg, R., and Atre, S. 2003. “The Problem with Unstructured Data,” Dm Review (13:42-49), p. 62 .

Bonnici, H. M., Richter, F. R., Yazar, Y., and Simons, J. S. 2016. "Multimodal Feature Integration in the Angular Gyrus during Episodic and Semantic Retrieval," Journal of Neuroscience (36:20), pp. 5462-5471.

Buhrmester, M., Kwang, T., and Gosling, S. D. 2011. “Amazon's Mechanical Turk a New Source of Inexpensive, yet High-Quality, Data?," Perspectives on Psychological Science (6:1), pp. 3-5.

Buneman, P., Davidson, S., Fernandez, M., and Suciu, D. 1997. "Adding Structure to Unstructured Data," in Database Theory-ICDT'97, Springer, pp. 336-350.

Burianova, H., McIntosh, A. R., and Grady, C. L. 2010. "A Common Functional Brain Network for Autobiographical, Episodic, and Semantic Memory Retrieval," Neuroimage (49:1), pp. 865-874.

Bursztein, E., Bethard, S., Fabry, C., Mitchell, J. C., and Jurafsky, D. 2010. "How Good Are Humans at Solving CAPTCHAs? A Large Scale Evaluation," in Security and Privacy (SP), 2010 IEEE Symposium On, IEEE, pp. 399-413.

(http://ieeexplore.ieee.org/abstract/document/5504799/).

Butters, N., Granholm, E., Salmon, D. P., Grant, I., and Wolfe, J. 1987. "Episodic and Semantic Memory: A Comparison of Amnesic and Demented Patients," Journal of Clinical and Experimental Neuropsychology (9:5), pp. 479-497.

Casler, K., Bickel, L., and Hackett, E. 2013. "Separate but Equal? A Comparison of Participants and Data Gathered via Amazon's MTurk, Social Media, and Face-to-Face Behavioral Testing," Computers in Human Behavior (29:6), pp. 2156-2160. 
Chandler, D., and Kapelner, A. 2013. "Breaking Monotony with Meaning: Motivation in Crowdsourcing Markets," Journal of Economic Behavior \& Organization (90), pp. 123133.

Chandra, P., and Ibrahim, A. 2015. "The Influence of Perceived System Quality and Perceived Information Quality towards Continuance Intention of Tax E-Filing System in Malaysia," Journal of Technology and Operations Management (10:2), pp. 52-63.

Chang, H. H., and Chen, S. W. 2008. "The Impact of Customer Interface Quality, Satisfaction and Switching Costs on e-Loyalty: Internet Experience as a Moderator," Computers in Human Behavior (24:6), pp. 2927-2944.

Chavez, R., Yu, W., Gimenez, C., Fynes, B., and Wiengarten, F. 2015. "Customer Integration and Operational Performance: The Mediating Role of Information Quality," Decision Support Systems (80), pp. 83-95.

Cho, V., Cheng, T. C. E., and Hung, H. 2009. "Continued Usage of Technology versus Situational Factors: An Empirical Analysis," Journal of Engineering and Technology Management (26:4), pp. 264-284.

Christine Roy, M., Dewit, O., and Aubert, B. A. 2001. "The Impact of Interface Usability on Trust in Web Retailers," Internet Research (11:5), pp. 388-398.

Click, A., and Petit, J. 2010. "Social Networking and Web 2.0 in Information Literacy.," The International Information \& Library Review (42:2), pp. 137-142.

Cocosila, M., and Trabelsi, H. 2016. "An Integrated Value-Risk Investigation of Contactless Mobile Payments Adoption," Electronic Commerce Research and Applications (20), pp. 159-170.

Collier, J. E., and Barnes, D. C. 2015. "Self-Service Delight: Exploring the Hedonic Aspects of Self-Service," Journal of Business Research (68:5), pp. 986-993.

Cowan, N. 2000. "The Magical Number 4 in Short-Term Memory: A Reconsideration of Mental Storage Capacity Behav Brain Sci 24: 87-185," Behavioural and Brain Sciences (24), pp. $87-125$.

Dabholkar, P. A., and Sheng, X. 2009. "The Role of Perceived Control and Gender in Consumer Reactions to Download Delays," Journal of Business Research (62:7), pp. 756-760.

Deng, X., Joshi, K. D., and Galliers, R. D. 2016. "The Duality of Empowerment and Marginalization in Microtask Crowdsourcing: Giving Voice to the Less Powerful through Value Sensitive Design," Mis Quarterly (40:2), pp. 279-302.

Dhar, V., and Chang, E. 2009. "Does Chatter Matter? The Impact of User-Generated Content on Music Sales.," Journal of Interactive Marketing (23:4), pp. 300-307.

Dickinson, J. L., Zuckerberg, B., and Bonter, D. N. 2010. "Citizen Science as an Ecological Research Tool: Challenges and Benefits," Annual Review of Ecology, Evolution, and Systematics (41:1), pp. 112-149. 
Dix, A. 2009. Human-Computer Interaction, Springer. (http://ink.springer.com/10.1007/978-0387-39940-9_192).

Ehrler, F., Haller, G., Sarrey, E., Walesa, M., Wipfli, R., and Lovis, C. 2015. "Assessing the Usability of Six Data Entry Mobile Interfaces for Caregivers: A Randomized Trial," JMIR Human Factors (2:2).

Eichenbaum, H. 1997. "Declarative Memory: Insights from Cognitive Neurobiology.," Annual Review of Psychology (48:1), pp. 547-572.

Engel, S., and Voshell, R. 2002. "Volunteer Biological Monitoring: Can It Accurately Assess the Ecological Condition of Streams?," American Entomologist (48:3), pp. 164-177.

Fielding, R. T., and Taylor, R. N. 2002. "Principled Design of the Modern Web Architecture," ACM Transactions on Internet Technology (TOIT) (2:2), pp. 115-150.

Flanagin, A., and Metzger, M. 2008. "The Credibility of Volunteered Geographic Information," GeoJournal (72:3), pp. 137-148.

Gardiner, J. M. 2001. "Episodic Memory and Autonoetic Consciousness: A First-Person Approach," Philosophical Transactions of the Royal Society of London B: Biological Sciences (356:1413), pp. 1351-1361.

Gibson, C. 1998. "Semi-structured and Unstructured Interviewing: A Comparison of Methodologies in Research with Patients Following Discharge from an Acute Psychiatric Hospital.," Journal of Psychiatric and Mental Health Nursing (5:6), pp. 469-477.

Goldstein, E. 2010. Cognitive Psychology: Connecting Mind, Research and Everyday Experience, Cengage Learning.

Gong, Y., Hua, L., and Wang, S. 2016. "Leveraging User's Performance in Reporting Patient Safety Events by Utilizing Text Prediction in Narrative Data Entry," Computer Methods and Programs in Biomedicine (131), pp. 181-189.

Goodhue, D., and Thompson, R. 1995. “Task-Technology Fit and Individual Performance,” MIS Quarterly (19:2), pp. 213-236.

Granello, D. H., and Wheaton, J. E. 2004. "Online Data Collection: Strategies for Research," Journal of Counseling \& Development (82:4), pp. 387-393.

Green, M. 2015. 25 Quotes That Show Just How Fed up Physicians Are with EHRs. (http://www.beckershospitalreview.com/healthcare-information-technology/25-quotesthat-show-just-how-fed-up-physicians-are-with-ehrs.html).

Greenberg, D. L., and Verfaellie, M. 2010. "Interdependence of Episodic and Semantic Memory: Evidence from Neuropsychology," Journal of the International Neuropsychological Society (16:5), pp. 748-753.

Gustafson, A. 2011. Improving the Tweet Box, (2). (http://webstandardssherpa.com/reviews/improving-the-tweet-box/). 
Haklay, M., and Weber, P. 2008. “OpenStreetMap: User-Generated Street Maps," IEEE Pervasive Computing (7:4), pp. 12-18.

Hanna, R., Rohm, A., and Crittenden, V. L. 2011. "We're All Connected: The Power of the Social Media Ecosystem,” Business Horizons (54:3), pp. 265-273.

Helander, M. G. 2014. Handbook of Human-Computer Interaction, Elsevier. (https://books.google.com/books?hl=en\&lr=\&id=6vnSAwAAQBAJ\&oi=fnd\&pg=PP1\& $\mathrm{dq}=$ hci + user + interface + design\&ots $=\mathrm{iiHMH}$ EwaH\&sig=dOyEyDpu0OvB7xoT7edNAU YuGGk).

Hernández, B., Jiménez, J., and José Martín, M. 2011. “Age, Gender and Income: Do They Really Moderate Online Shopping Behaviour?," Online Information Review (35:1), pp. 113-133.

Herz, M., and Brunk, K. H. 2017. "Conceptual Advances in Consumers' Semantic and Episodic Brand Memories: A Mixed Methods Exploration," Psychology \& Marketing (34:1), pp. 70-91.

Hill, S., and Ready-Campbell, N. 2011. "Expert Stock Picker: The Wisdom of (the Experts in) Crowds," International Journal of Electronic Commerce (15:3), pp. 73-101.

Hofstede, G. 1990. “A Reply and Comment on Joginder P. Singh:’Managerial Culture and WorkRelated Values in India'," Organization Studies (11:1), pp. 103-106.

Holzinger, A. 2002. "User-Centered Interface Design for Disabled and Elderly People: First Experiences with Designing a Patient Communication System (PACOSY)," Computers Helping People with Special Needs, pp. 467-484.

Hua, L., Wang, S., and Gong, Y. 2014. "Text Prediction on Structured Data Entry in Healthcare: A Two-Group Randomized Usability Study Measuring the Prediction Impact on User Performance," Applied Clinical Informatics (5:1), p. 249.

Ipeirotis, P. G., Provost, F., and Wang, J. 2010. "Quality Management on Amazon Mechanical Turk," in Proceedings of the ACM SIGKDD Workshop on Human Computation, ACM, pp. 64-67.

Iyer, K. N., Germain, R., and Claycomb, C. 2009. "B2B E-Commerce Supply Chain Integration and Performance: A Contingency Fit Perspective on the Role of Environment," Information \& Management (46:6), pp. 313-322.

Jacko, J. A. 2012. Human Computer Interaction Handbook: Fundamentals, Evolving Technologies, and Emerging Applications, CRC press. (https://books.google.com/books?hl=en\&lr=\&id=dVrRBQAAQBAJ\&oi=fnd\&pg=PP1\& $\mathrm{dq}=$ Human + Computer+Interaction+Handbook:+Fundamentals,\&ots=wUekggnwe0\&sig= KC3Q7K07TdAKhrjlHPRGO99gQ7w).

Jin, Y., Wen, Y., Shi, G., Wang, G., and Vasilakos, A. V. 2012. “CoDaaS: An Experimental Cloud-Centric Content Delivery Platform for User-Generated Contents," in Computing, 
Networking and Communications (ICNC), 2012 International Conference On, IEEE, pp. 934-938. (http://ieeexplore.ieee.org/abstract/document/6167562/).

Ju, Q. Q., and Ding, L. Y. 2015. “A Web-Based System for Interface Management of Metro Equipment Engineering,” Journal of Intelligent \& Robotic Systems (79:3-4), p. 577.

Kaplan, A., and Haenlein, M. 2010. "Users of the World, Unite! The Challenges and Opportunities of Social Media.," Business Horizons (53:1), pp. 59-68.

Kaufmann, N., Schulze, T., and Veit, D. 2011. More than Fun and Money. Worker Motivation in Crowdsourcing-A Study on Mechanical Turk., in (Vol. 11), presented at the AMCIS, pp. $1-11$.

Kees, J., Berry, C., Burton, S., and Sheehan, K. 2017. “An Analysis of Data Quality: Professional Panels, Student Subject Pools, and Amazon's Mechanical Turk," Journal of Advertising (46:1), pp. 141-155.

Keller, K. L., and Staelin, R. 1987. "Effects of Quality and Quantity of Information on Decision Effectiveness.," Journal of Consumer Research (14:2), pp. 200-213.

Kim, E., Eom, S., and Uoo, S. 2001. "Effective User Interface Design for Online Stores in the Asia Pacific Region: A Survey Study," AMCIS 2001 Proceedings, p. 168.

Kim, Y. 2010. "Accessibility and Usability of User-Centric Web Interaction with a UnifiedUbiquitous Name-Based Directory Service," World Wide Web (13:1), pp. 105-120.

Klonner, C., Barron, C., Neis, P., and Hofle, B. 2015. "Updating Digital Elevation Models via Change Detection and Fusion of Human and Remote Sensor Data in Urban Environments.," International Journal of Digital Earth (8:2), pp. 153-171.

Kramer, J., Noronha, S., and Vergo, J. 2000. "A User-Centered Design Approach to Personalization," Communications of the ACM (43:8), pp. 44-48.

Kramer, T. 2007. "The Effect of Measurement Task Transparency on Preference Construction and Evaluations of Personalized Recommendations," Journal of Marketing Research (44:2), pp. 224-233.

Lachman, R., Lachman, J., and Butterfield, E. C. 1979. Cognitive Psychology and Information Processing: An Introduction.[AAK].

Lahl, D. 2011. "Make Better Decisions by Analyzing Structured and Unstructured Data Together," Business Intelligence Journal (16:1), pp. 9-16.

Larry, S. 2004. "Memory Systems of the Brain: A Brief History and Current Perspective.," Neurobiology of Learning and Memory (82:3), pp. 171-177.

Laske, O. 1978. "Considering Human Memory in Designing User Interfaces for Computer Music.," Computer Music Journal (2:4), pp. 39-45. 
Lederer, A. L., Maupin, D. J., Sena, M. P., and Zhuang, Y. 2000. "The Technology Acceptance Model and the World Wide Web," Decision Support Systems (29:3), pp. 269-282.

Lee, Y. W., Pipino, L. L., Funk, J. D., and Wang, R. Y. 2006. Journey to Data Quality, Cambridge, Mass: MIT Press.

Lee, Y. W., and Strong, D. M. 2003. "Knowing-Why about Data Processes and Data Quality," Journal of Management Information Systems (20:3), pp. 13-39.

Lee, Y. W., Strong, D. M., Kahn, B. K., and Wang, R. Y. 2002. “AIMQ: A Methodology for Information Quality Assessment," Information \& Management (40:2), pp. 133-146.

Lesley. 2016. "Why People Don't Leave Reviews."

(https://www.etsy.com/teams/7722/discussions/discuss/17373890/).

Li, C. 2010. "Groundswell. Winning in a World Transformed by Social Technologies.," Strategic Direction (26:8).

Losee, R. 2006. "Browsing Mixed Structured and Unstructured Data.," Information Processing \& Management (42:2), pp. 440-452.

Losee, R. M. 2006. "Browsing Mixed Structured and Unstructured Data," Information Processing \& Management (42:2), pp. 440-452.

Lukyanenko, R., and Parsons, J. 2015. "Information Quality Research Challenge: Adapting Information Quality Principles to User-Generated Content," ACM Journal of Data and Information Quality (6:1), pp. 1-3.

Lukyanenko, R., Parsons, J., and Wiersma, Y. 2014. "The IQ of the Crowd: Understanding and Improving Information Quality in Structured User-Generated Content," Information Systems Research (25:4), pp. 669-689.

Lukyanenko, Roman, Parsons, J., and Wiersma, Y. 2014. "The Impact of Conceptual Modeling on Dataset Completeness: A Field Experiment," in International Conference on Information Systems, pp. 1-18.

Lukyanenko, R., Parsons, J., Wiersma, Y., and Maddah, M. 2019. "Expecting the Unexpected: Effects of Data Collection Design Choices on the Quality of Crowdsourced UserGenerated Content.," MIS Quarterly (43:2).

Maddah, M., Lukyanenko, R., and Chiarini Tremblay, M. 2016. Toward Theory and Method of Hybrid Data Collection, presented at the International Conference on Design Science Research in Information Systems and Technology (DESRIST), St. John's, NL Canada, pp. 93-95.

Madnick, S. E., Wang, R. Y., Lee, Y. W., and Zhu, H. 2009. “Overview and Framework for Data and Information Quality Research," Journal of Data and Information Quality (1:1), pp. $1-22$. 
Marcus, A., and Gould, E. W. 2000. "Crosscurrents: Cultural Dimensions and Global Web UserInterface Design," Interactions (7:4), pp. 32-46.

Marge, M., Banerjee, S., and Rudnicky, A. I. 2010. "Using the Amazon Mechanical Turk for Transcription of Spoken Language," in Acoustics Speech and Signal Processing (ICASSP), 2010 IEEE International Conference On, IEEE, pp. 5270-5273. (http://ieeexplore.ieee.org/abstract/document/5494979/).

Mason, W., and Suri, S. 2012a. "Conducting Behavioral Research on Amazon's Mechanical Turk," Behavior Research Methods (44:1), pp. 1-23.

Mason, W., and Suri, S. 2012b. “Conducting Behavioral Research on Amazon's Mechanical Turk,” Behavior Research Methods (44:1), pp. 1-23.

Mathioudakis, M., and Koudas, N. 2010. "Twittermonitor: Trend Detection over the Twitter Stream.," in Proceedings of the 2010 ACM SIGMOD, ACM.

McClelland, J. L., and Rogers, T. T. 2003. "The Parallel Distributed Processing Approach to Semantic Cognition,” Nature Reviews. Neuroscience (4:4), p. 310.

McClelland, J. L., and Rumelhart, D. E. 1985. "Distributed Memory and the Representation of General and Specific Information.," Journal of Experimental Psychology: General (114:2), p. 159.

Misra, S. C., Kumar, V., and Kumar, U. 2009. "Identifying Some Important Success Factors in Adopting Agile Software Development Practices," Journal of Systems and Software (82:11), pp. 1869-1890.

Mitchell, D. B. 1989. "How Many Memory Systems? Evidence from Aging.," Journal of Experimental Psychology: Learning, Memory, and Cognition (15:1), p. 31.

Mogilner, C., Aaker, J., and Kamvar, S. D. 2012. "How Happiness Affects Choice," Journal of Consumer Research (39:2), pp. 429-443.

Nicolaou, A. I., and McKnight, D. H. 2006. "Perceived Information Quality in Data Exchanges: Effects on Risk, Trust, and Intention to Use," Information Systems Research (17:4), pp. 332-351.

Norman, D. A., and Draper, S. W. 1986. "User Centered System Design," New Perspectives on Human-Computer Interaction, L. Erlbaum Associates Inc., Hillsdale, NJ (3). (http://tocs.ulb.tu-darmstadt.de/7187823.pdf).

Nov, O., Arazy, O., and Anderson, D. 2011. "Dusting for Science: Motivation and Participation of Digital Citizen Science Volunteers," 2011 IConference, pp. 68-74.

Obrist, M., Geerts, D., Brandtzla eg, P. B., and Tscheligi, M. 2008. "Design for Creating, Uploading and Sharing User Generated Content," in CHI'08 Extended Abstracts on Human Factors in Computing Systems, ACM, pp. 2391-2394.

(http://dl.acm.org/citation.cfm?id=1358692). 
O'Leary, M. B., Wilson, J. M., and Metiu, A. 2014. "Beyond Being There: The Symbolic Role of Communication and Identification in Perceptions of Proximity to Geographically Dispersed Colleagues.," MIS Quarterly (38:4), pp. 1219-1243.

Ong, C.-S., and Lai, J.-Y. 2006. "Gender Differences in Perceptions and Relationships among Dominants of E-Learning Acceptance," Computers in Human Behavior (22:5), pp. 816829.

O'Reilly, C. 1982. "Variations in Decision Makers' Use of Information Sources: The Impact of Quality and Accessibility of Information.," Academy of Management Journal (25:4), pp. 756-771.

Paolacci, G., Chandler, J., and Ipeirotis, P. G. 2010. "Running Experiments on Amazon Mechanical Turk," Judgment and Decision Making (5:5), pp. 411-419.

Parsons, J., Lukyanenko, R., and Wiersma, Y. 2011. "Easier Citizen Science Is Better," Nature (471:7336), pp. 37-37.

Parssian, A., Sarkar, S., and Jacob, V. S. 2004. “Assessing Data Quality for Information Products: Impact of Selection, Projection, and Cartesian Product," Management Science (50:7), pp. 967-982.

Petter, S., DeLone, W., and McLean, E. R. 2013. "Information Systems Success: The Quest for the Independent Variables," Journal of Management Information Systems (29:4), pp. 762 .

Pikkarainen, T., Pikkarainen, K., Karjaluoto, H., and Pahnila, S. 2004. "Consumer Acceptance of Online Banking: An Extension of the Technology Acceptance Model," Internet Research (14:3), pp. 224-235.

Pipino, L. L., Lee, Y. W., and Wang, R. Y. 2002. "Data Quality Assessment," Communications of the ACM (45:4), pp. 211-218.

Plaisant, C., and Shneiderman, B. 2010. Designing the User Interface, Pearson Education Inc.

Rahman, Q. S., Islam, M. S., Hossain, B., Hossain, T., Connor, N. E., Jaman, M. J., Rahman, M. M., Ahmed, A. N. U., Ahmed, I., and Ali, M. 2016. "Centralized Data Management in a Multicountry, Multisite Population-Based Study," The Pediatric Infectious Disease Journal (35:5), pp. S23-S28.

Rajan, C. A., and Baral, R. 2015. “Adoption of ERP System: An Empirical Study of Factors Influencing the Usage of ERP and Its Impact on End User," IIMB Management Review (27:2), pp. 105-117.

Redman, T. C. 1998. "The Impact of Poor Data Quality on the Typical Enterprise," Communications of the ACM (41:2), pp. 79-82.

Reinecke, K., and Bernstein, A. 2011. "Improving Performance, Perceived Usability, and Aesthetics with Culturally Adaptive User Interfaces," ACM Transactions on ComputerHuman Interaction (TOCHI) (18:2), p. 8. 
Rogers, T. T., and McClelland, J. L. 2004. Semantic Cognition: A Parallel Distributed Processing Approach, MIT press.

Ross, J., Irani, L., Silberman, M., Zaldivar, A., and Tomlinson, B. 2010. "Who Are the Crowdworkers?: Shifting Demographics in Mechanical Turk," in CHI'10 Extended Abstracts on Human Factors in Computing Systems, ACM, pp. 2863-2872. (http://dl.acm.org/citation.cfm?id=1753873).

Scannapieco, M., Missier, P., and Batini, C. 2005. "Data Quality at a Glance.," DatenbankSpektrum (14), pp. 6-14.

Sharp, H., Rogers, Y., and Preece, J. 2007. Interaction Design: Beyond Human-Computer Interaction.

(https://www.mysciencework.com/publication/show/5f873a3b5156e3e28d5080dc875174 b2).

Shneiderman, B., and Plaisant, C. 1987. "Designing the User Interface: Strategies for Effective Human-Computer Interaction,” ACM SIGBIO Newsletter (9:1), p. 6.

Sorokin, A., Berenson, D., Srinivasa, S. S., and Hebert, M. 2010. "People Helping Robots Helping People: Crowdsourcing for Grasping Novel Objects," in Intelligent Robots and Systems (IROS), 2010 IEEE/RSJ International Conference On, IEEE, pp. 2117-2122. (http://ieeexplore.ieee.org/abstract/document/5650464/).

Speier, C., Valacich, J., and Vesser, I. 1999. "The Influence of Task Interruption on Individual Decision Making: An Information Overload Perspective.," Decision Sciences (30:2), pp. 337-360.

Squire, L. R., and Zola, S. M. 1998. "Episodic Memory, Semantic Memory, and Amnesia," Hippocampus (8:3), pp. 205-211.

Steelman, Z. R., Hammer, B. I., and Limayem, M. 2014a. "Data Collection in the Digital Age: Innovative Alternatives to Student Samples.," Mis Quarterly (38:2).

Steelman, Z. R., Hammer, B. I., and Limayem, M. 2014b. "Data Collection in the Digital Age: Innovative Alterantives to Student Samples.," Mis Quarterly (38:2), pp. 355-378.

Stoeckl, R., Rohrmeier, P., and Hess, T. 2007. "Motivations to Produce User Generated Content: Differences between Webloggers and Videobloggers," BLED 2007 Proceedings, p. 30.

Strong, D. M., Lee, Y. W., and Wang, R. Y. 1997. "Data Quality in Context," Communications of the ACM (40:5), pp. 103-110.

Susarla, A., Oh, J.-H., and Tan, Y. 2012. "Social Networks and the Diffusion of User-Generated Content: Evidence from YouTube," Information Systems Research (23:1), pp. 23-41.

Sutcliffe, A. 1988. Human-Computer Interface Design., Springer.

Sykes, J., Oskoz, A., and Thorne, S. 2008. "Web 2.0, Synthetic Immersive Environments, and Mobile Resources for Language Education.," Calico Journal (25:3), pp. 528-546. 
Takashima, A., Bakker, I., Van Hell, J. G., Janzen, G., and McQueen, J. M. 2017. “Interaction between Episodic and Semantic Memory Networks in the Acquisition and Consolidation of Novel Spoken Words," Brain and Language (167), pp. 44-60.

Thyvalikakath, T. P., Dziabiak, M. P., Johnson, R., Torres-Urquidy, M. H., Acharya, A., Yabes, J., and Schleyer, T. K. 2014. "Advancing Cognitive Engineering Methods to Support User Interface Design for Electronic Health Records," International Journal of Medical Informatics (83:4), pp. 292-302.

Tremblay, M. C., Fuller, R., Berndt, D., and Studnicki, J. 2007. "Doing More with More Information: Changing Healthcare Planning with OLAP Tools," Decision Support Systems (43:4), pp. 1305-1320.

Tulving, E. 1972. "Episodic and Semantic Memory 1," Organization of Memory (381:4).

Tulving, E. 1985. "How Many Memory Systems Are There?," American Psychologist (40:4), p. 385.

Tulving, E. 2002a. "Episodic Memory: From Mind to Brain," Annual Review of Psychology (53:1), pp. 1-25.

Tulving, E. 2002b. "Episodic Memory: From Mind to Brain," Annual Review of Psychology (53:1), pp. 1-25.

Turoff, M., Chumer, M., Van de Walle, B., and Yao, X. 2004. "The Design of a Dynamic Emergency Response Management Information System (DERMIS)," JITTA: Journal of Information Technology Theory and Application (5:4), p. 1.

Van Dolen, W. M., Dabholkar, P. A., and De Ruyter, K. 2007. "Satisfaction with Online Commercial Group Chat: The Influence of Perceived Technology Attributes, Chat Group Characteristics, and Advisor Communication Style," Journal of Retailing (83:3), pp. 339-358.

Walters, H. 1961. "Structured or Unstructured Techniques?.," The Journal of Marketing (25:4), pp. 58-62.

Wand, Y., and Wang, R. Y. 1996. "Anchoring Data Quality Dimensions in Ontological Foundations," Communications of the ACM (39:11), pp. 86-95.

Wand, Y., and Weber, R. 1990. "Toward a Theory of the Deep Structure of Information Systems," in International Conference on Information Systems, Copenhagen, Denmark, pp. 61-71.

Wand, Y., and Weber, R. 1993. "On the Ontological Expressiveness of Information Systems Analysis and Design Grammars," Information Systems Journal (3:4), pp. 217-237.

Wand, Y., and Weber, R. 1995. "On the Deep-Structure of Information-Systems," Information Systems Journal (5:3), pp. 203-223. 
Wang, R. Y., Storey, V. C., and Firth, C. P. 1995. "A Framework for Analysis of Data Quality Research," Knowledge and Data Engineering, IEEE Transactions On (7:4), pp. 623-640.

Wang, W., and Benbasat, I. 2008. "Attributions of Trust in Decision Support Technologies: A Study of Recommendation Agents for E-Commerce," Journal of Management Information Systems (24:4), pp. 249-273.

Wang, X., and Keh, H. T. 2017. "Consumer Susceptibility to Cross-Selling Persuasion: The Roles of Self-Construal and Interpersonal Harmony," Journal of Retailing and Consumer Services (34), pp. 177-184.

Ward, M. K., and Broniarczyk, S. M. 2011. "It's Not Me, It's You: How Gift Giving Creates Giver Identity Threat as a Function of Social Closeness," Journal of Consumer Research (38:1), pp. 164-181.

Wiggins, A., Newman, G., Stevenson, R. D., and Crowston, K. 2011. "Mechanisms for Data Quality and Validation in Citizen Science," in "Computing for Citizen Science" Workshop, Stockholm, SE, pp. 14-19.

Wixom, B. H., and Todd, P. A. 2005. "A Theoretical Integration of User Satisfaction and Technology Acceptance,” Information Systems Research (16:1), pp. 85-102.

Wyrwoll, C. 2014. "User-Generated Content.," in Social Media, Springer Fachmedien Wiesbaden, pp. 11-45.

Xu, H., Nord, J. H., Brown, N., and Nord, D. 2002. "Data Quality Issues in Implementing an ERP.," Industrial Management \& Data Systems (102:1), pp. 47-58.

Xu, J. D., Benbasat, I., and Cenfetelli, R. T. 2013. "Integrating Service Quality with System and Information Quality: An Empirical Test in the e-Service Context.," Mis Quarterly (37:3).

Yu, L. L., and Nickerson, J. V. 2011. Generating Creative Ideas through Crowds: An Experimental Study of Combination. (https://papers.ssrn.com/sol3/papers.cfm?abstract_id=2039547).

Zhang, X., Yu, Y., Li, H., and Lin, Z. 2016. "Sentimental Interplay between Structured and Unstructured User-Generated Contents-An Empirical Study on Online Hotel Reviews," Online Information Review (40:1).

Zheng, Y., Zhao, K., and Stylianou, A. 2013. "The Impacts of Information Quality and System Quality on Users' Continuance Intention in Information-Exchange Virtual Communities: An Empirical Investigation," Decision Support Systems (56), pp. 513-524.

Zwass, V. 2010. "Co-Creation: Toward a Taxonomy and an Integrated Research Perspective," International Journal of Electronic Commerce (15:1), pp. 11-48. 


\section{APPENDICES}

\section{Appendix A}

Screenshots of interfaces offering differently structured options:

- Facebook:

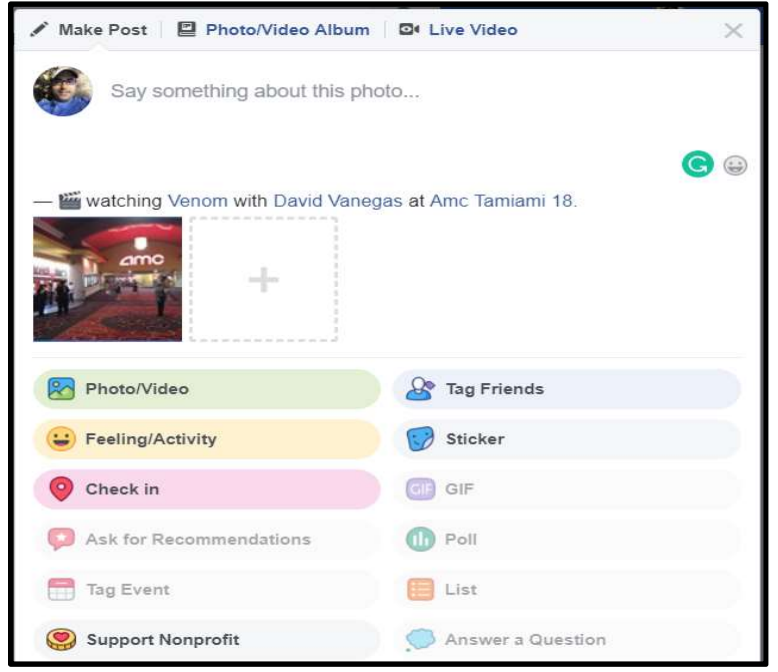

- Imdb:

Review preferences:
Name: $\quad$ Mahed Maddah
Location: $\quad$ United States

Enter review below:

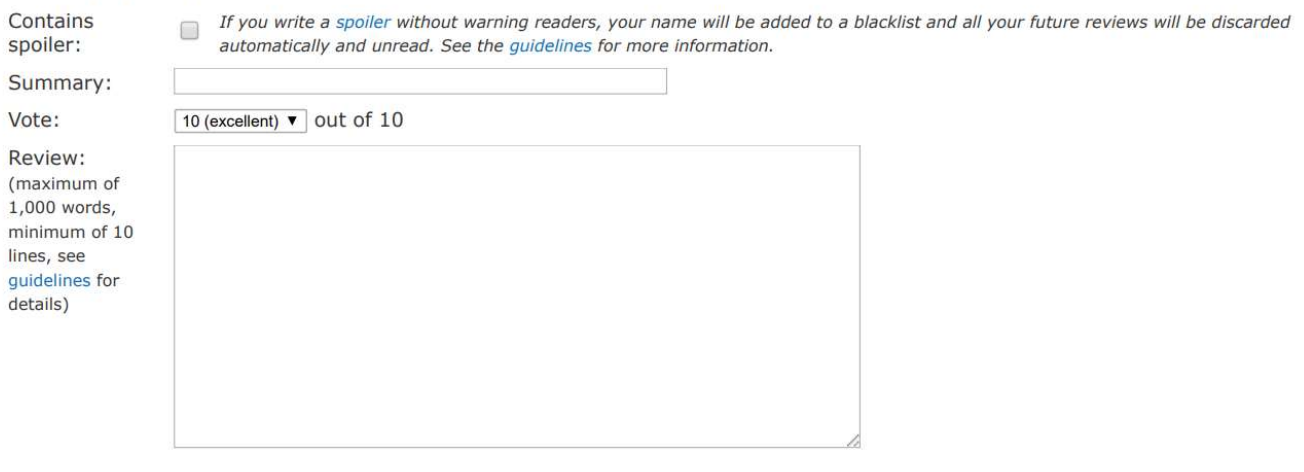

Your review is not yet ready for submission.

- Yahoo!: 


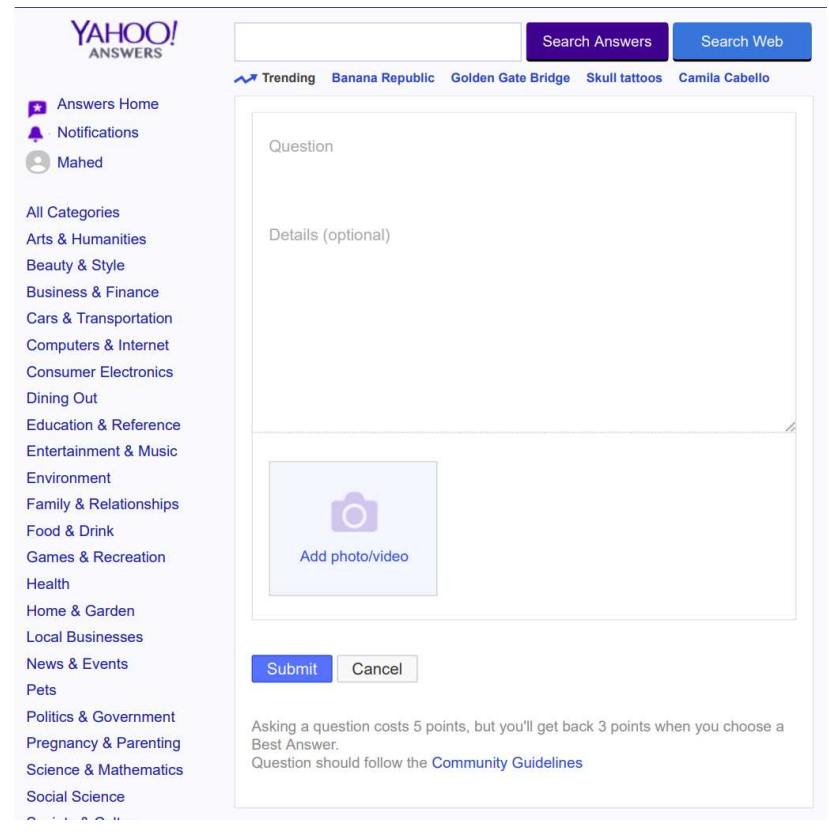

\section{Appendix B}

\begin{tabular}{|c|c|}
\hline \multicolumn{2}{|r|}{ Unstructured format: } \\
\hline Task: & $\begin{array}{l}\text { Have you ever traveled by airplane? Could you remember and share your } \\
\text { experience of the last time (or a memorable time) you traveled by airplane? If } \\
\text { No, you are not qualified to take part in this experiment.... If that's the case for } \\
\text { you, please close this page! And thank you for your time!.... If yes, you are } \\
\text { definitely qualified to take part in this experiment. } \\
\text { Remember your last trip on an airplane (or any memorable trip on an airplane)... } \\
\text { We want you to please share your pre-flight experience as much as you can } \\
\text { remember. Let's consider "Pre-flight experience" any flight-related activity } \\
\text { between the moment that you get to the airport and the moment that you get on } \\
\text { the plane, including checking-in your bags, getting boarding pass, going through } \\
\text { security check, looking for and finding the boarding gate, waiting in lines, } \\
\text { waiting at the gate, visiting a shopping/dining/entertaining place, using airport } \\
\text { train system/golf carts/moving walkways, boarding the plane, dealing with } \\
\text { airport's staff and so on... } \\
\text { Please take your time and write whatever you remember about this } \\
\text { experience. Assume that you are writing your experience as a story (include any } \\
\text { details that you want). Please write as much as you can. }\end{array}$ \\
\hline Interface: & An open box field is provided to collect the response. \\
\hline \multicolumn{2}{|r|}{ Semi-structured format: } \\
\hline Task: & $\begin{array}{l}\text { Have you ever traveled by airplane? Could you remember and share your } \\
\text { experience of the last time (or a memorable time) you traveled by airplane? If } \\
\text { No, you are not qualified to take part in this experiment.... If that's the case for }\end{array}$ \\
\hline
\end{tabular}




\begin{tabular}{|c|c|}
\hline & $\begin{array}{l}\text { you, please close this page! And thank you for your time!.... If yes, you are } \\
\text { definitely qualified to take part in this experiment. } \\
\text { Remember your last trip on an airplane (or any memorable trip on an airplane)... } \\
\text { We want you to please share your pre-flight experience as much as you can } \\
\text { remember. Let's consider "Pre-flight experience" any flight-related activity } \\
\text { between the moment that you get to the airport and the moment that you get on } \\
\text { the plane, including checking-in your bags, getting boarding pass, going through } \\
\text { security check, looking for and finding the boarding gate, waiting in lines, } \\
\text { waiting at the gate, visiting a shopping/dining/entertaining place, using airport } \\
\text { train system/golf carts/moving walkways, boarding the plane, dealing with } \\
\text { airport's staff and so on... } \\
\text { Please take your time and write whatever you remember about this } \\
\text { experience. Assume that you are writing your experience as a story (include any } \\
\text { details that you want). Please write as much as you can. Also, write three } \\
\text { hashtags. } \\
\text { As you may have seen in social media, hashtags are used to allow users to apply } \\
\text { dynamic tagging to their content. So, any keyword or phrase (can not contain } \\
\text { space) that seems important in your writing can come after \# sign to make a } \\
\text { hashtag. For example: } \\
\text { Amazon.com } \\
\text { Smaman } \\
\text { Amazon. We asked a few friends to share } \\
\text { some advice for these entrepreneurs: } \\
\text { amzn.to/twlnsights \#DayOnelnsights } \\
\text { \#entrepreneurship }\end{array}$ \\
\hline Interface: & $\begin{array}{l}\text { An open box field is provided to collect the response. Furthermore, three } \\
\text { separate interfaces are provided to collect each hashtag. }\end{array}$ \\
\hline \multicolumn{2}{|r|}{ Structured format: } \\
\hline Task: & $\begin{array}{l}\text { Have you ever traveled by airplane? Could you remember and share your } \\
\text { experience of the last time (or a memorable time) you traveled by airplane? If } \\
\text { No, you are not qualified to take part in this experiment.... If that's the case for } \\
\text { you, please close this page! And thank you for your time!.... If yes, you are } \\
\text { definitely qualified to take part in this experiment. } \\
\text { Remember your last trip on an airplane (or any memorable trip on an } \\
\text { airplane).Please answer the following questions about this experience. }\end{array}$ \\
\hline Interface: & A list of questions and detailed provided choices are available on Figure 8. \\
\hline
\end{tabular}




\section{Appendix C}

Survey for Data Consumers' experiment:

- In your opinion, how complete and comprehensive is the above description of all the events that actually occurred? Very incomplete----- Very complete

- What (if any) details do you think were omitted by this person? Why?

- In your opinion, how accurate or truthful the above passage describes what actually happened to this person? Very inaccurate----- very accurate

- Which, if any, parts of this description may be inaccurate or untruthful? Why?

- Providing information creation takes time and effort, how effortful do you think it was for this person to provide the description above? Required no effort at all ----- Required extreme effort

- Assuming that you want to use this description for future decisions, how well structured was this description for future use? Extremely disordered ----- Extremely well-structured

- Assuming that you want to use this description for future decisions, how useful is this description to you? Extremely useless ----- Extremely useful

- In your opinion, how genuine/sincere was the author? Extremely insincere----- Extremely sincere

- Finally, what, if anything, can you tell about this person from the description he or she provided?

\section{Appendix D}

\section{Episodic Content}

\section{Unstructured format:}

\begin{tabular}{l|l|} 
Task: & Have you ever caught cold, the Flu or any similar disease? Could you remember
\end{tabular} and describe the last time (or a memorable time) that you got sick? If No, you are not qualified to take part in this experiment.... If that's the case for you, please close this page! And thank you for your time!.... If yes, you are definitely qualified to take part in this experiment. 


\begin{tabular}{|c|c|}
\hline & $\begin{array}{l}\text { Remember the last time (or a memorable time) you got sick (cold, the flu,...). } \\
\text { We want you to share your experience through out the sickness period as much } \\
\text { as you remember. Let's consider "the sickness period" the moment the first } \\
\text { vague, general symptoms showed up (onset phase) to the moment that you felt } \\
\text { totally fine (all symptoms were gone). Your experience during this sickness } \\
\text { period can be related to the onset phase, illness phase, convalescence phase, the } \\
\text { duration of each phase, symptoms, severity of each symptom in each period, } \\
\text { medicines that you took, people who you consulted with, places that you visited } \\
\text { for treatment, the money that you spend on treatment, everything you did to } \\
\text { accelerate the treatment process and so on ... } \\
\text { Please take your time and write whatever you remember about this experience. } \\
\text { Assume that you are writing your experience as a story (include any details that } \\
\text { you want). Please write as much as you can. }\end{array}$ \\
\hline Interface: & An open box field is provided to collect the response. \\
\hline & Semi-structured format: \\
\hline Task: & $\begin{array}{l}\text { Have you ever caught cold, the Flu or any similar disease? Could you remember } \\
\text { and describe the last time (or a memorable time) that you got sick? If No, you } \\
\text { are not qualified to take part in this experiment.... If that's the case for you, } \\
\text { please close this page! And thank you for your time!.... If yes, you are definitely } \\
\text { qualified to take part in this experiment. } \\
\text { Remember the last time (or a memorable time) you got sick (cold, the flu,...). } \\
\text { We want you to share your experience through out the sickness period as much } \\
\text { as you remember. Let's consider "the sickness period" the moment the first } \\
\text { vague, general symptoms showed up (onset phase) to the moment that you felt } \\
\text { totally fine (all symptoms were gone). Your experience during this sickness } \\
\text { period can be related to the onset phase, illness phase, convalescence phase, the } \\
\text { duration of each phase, symptoms, severity of each symptom in each period, } \\
\text { medicines that you took, people who you consulted with, places that you visited } \\
\text { for treatment, the money that you spend on treatment, everything you did to } \\
\text { accelerate the treatment process and so on ... } \\
\text { Please take your time and write whatever you remember about this experience. } \\
\text { Assume that you are writing your experience as a story (include any details that } \\
\text { you want). Please write as much as you can. Also, write three hashtags. } \\
\text { As you may have seen in social media, hashtags are used to allow users to apply } \\
\text { dynamic tagging to their content. So, any keyword or phrase (can not contain } \\
\text { space) that seems important in your writing can come after \# sign to make a } \\
\text { hashtag. For example: }\end{array}$ \\
\hline
\end{tabular}




\begin{tabular}{|c|c|}
\hline & $\begin{array}{l}\text { Amazon.com } \\
\text { Small businesses around the world sell on } \\
\text { Amazon. We asked a few friends to share } \\
\text { some advice for these entrepreneurs: } \\
\text { amzn.to/twinsights \#DayOnelnsights } \\
\text { \#entrepreneurship }\end{array}$ \\
\hline Interface: & $\begin{array}{l}\text { An open box field is provided to collect the response. Furthermore, three } \\
\text { separate interfaces are provided to collect each hashtag. }\end{array}$ \\
\hline \multicolumn{2}{|r|}{ Structured format: } \\
\hline Task: & $\begin{array}{l}\text { Have you ever caught cold, the Flu or any similar disease? Could you remember } \\
\text { and describe the last time (or a memorable time) that you got sick? If No, you } \\
\text { are not qualified to take part in this experiment.... If that's the case for you, } \\
\text { please close this page! And thank you for your time!.... If yes, you are definitely } \\
\text { qualified to take part in this experiment. } \\
\text { Remember the last time (or a memorable time) you got sick (cold, the flu,...). } \\
\text { Please answer the following questions about this experience. }\end{array}$ \\
\hline Interface: & A list of questions and detailed provided choices are available on Figure 21. \\
\hline
\end{tabular}

\section{$\underline{\text { Semantic Content }}$}

\begin{tabular}{|l|l|}
\hline \multicolumn{2}{|l|}{ Unstructured format: } \\
\hline Task: & $\begin{array}{l}\text { Are you familiar with Influenza (the Flu)? Could you describe this disease based } \\
\text { on your general knowledge? If No, you are not qualified to take part in this } \\
\text { experiment.... If that's the case for you, please close this page! And thank you } \\
\text { for your time!.... If yes, you are definitely qualified to take part in this } \\
\text { experiment. }\end{array}$ \\
$\begin{array}{l}\text { We want you to describe the Influenza disease. Based on your general } \\
\text { knowledge, share whatever you know about this disease. Try to mention all the } \\
\text { facts that you know about Influenza. This can include the types of Influenza, } \\
\text { causes of disease, its symptoms, its different phases, its duration, suggested } \\
\text { medicine, suggested lifestyle changes, suggested eating habits, its possible } \\
\text { consequences, ways to control the disease and so on... } \\
\text { Please take your time and write whatever you know about this disease. Assume } \\
\text { that you are describing Influenza to someone who doesn't know anything about } \\
\text { it. Please write as much as you can. }\end{array}$ \\
\hline Interface: & \begin{tabular}{l} 
An open box field is provided to collect the response. \\
\hline
\end{tabular} \\
\hline
\end{tabular}




\begin{tabular}{|c|c|}
\hline \multicolumn{2}{|r|}{ Semi-structured format: } \\
\hline Task: & $\begin{array}{l}\text { Are you familiar with Influenza ( the Flu)? Could you describe this disease } \\
\text { based on your general knowledge? If No, you are not qualified to take part in } \\
\text { this experiment.... If that's the case for you, please close this page! And thank } \\
\text { you for your time!.... If yes, you are definitely qualified to take part in this } \\
\text { experiment. } \\
\text { We want you to describe the Influenza disease. Based on your general } \\
\text { knowledge, share whatever you know about this disease. Try to mention all the } \\
\text { facts that you know about Influenza. This can include the types of Influenza, } \\
\text { causes of disease, its symptoms, its different phases, its duration, suggested } \\
\text { medicine, suggested lifestyle changes, suggested eating habits, its possible } \\
\text { consequences, ways to control the disease and so on... } \\
\text { Please take your time and write whatever you know about this disease. Assume } \\
\text { that you are describing Influenza to someone who doesn't know anything about } \\
\text { it. Please write as much as you can. Also, write three hashtags. } \\
\text { As you may have seen in social media, hashtags are used to allow users to apply } \\
\text { dynamic tagging to their content. So, any keyword or phrase (can not contain } \\
\text { space) that seems important in your writing can come after \# sign to make a } \\
\text { hashtag. For example: } \\
\text { Amazon.com } \\
\text { @amazon } \\
\text { Amall businesses around the world sell on } \\
\text { some advice for these entrepreneurs: } \\
\text { amzn.to/twlnsights \#DayOnelnsights } \\
\text { \#entrepreneurship }\end{array}$ \\
\hline Interface: & $\begin{array}{l}\text { An open box field is provided to collect the response. Furthermore, three } \\
\text { separate interfaces are provided to collect each hashtag. }\end{array}$ \\
\hline \multicolumn{2}{|r|}{ Structured format: } \\
\hline Task: & $\begin{array}{l}\text { Are you familiar with Influenza ( the Flu)? Could you describe this disease } \\
\text { based on your general knowledge? If No, you are not qualified to take part in } \\
\text { this experiment.... If that's the case for you, please close this page! And thank } \\
\text { you for your time!.... If yes, you are definitely qualified to take part in this } \\
\text { experiment. } \\
\text { We want you to describe the Influenza disease. Please answer the following } \\
\text { questions about Influenza based on your general knowledge. }\end{array}$ \\
\hline Interface: & A list of questions and detailed provided choices are available on Figure 22. \\
\hline
\end{tabular}




\section{MAHED MADDAH}

2014-2019

2011-2014

2005-2009
Ph.D. Business

Management Information Systems

College of Business, Florida International University

Miami, FL

Master of Business Administration

University of Tehran

Tehran, Iran

B.Sc., Industrial Engineering

Khaje Nasir Toosi University of Technology

Tehran, Iran

\section{PUBLICATIONS AND PRESENTATIONS}

Lukyanenko Roman, Jeffrey Parsons, Yolanda Wiersma and Mahed Maddah; "Expecting the Unexpected: Effects of Class-based versus Instance-based Data Collection on the Quality of Crowdsourced User-generated Content”, MIS Quarterly, 2019. (Forthcoming)

Lukyanenko, Roman, Jeffrey Parsons, Yolanda Wiersma, Renee Sieber, and Mahed Maddah. "Participatory Design for User-generated Content: Understanding the challenges and moving forward." Scandinavian Journal of Information Systems, vol. 28, no. 1 (2016): 37-70.

Maddah Mahed, Roman Lukyanenko and Debra VanderMeer; "Designing UGC Interfaces: Considering Level of Structure and Type of Data”, SIGSAND 2018, Syracuse, NY.

Maddah Mahed, Roman Lukyanenko and Debra VanderMeer; "Impact of Collection Structures and Type of Data on Quality of User-generated Content”, WITS 2018, Santa Clara, CA.

Maddah Mahed, Roman Lukyanenko and Debra VanderMeer; "Role of Data Structure and Human Memory in Improving Quality of UGC”, ICIS TREO Talks 2018, San Francisco, CA.

Maddah Mahed, Roman Lukyanenko and Debra VanderMeer; "The Impact of Data Structure on Information Quality in User-Generated Content: Considering Type of Data in Designing Information Systems”, FIU GSAW 2018, Miami, FL. 